\title{
ANÁLISE TEÓRICO-EXPERIMENTAL DE CONSOLOS DE CONCRETO ARMADO
}

FERNANDO MONTENEGRO TORRES

Dissertação apresentada à Escola de Engenharia de São Carlos, da Universidade de São Paulo, como parte dos requisitos para obtenção do Título de Mestre em Engenharia de Estruturas.

ORIENTADOR: Prof. Dr. Libânio Miranda Pinheiro 
Ficha catalográfica preparada pela Seção de Tratamento da Informação do Serviço de Biblioteca - EESC-USP

Análise teórico-experimental de consolos de concreto armado / Fernando Montenegro Torres. São Carlos, 1998.

Dissertação (Mestrado) -- Escola de Engenharia de São Carlos-Universidade de São Paulo, 1998.

Área: Engenharia de Estruturas.

Orientador: Prof. Dr. Libânio Miranda Pinheiro.

1. Consolos. 2. Concreto armado. 3. Concreto de alta resistência. 4. Estudo experimental.

I. Título. 
A Deus, aos meus pais Roberto e Maria Eleusa, o meu avô Waldik. 


\section{AGRADECIMENTOS}

Agradeço a Deus, pela proteção e pelas oportunidades oferecidas.

Ao Prof. Dr. Libânio Miranda Pinheiro, pela orientação e apoio ao longo deste trabalho.

À Lorena Carvalho Barbosa, pelo auxilio, dedicação e carinho dispensados na fase final do trabalho.

Aos professores do Departamento de Engenharia de Estruturas da EESC - USP, pelas importantes contribuições e sugestões relativas ao trabalho.

Aos colegas do curso de pós-graduação, pelo apoio e companheirismo.

Aos funcionários do Laboratório de Estruturas, pelo auxílio dispensado na realização dos ensaios.

À Maria Nadir Minatel, pela dedicação e disposição para pesquisas e revisões bibliográficas.

Às secretárias do Departamento de Engenharia de Estruturas da EESC - USP, Rosy A. J. Rodrigues, Marta R. C. Faria e demais funcionários, pela eficiência nos serviços prestados.

Ao CNPq e à FAPESP, pelo auxílio financeiro concedido. 


\section{SUMÁRIO}

LISTA DE FIGURAS

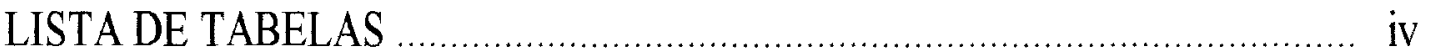

LISTA DE SÍMBOLOS …...........................................................

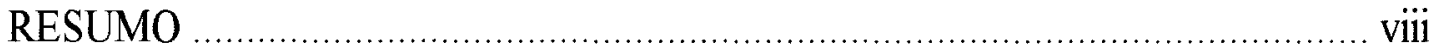

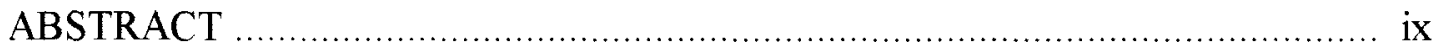

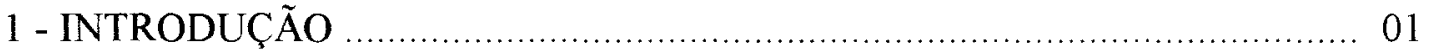

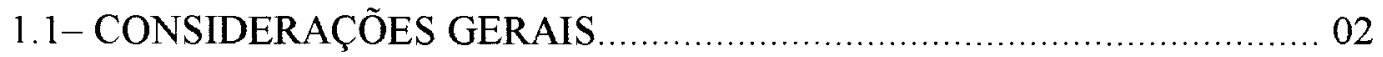

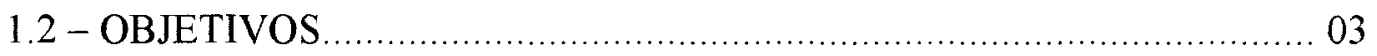

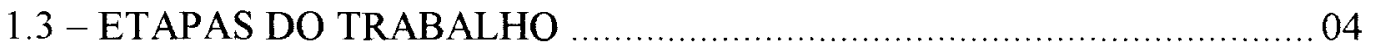

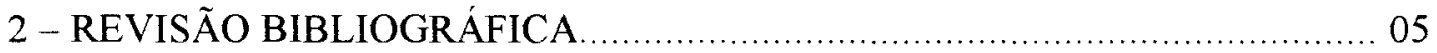

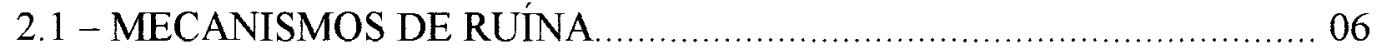

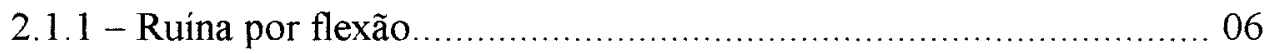

2.1.2 - Ruína por fendilhamento da biela comprimida.......................... 06

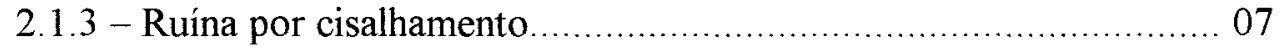

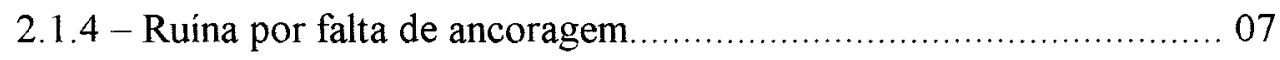

2.1.5 - Ruina devida à ação horizontal................................................. 08

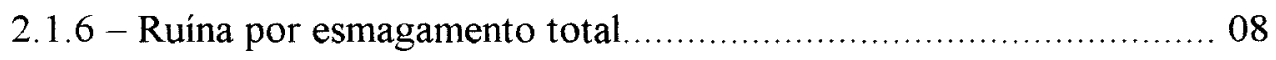

2.2 - COMPORTAMENTO ESTRUTURAL DOS CONSOLOS .................... 08

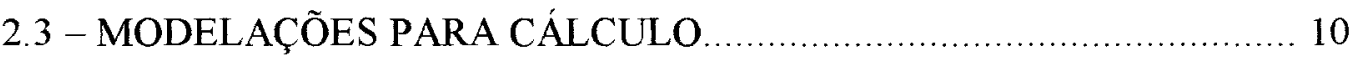

2.3.1 - Modelo de bielas e tirantes................................................... 10

2.3.2 - Modelo de atrito-cisalhamento................................................ 13

2.4 - CÁlCULO DE CONSOLOS DE ACORDO COM AS NORMAS .......... 15

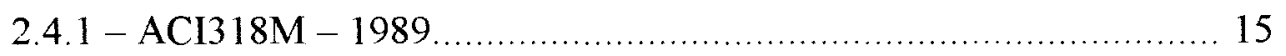

2.4 .2 - CAN3 - A23.3 - M1984 ................................................... 18

2.4.3 - CEB - Model Code 1991_................................................. 21 
$2.4 .4-\mathrm{NBR}-9062$

2.4.4.1 - Consolos curtos.

2.4.4.2 - Consolos muito curtos.............................................. 28

2.5 - ESTUDOS REALIZADOS POR OUTROS PESQUIZADORES. 29

2.5.1 - Consolos de concreto com fibras. 33

2.5.2 - Consolos de concreto de alta resistência. 33

3 - ANÁLISE DOS CONSOLOS ENSAIADOS POR OUTROS

PESQUISADORES 35

3.1 - CONSOLOS SEM ARMADURA DE COSTURA COM CARREGAMENTO VERTICAL 36

3.2 - CONSOLO SEM ARMADURAS DE COSTURA COM CARREGAMENTOS VERTICAIS E HORIZONTAIS 45

3.3 - CONSOLOS COM ARMADURA DE COSTURA, SUJEITOS A CARREGAMENTO VERTICAL

3.4 - CONSOLOS COM ARMADURA DE COSTURA SUJEITOS A CARREGAMENTOS VERTICAIS E HORIZONTAIS ....................... 55

3.5 - CONSIDERAÇÕES GERAIS. 58

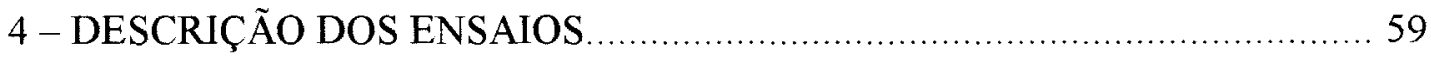

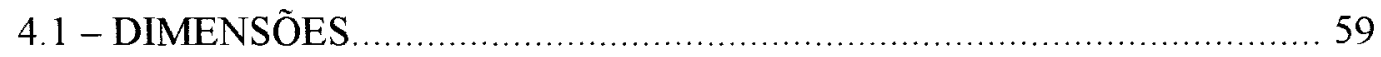

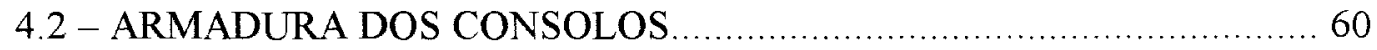

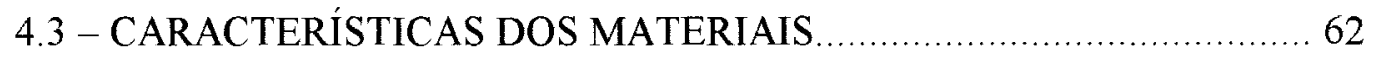

4.3.1 - Características de aço utilizado ................................................ 62

4.3.2 - Características do concreto e procedimento de mistura.................63

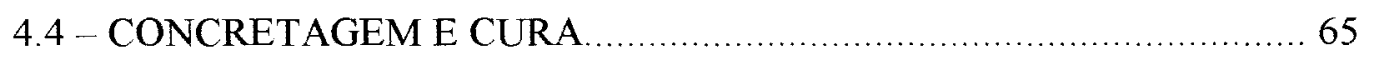

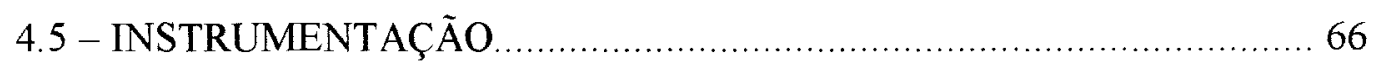

4.5.1 - Extensômetros colocados na armadura........................................ 66

4.5 .2 - Instrumentação na superficie do concreto................................. 68

4.6 - ESQUEMA E PROCEDIMENTO DE ENSAIO .................................69 
5 - APRESENTAÇÃO E ANÁLISE DOS RESULTADOS.

5.1 - DESENVOLVIMENTO DAS FISSURAS E MACANISMOS DE RUINA. 71

5.1.1 - Desenvolvimento das fissuras 71

5.1.2 - Mecanismos de Ruína. 73

5.2 - DIAGRAMA FORÇA APLICADA VERSUS DEFORMAÇÃO NA ARMADURA. 73

5.3 - DIAGRAMAS FORÇA APLICADA VERSUS ROTAÇÃO DO CONSOLOS EM RELAÇÃO AO PILAR 78

5.4 - ANÁLISE DOS CONSOLOS SEGUNDO NORMAS INTERNACIONAIS E NACIONAIS 83

5.5 - ANÁLISE DE ÂNGULO DE INCLINAÇÃO DAS TENSÕES PRINCIPAIS NO CENTRO DO CONSOLO ...................................... 84

5.6 - ANÁLISE PARAMÉTRICA. 85

6 - CONCLUSÕES E SUGESTÕES. 88

6.1- CONCLUSÕES. 88

6.2 - SUGESTÕES. 90

REFERÊNCIAS BIBLIOGRÁFICAS. 91 BIBLIOGRAFIA COMPLEMENTAR 94 


\section{LISTA DE FIGURAS}

Figura 1.1 - Tipos de carregamento e notação utilizada ............................................ 03

Figura 2.1 - Mecanismo de ruína .......................................................................... 07

Figura 2.2 - Trajetórias de tensão em consolos .................................................. 09

Figura 2.3 - Modelação das trajetórias de tensão existentes nos consolos.............. 11

Figura 2.4 - Treliças idealizadas para carregamento indireto............................ 12

Figura 2.5 - Armaduras de suspensão............................................................. 13

Figura 2.6 - Modelo atrito-cisalhamento ................................................. 14

Figura 2.7 - Esquema estrutural de acordo com ACI 318M - 89..................... 16

Figura 2.8 - Modelo estrutural de acordo com CAN3 - A23.3 - M1984 _............. 19

Figura 2.9-Modelo estrutural de consolos de acordo com CEB Model

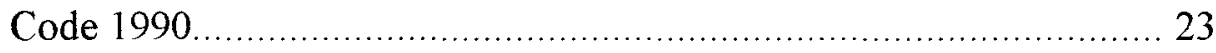

Figura 2.10 - Modelo estrutural NBR-9062/LEONHARDT \& MÖNNIG (1978)... 25

Figura 3.1 - Gráfico $F_{r}$ versus taxa de armadura de costura.......................... 50 $\mathrm{F}_{\mathrm{c}} \mathrm{bd}$

Figura 4.1 - Dimensões dos consolos ............................................................... 59

Figura 4.2 - Esquema geral de armadura dos consolos .....................................6 60

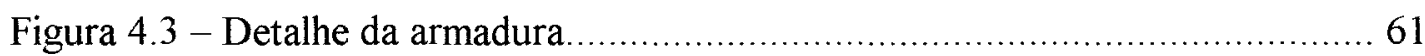

Figura 4.4 - Gráfico tensão versus deformação da armadura..............................63 63

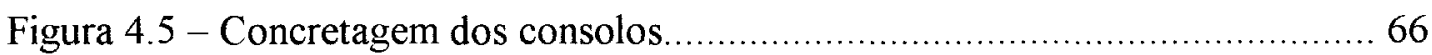

Figura 4.6 - Instrumentação na armadura dos consolos........................................ 67

Figura 4.7 - Instrumentação na superficie do concreto ..........................................6

Figura 4.8 - Esquema de ensaio dos consolos...................................................69

Figura 5.1 - Exemplo de fissuração e ruína dos consolos..................................... 72

Figura 5.2 - Diagramas força aplicada versus deformação na armadura para consolo CHOVO. 
Figura 5.3 - Diagrama força aplicada versus deformação na armadura para consolo CH5V5

Figura 5.4 - Diagrama força aplicada versus deformação na armadura para consolo CH5V0

Figura 5.5 - Diagrama força aplicada versus deformação na armadura para consolo CH0V5.

Figura 5.6 - Diagrama força aplicada versus deformação na armadura para consolo

CH4V4. .76

Figura 5.7 - Diagrama força aplicada versus deformação na armadura para consolo CH4VO

Figura 5.8 - Diagrama força aplicada versus deformação na armadura para consolo CH6VO

Figura 5.9 - Diagrama força aplicada versus deformação na armadura para consolo CH4V4*

Figura 5.10 - Diagramas força aplicada x rotação do consolo em relação ao pilar para o consolo CHOVO 79

Figura 5.11 - Diagramas força aplicada x rotação do consolo em relação ao pilar para o consolo CH5V5.

Figura 5.12 - Diagramas força aplicada x rotação do consolo em relação ao pilar para o consolo CH5VO

Figura 5.13 - Diagramas força aplicada x rotação do consolo em relação ao pilar para o consolo CHOV5.

Figura 5.14 - Diagramas força aplicada x rotação do consolo em relação ao pilar para o consolo CH4V4.

Figura 5.15 - Diagramas força aplicada x rotação do consolo em relação ao pilar para o consolo CH4VO.

Figura 5.16 - Diagramas força aplicada x rotação do consolo em relação ao pilar para o consolo CH6V0.

Figura 5.17 - Diagramas força aplicada x rotação do consolo em relação ao pilar para o consolo $\mathrm{CH} 4 \mathrm{~V} 4$ *. 
Figura 5.18 - Diagrama força aplicada $\mathrm{x}$ inclinação das tensões principais no centro

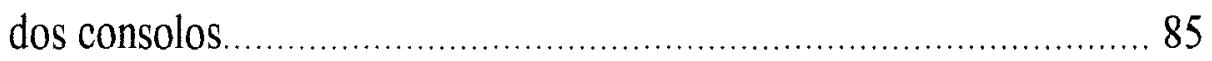

Figura 5.19- Gráfico $\mathrm{F}_{\mathrm{r}}$ versus taxa de armadura de costura ..................... 86 $\overline{f_{c} b d}$

Figura 5.20-Gráfico resistência de concreto versus $\quad F_{r}$ 87

$$
\overline{A_{s} f_{y}+A_{s h}} f_{y}
$$




\section{LISTA DE TABELAS}

Tabela 3.1 - Consolos sem armadura de costura e com força vertical................... 38

Tabela 3.2-Consolos sem armadura de costura e com forças verticais e horizontais 39

Tabela 3.3 - Consolos com armadura de costura e com força vertical................... 51

Tabela 3.4 - Consolos com armadura de costura e forças verticais e horizontais.... 56

Tabela 4.1 - Quantidade e diâmetro da armadura usada em cada consolo............... 62

Tabela 4.2 - Caracteristicas do aço das armaduras utilizadas ............................. 63

Tabela 4.3 - Traço de concreto utilizado nos ensaios......................................... 64

Tabela 4.4 - Características do concreto utilizado........................................... 65

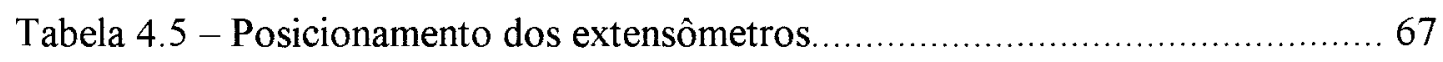

Tabela 5.1 - Forças de fissuração e de ruína das peças ....................................... 72

Tabela 5.2 - Cálculo dos consolos segundo as normas....................................... 84 


\section{LISTA DE SÍMBULOS}

F - força aplicada;

$\mathrm{H}$ - força horizontal;

$h_{1}$ - altura do consolo em seu bordo externo;

$\mathrm{h}$ - altura do consolo junto ao pilar;

LE-EESC - Laboratório de Estruturas da Escola de Engenharia de São Carlos;

a - distância de aplicação do carregamento;

d - altura útil;

$\mathrm{a}_{1}$ - comprimento total do consolo;

$a_{2}$ - distância da face externa do consolo até a placa de apoio;

$\mathrm{x}_{1}$ - comprimento de aparelho de apoio;

$\mathrm{A}_{\mathrm{s}}$ - área da armadura principal;

$\Delta \mathrm{d}$ - altura do consolo menos altura útil do consolo $(\mathrm{h}-\mathrm{d})$;

$\mathrm{d}$ - altura útil do consolo;

b - largura do consolo;

$F_{d^{-}}$força de dimensionamento;

M - momento;

$\gamma$ - coeficiente majorador de carga;

$\varnothing$ - coeficiente redutor de carga;

$\mathrm{N}$ - força horizontal;

$\mathrm{f}_{\mathrm{yk}}$ - tensão característica de escoamento de aço;

$\mathrm{A}_{\mathrm{f}}$ - armadura de flexão;

$\mathrm{M}_{\mathrm{d}}$ - momento de dimensionamento;

$\mathrm{x}$ - região comprimida no pilar para Norma Americana;

$\mathrm{f}_{\mathrm{ck}}$ - resistência característica do concreto;

$\mathrm{A}_{\mathrm{vf}}$ - armadura necessária pela teoria de atrito - cisalhamento de acordo com ACI;

$\mu$ - coeficiente de atrito;

$\lambda$ - fator relativo à baixa densidade do concreto;

$A_{n}$ - armadura para resistir a força horizontal;

$\mathrm{H}_{\mathrm{d}}$ - força horizontal de dimensionamento; 
$\mathrm{f}_{\mathrm{c}}$ - resistência do concreto;

$\rho$ - taxa de armadura;

$\mathrm{f}_{\mathrm{y}}$ - tensão de escoamento do aço;

l' - distância da face do pilar até o centro de gravidade da armadura na face oposta;

$\mathrm{N}_{\mathrm{c}}$ - resultante dos esforços de compressão distribuídos na largura a" do pilar;

a" - largura da região comprimida do pilar em função das cargas aplicadas no consolo;

$\phi_{\mathrm{c}}$ - fator de resistência do concreto;

d' - distância da face superior do consolo ao centro de gravidade da armadura principal;

$\theta$ - ângulo de inclinação da biela;

$\mathrm{f}_{2}$ - tensão de compressão atuante nas barras compridas;

$\mathrm{f}_{2 \operatorname{máx}}$ - tensão limite de compressão nas barras de aço para a norma CAN3-A23.3M84

$\mathrm{V}$ - carga vertical aplicada no consolo;

$\theta$ - ângulo de inclinação da tensão da diagonal comprimida em relação à horizontal

$\varepsilon_{1}$ - deformação principal no concreto;

$\varepsilon_{\mathrm{x}}$ - deformação longitudinal no meio da altura do membro, quando sujeito aos esforços M, V e H;

$\mathrm{Z}$ - braço de alavanca;

$\mathrm{F}_{\mathrm{t}}$ - força principal de tração;

$F_{v}$ - força vertical;

$\mathrm{f}_{\mathrm{cd}}$ - resistência de cálculo à compreensão atuante nas barras comprimidas

$\mathrm{F}_{\mathrm{cdl}}$ - limite de tensão do concreto para nós submetidos apenas à compressão;

$\mathrm{F}_{\mathrm{c} 2} ; \mathrm{F}_{\mathrm{c} 3}$ - esforços de compressão atuantes nas barras de treliça segundo CEB Model

Code 1991.

$F_{w}$ - resultante das forças $F_{c 2}, F_{c 3}$ existentes no consolo;

$\gamma_{n}$ - coeficiente de segurança adicional para NBR - 9062;

$\phi_{\mathrm{a}}$ - coeficiente redutor de resistência do concreto;

$\mathrm{R}_{\mathrm{s}}$ - força de tração no tirante;

$\mathrm{R}_{\mathrm{cb}}$ - força de compressão na biela; 
$\sigma_{\mathrm{cb}}-$ tensão de compressão na biela;

$f_{\mathrm{yd}}$ - tensão de escoamento de cálculo de aço;

$\tau_{\mathrm{d}}$ - tensão atuante na biela para consolos muito curtos;

$\tau_{\mathrm{wu}}$ - tensão máxima resistente do concreto;

$\omega$ - taxa mecânica de armadura do tirante;

$\mathrm{A}_{\mathrm{s} \text { vert }}$ - Área da armadura vertical;

$\mathrm{F}_{\mathrm{h}}$ - força horizontal;

$\mathrm{F}_{\mathrm{r}}$ - força de ruína;

$F_{c}$ - força de ruína calculada;

$\rho_{c}$ - taxa de armadura de costura;

$\mathrm{A}_{\mathrm{sc}}$ - área de armadura de costura;

$\mathrm{f}_{\mathrm{yc}}$ - tensão de escoamento da armadura de costura;

$\mathrm{h}$ - altura do consolo;

$\phi$ - diâmetro de armadura;

ext - extensômetro. 


\section{RESUMO}

TORRES, F.M. (1998) Análise teórico-experimental de consolos de concreto armado. São Carlos, 110p. Dissertação (mestrado) - Escola de Engenharia de São Carlos. Universidade de São Paulo

Este trabalho tem o objetivo de analisar teórica e experimentalmente o comportamento de consolos de concreto armado. Para tal, foi realizada uma revisão bibliográfica, buscando os artigos mais recentes e as principais normas que tratam deste assunto.

Foram analisados mais de trezentos consolos encontrados na literatura. Nesta análise, as forças de ruína experimentais foram comparadas com a forças de ruínas calculadas segundo as normas: ACI-318M-89, CAN3-A23.3-M-84 e NBR-9062/85.

Para complementar este estudo, foram ensaiados oito consolos de concreto de alta resistência, os quais apresentavam: as mesmas dimensões, a mesma armadura principal e diferentes taxas de armadura de costura. A resistência do concreto variou de $50 \mathrm{MPa}$ a $80 \mathrm{MPa}$.

Estes consolos tiveram suas forças de ruína comparadas com as previstas pelas normas já citadas. Além disto, foram analisadas: as deformações na armadura, medidas a cada nivel de carregamento, e o ângulo de inclinação das tensões principais, medidos no centro geométrico da provável biela comprimida.

De acordo com as análises realizadas, pode-se observar que o uso de concreto de alto desempenho na confeç̧ão de consolos é bastante eficaz. Entretanto, é necessário o uso de taxas adequadas de armadura, que são basicamente as mesmas indicadas para consolos de concreto de resistência convencional. O dimensionamento de consolos segundo as normas citadas foi bastante satisfatório. Entretanto, no cálculo da força de ruína das peças ensaiadas por outros pesquisadores, os resultados não foram tão satisfatórios, pois estes consolos analisados nem sempre apresentavam o detalhamento conforme recomendam estas normas.

Palavras-chave: Consolos; Concreto armado; Concreto de alta resistência. 
ABSTRACT

TORRES, F.M. (1998) Theoretic-experimental analysis of reinforced concrete corbels. São Carlos. 110p. Dissertação (mestrado) - Escola de Engenharia de São Carlos. Universidade de São Paulo.

The aim of this work is to analyze theoretically and experimentally the behavior of reinforced concrete corbels. A bibliographic review was done, searching for the most recent papers and the main codes concerning to this subject.

It was analyzed more than there hundred corbels found in the literature. In this analysis, the experimental failures forces were compared to the failure forces calculated by the followings codes: ACI-318M-89; CAN3-A23.3-M-84 and NBR$9062 / 85$.

To complement this work, eight corbels of high-strength concrete were made with the same dimensions, the same main reinforcement and different rates of secondary reinforcement. The strength of the concrete ranged from $50 \mathrm{MPa}$ to 80 $\mathrm{MPa}$.

These corbels had their failure forces compared with the failure forces postulated by the codes. It was also evaluated the deformations of the reinforcement, considered in each level of loading, and the angle of inclination of the main stresses, measured in the geometric center of probable compressed diagonal.

By this analysis, it was observed that the use of high-strength concrete in the construction of corbels is quitely efficient. Although, it is necessary the use of proper reinforcement ratios, that are basically the same indicated for corbels with low-strength concrete. The design of corbels by the cited codes was quitely satisfactory. By the way, the calculation of the failure force of corbels made by others researchers were not satisfactory. The probable reason was that the corbels did not present the reinforcement details recomended by these codes.

Keywords: Corbels; Reinforced Concrete; High-strength concrete. 


\section{CAPÍTULO 1 - INTRODUÇÃO}

O estudo do comportamento estrutural e do dimensionamento de consolos teve um grande avanço nas décadas de 60 e 70, em decorrência principalmente dos trabalhos realizados por FRANZ \& NIEDENHOFF (1963), KRIZ \& RATHS (1965), LEONHARD \& MÖNNIG (1978), MATTOCK (1976) e outros pesquisadores. Entretanto, ainda hoje não há um consenso sobre a melhor maneira de se dimensionar e detalhar consolos.

Neste trabalho são descritos e analisados os modelos de cálculo indicados pelas normas: ACI-318M-89, CAN3-A23.3-M1984, CEB- Model Code 1991 e NBR9062/85. Estas análises são realizadas a partir da comparação de resultados de força de ruína teórica com força de ruína experimental, para 8 consolos que foram ensaiados no Laboratório de Estruturas da Escola de Engenharia de São Carlos (LE-EESC) e mais de 300 consolos encontrados na literatura.

Além da força de ruína, deverão ser analisados os mecanismos de ruína, força de início de fissuração, relação força aplicada versus deformação na armadura para os consolos ensaiados no LE-EESC.

Estes consolos deverão apresentar a mesma armadura principal e resistência do concreto em torno de 50 a $80 \mathrm{MPa}$. Entretanto, deverão apresentar variações nas armaduras verticais e de costura, a fim de se analisar a influência dos estribos verticais no comportamento do consolo e comparar os resultados experimentais de consolos que apresentam: apenas armadura principal, armadura principal e armadura de costura, armadura principal e estribos verticais e armadura principal, armadura de costura e estribos verticais. Estes ensaios visam obter indícios de qual deve ser a 
quantidade mínima destas armaduras, para ser ter um bom comportamento estrutural dos consolos.

\section{1 - CONSIDERAÇÕES GERAIS}

Consolos são peças de concreto armado salientes a pilares, que são carregadas na extremidade livre com forças concentradas, aplicadas a uma distância "a", medida desde a linha de ação da força vertical até a face do pilar adjacente (Ver figura 1.1). Os consolos podem ser classificados em função da distância "a" dividida pela altura útil "d", conforme o seguinte critério:

$$
\begin{array}{ll}
\text { Consolo curto: } & 0,5<\frac{a}{d}<1,0 \\
\text { Consolo muito curto : } & \frac{\mathrm{a}}{\mathrm{d}} \leq 0,5
\end{array}
$$

Os consolos podem apresentar carregamentos diretos ou indiretos, de acordo com a forma de aplicação da ação vertical. No caso de carregamento indireto, a ação vertical está aplicada ao longo de toda a altura do consolo ou está concentrada na face inferior deste elemento, impossibilitando a execução de chanfros. Estas formas de carregamento podem ser melhor visualizadas através da figura 1.1 , onde se indica também a notação utilizada.

Estes elementos geralmente estão ligados a pilares, mas podem ser também ligados a vigas, principalmente quando se tratam de estruturas pré-moldadas. Sua utilização principal é servir como apoio para equipamentos, tais como pontes rolantes, ou então, como apoio para outros elementos estruturais, principalmente em edifícios que necessitam de juntas de dilatação.

Inicialmente, o dimensionamento desse tipo de estrutura era feito como se fosse uma viga em balanço (elemento linear). Entretanto, os consolos curtos ou muito curtos são elementos tridimensionais, pois suas dimensões têm a mesma ordem de grandeza. Sendo assim, estas peças representam trechos de singularidade para os 
quais não vale a Teoria da Flexão, evidenciando a necessidade de um método de cálculo especifico.

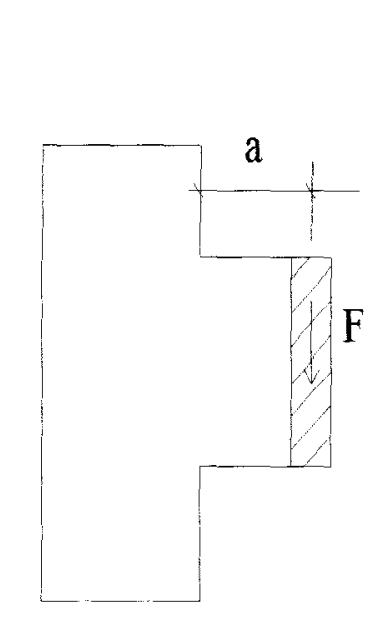

a) Carregamento indireto

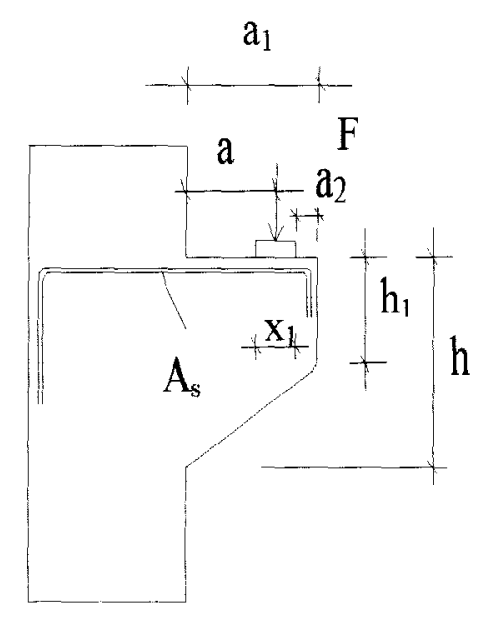

b) Carregamento direto

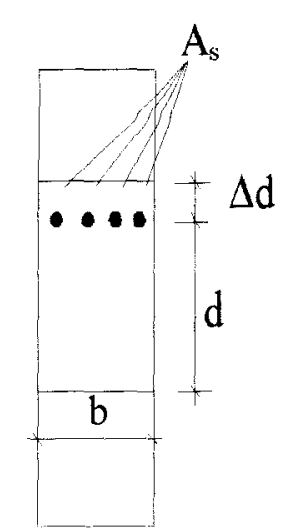

c) Vista frontal

\section{Figura 1.1 - Tipos de carregamento e notação utilizada}

Para o caso de $\mathrm{a} / \mathrm{d} \geq 1$, o consolo pode ser tratado como viga em balanço, pois mobiliza os esforços de flexão (cortante e momento fletor), conforme indica a NBR 9062/85.

\section{2 - OBJETIVOS}

Este trabalho tem o objetivo de complementar o estudo teórico-experimental de consolos simétricos de concreto armado, dando continuidade à pesquisa desenvolvida por REIS \& TORRES (1996), na qual foram ensaiadas 12 peças de tamanho real, com relação $a / d=0,37$, com carregamento apenas vertical e com diferentes distribuições de armadura.

Para complementar este estudo, foram ensaiados 8 consolos de concreto de alta resistência, os quais apresentavam: as mesmas dimensões, a mesma armadura 
principal e diferentes taxas de armadura de costura e de estribos verticais. A resistência do concreto destes consolos variou de 50 a $80 \mathrm{MPa}$.

Neste estudo, pretende-se comparar resultados experimentais com resultados teóricos obtidos através da análise de normas como: ACI-318M-89, CAN3-A23.3M1984 e NBR-9062. Para tal, foram utilizadas as forças de ruína dos consolos, determinadas nos ensaios, comparando-as com os valores das forças de ruína obtidas através do cálculo.

O estudo teórico deste trabalho objetivou o estudo das metodologias de cálculo propostas pelas normas, bem como o estudo de artigos sobre o tema ou sobre temas correlatos.

Além disto, foram analisadas: forças de início da fissuração e forma de ruína em função do tipo e da quantidade de armadura adotada. Ainda foi feito um estudo da relação entre força aplicada e deformação na armadura.

Outro objetivo deste trabalho foi o de analisar o comportamento de consolos de concreto de alta resistência, principalmente nas análises das forças e mecanismos de ruína.

Além destes objetivos, esta pesquisa pretende dar algumas indicações de qual metodologia apresenta um melhor desempenho no dimensionamento de consolos duplos simétricos. Para tal, serão usados os dados já obtidos nos trabalhos de KRIZ \& RATHS (1965), MATTOCK (1976), FATTUHI (1994), REIS \& TORRES (1996) e outros pesquisadores.

\section{3 - ETAPAS DO TRABALHO}

$\mathrm{Na}$ realização deste estudo, o trabalho foi dividido em algumas etapas, apresentadas a seguir.

Inicialmente foi realizada uma revisão bibliográfica sobre o tema da dissertação e temas correlatos. Em seguida, analisaram-se os consolos ensaiados por outros pesquisadores, comparando os resultados experimentais da força de ruína com os resultados teóricos obtidos através dos cálculos, utilizando as normas ACI 318M-89, CAN3-A23.3-M1984 e NBR-9062. 
Após a análise teórica, foram planejados e ensaiados, no Laboratório de Estruturas da Escola de Engenharia de São Carlos, oito consolos de concreto de alta resistência.

Dando continuidade ao trabalho, os oito consolos ensaiados foram analisados considerando: forças de início de fissuração junto ao pilar e na região da biela, forças de ruína, diagramas força aplicada versus deformação na armadura, força aplicada versus rotação dos consolos em relação ao pilar, força aplicada versus ângulo de inclinação das tensões principais no centro geométrico dos consolos, cálculo dos consolos de acordo com normas nacionais e internacionais e uma análise paramétrica, em função da resistência do concreto e da taxa de armadura de distribuição dos consolos.

Finalizando o trabalho, foram apresentadas as conclusões finais e algumas sugestões, para dar continuidade ao estudo. 


\section{CAPÍTULO 2 - REVISÃo BIBLIOGRÁFICA}

Neste capítulo serão apresentados: os principais mecanismos de ruina, o comportamento estrutural, as teorias usadas no dimensionamento de consolos, o dimensionamento de consolos de acordo com algumas normas internacionais e nacionais e uma análise dos trabalhos realizados por outros pesquisadores.

\section{1 - MECANISMOS DE RUÍNA}

Os principais mecanismos de ruína observados em consolos, de acordo com PARK \& PAULAY (1983), são indicados a seguir.

\subsection{1 - Ruína por flexão}

A ruína por flexão é caracterizada pelo aparecimento de uma fissura principal, que apresenta abertura muito grande na parte superior do consolo e esmagamento da parte inferior. Esta ruína ocorre devido ao escoamento da armadura principal (ver figura 2.1.a.).

\subsection{2 - Ruína por fendilhamento da biela comprimida}

Forma-se inicialmente uma fissura de flexão e em seguida surgem fissuras na biela comprimida. Próximo à carga de ruína aparece uma fissura que se estende desde o bordo da placa de apoio até o canto inferior do consolo (ver figura 2.1.b). Ocorre, 
geralmente, em consolos com pequena área de concreto para resistir aos esforços na biela comprimida ou em consolos sem armadura distribuída ao longo da altura.

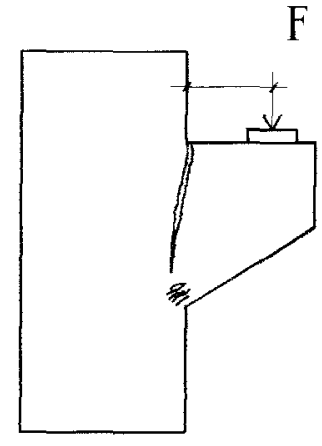

(a)

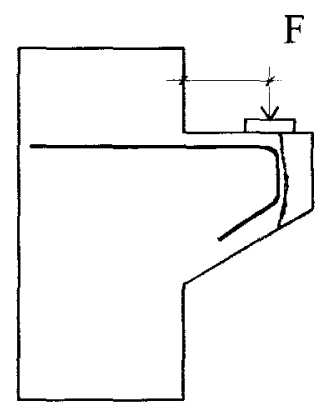

(d)

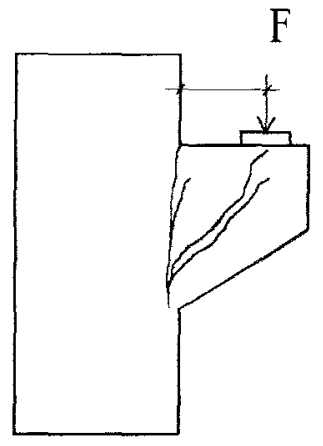

(b)

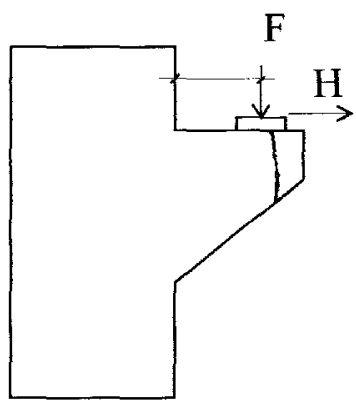

(e)

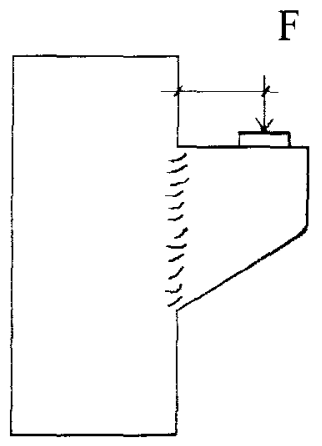

(c)

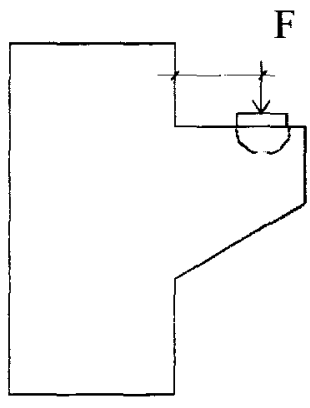

( f)

Figura 2.1 - Mecanismos de ruína

\subsection{3 - Ruína por cisalhamento}

A ruína por cisalhamento é caracterizada pela formação de várias pequenas fissuras inclinadas, no plano de intersecção do consolo com o pilar, que provocam o escorregamento desta peça estrutural. Esta ruína ocorre, geralmente, em consolos muito curtos ou quando estes elementos são fortemente armados à flexão (ver figura 2.1.c).

\subsection{4 - Ruína por falta de ancoragem}

É caracterizada por fissuras que seguem o contorno da armação (ver figura 2.1.d). Ocorre quando a força está aplicada muito próxima da extremidade do 
consolo, de forma que a ancoragem não seja suficiente, ou ocorre devido a um detalhamento inadequado da armadura, de forma a não envolver o carregamento aplicado no consolo

\subsection{5 - Ruína devida à ação horizontal}

Uma ação horizontal agrava consideravelmente os mecanismos de ruína anteriores. $\mathrm{O}$ esforço horizontal nem sempre é conhecido e pode ser decorrente de pontes rolantes, retração da peça de concreto apoiada sobre o consolo ou, ainda, devido à ação do vento. Um caso típico de ruína, agravada pela existência de um esforço horizontal, ocorre quando a altura do consolo em seu bordo externo $h_{1}$, é muito pequena se comparada à altura $\mathrm{h}$ do consolo junto ao pilar. Isto provoca o surgimento de fissuras que não se desenvolvem até o pilar, mas atravessam o consolo, chegando até o bordo inferior (ver figura 2.1.e).

\subsection{6 - Ruína por esmagamento local}

A ruína por esmagamento local surge quando, na região de aplicação do carregamento, a tensão de compressão é muito alta, provocando o esmagamento do concreto (ver figura 2.1.f). Isto pode ocorrer quando existir uma área muito pequena para distribuição da força $F$.

\section{2 - COMPORTAMENTO ESTRUTURAL DOS CONSOLOS}

Estudos experimentais de fotoelasticidade, realizados por FRANZ e NIEDENHOFF (1963), permitem definir e avaliar a distribuição das tensões existentes nos consolos. A partir das trajetórias de tensão ilustradas na figura 2.2, é possivel compreender melhor o comportamento destas peças. Estas trajetórias foram traçadas observando o comportamento de consolos com relação $\mathrm{a} / \mathrm{d}=0,5$ e levandose em conta apenas a força vertical, sem considerar o carregamento axial de 
compressão no pilar. Com base nestes estudos e observando a figura 2.2, pode-se indicar as seguintes regiões de tensão:

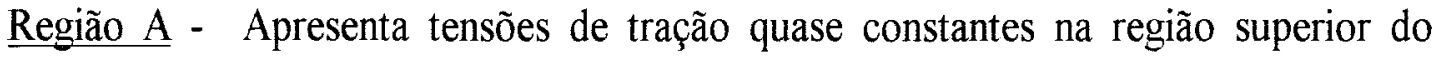
consolo, entre o ponto de carregamento e a face do pilar, caracterizando a área onde deve ser colocada a armadura principal.

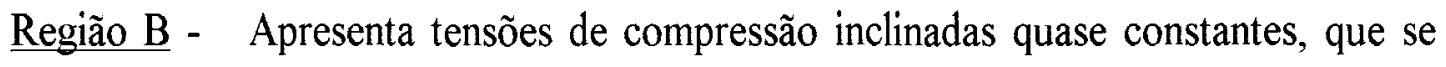
iniciam no ponto de aplicação da carga, caracterizando a formação de uma biela comprimida.

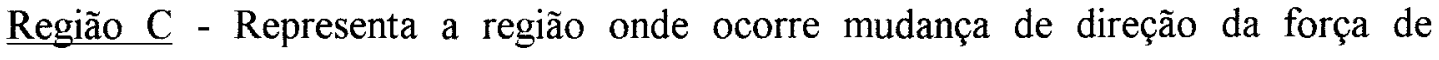
compressão, provocando o surgimento de tensões de tração inclinadas, que são relativamente pequenas

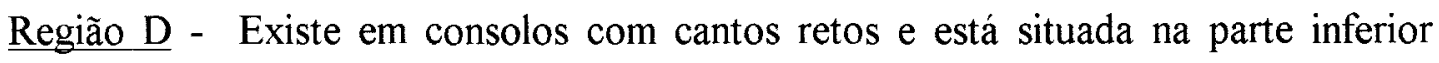
externa da estrutura. Nesta região praticamente não há tensões, justificando a utilização de consolos com altura variável, denominados consolos chanfrados.

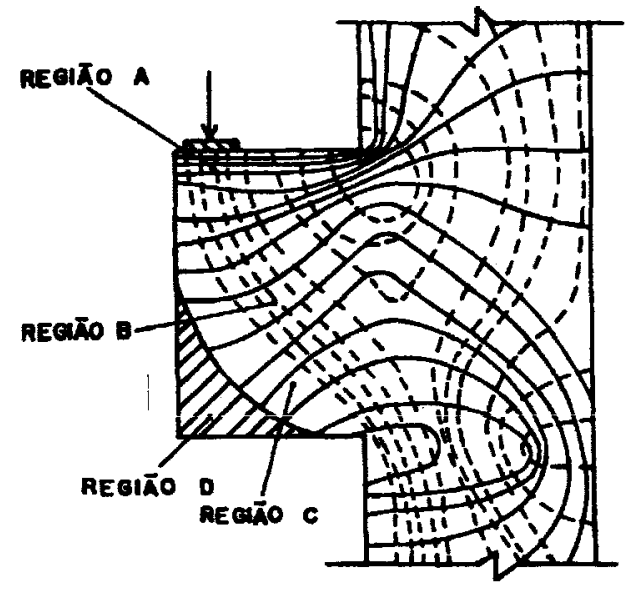

(a) Consolo assimétrico retangular

- . - . Tensões de compressão

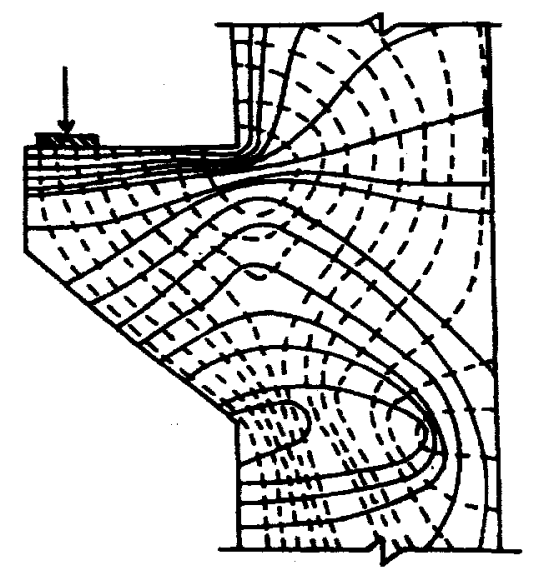

(b) Consolo assimétrico chanfrado Tensões de tração

Figura 2.2 - Trajetórias de tensão em consolos 


\section{3 - MODELAÇÕES PARA CÁLCULO}

As principais teorias para cálculo e dimensionamento de consolos foram obtidas dos estudos das trajetórias de tensão realizados por FRANZ \& NIEDENHOFF (1963), dos modelos de atrito-cisalhamento e das análises plásticas.

A partir destas teorias surgiram uma série de métodos de cálculo. O que diferencia estes métodos são: a utilização de uma ou mais das teorias citadas, a adoção de coeficientes de segurança diferenciados e o grau de simplificação utilizado em cada norma.

As principais modelações utilizadas no cálculo de consolos são:

- modelos de bielas e tirantes;

- modelo de atrito-cisalhamento;

- modelos de plasticidade.

Neste trabalho serão abordados os dois principais modelos que são: modelos de bielas e tirantes e modelo de atrito-cisalhamento.

\subsection{1 - Modelo de bielas e tirantes}

O cálculo de consolos curtos é feito usualmente através do modelo de bielas e tirantes, também chamado de modelo de treliça. Este modelo consiste em idealizar o comportamento da estrutura, substituindo os fluxos de tensões de compressão e de tração respectivamente por elementos comprimidos (bielas) e elementos tracionados (tirantes). Estes elementos são interconectados por nós, resultando na formação de uma treliça idealizada. A posição das bielas e dos tirantes é escolhida a partir das tensões que ocorrem em cada região.

Adotando uma modelação adequada de treliça, as forças nas bielas e nos tirantes são calculadas através do equilibrio de forças internas e externas. Em seguida, pode ser feito o dimensionamento do tirante e as verificações na biela.

A capacidade resistente dos elementos comprimidos depende da resistência do concreto e da área da seção transversal da biela. Os esforços de tração nos tirantes 
são resistidos pela armadura e portanto, sua capacidade resistente é uma função da área de aço adotada e da resistência ao escoamento.

É importante ressaltar que existem várias formas de modelar a distribuição dos campos de tensão existentes nos consolos. Esta modelação depende do grau de sofisticação que se deseja na análise do comportamento da estrutura. Na figura 2.3 são ilustradas modelações de treliça simplificadas e refinadas, para consolos ligados a pilares ou a abas de vigas, apresentando carregamento direto aplicado na face superior.

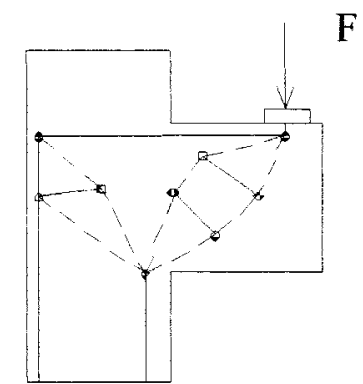

a) Modelo refinado

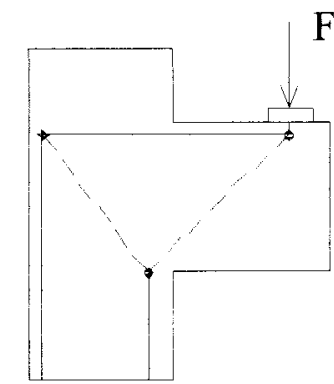

b) Modelo simplificado

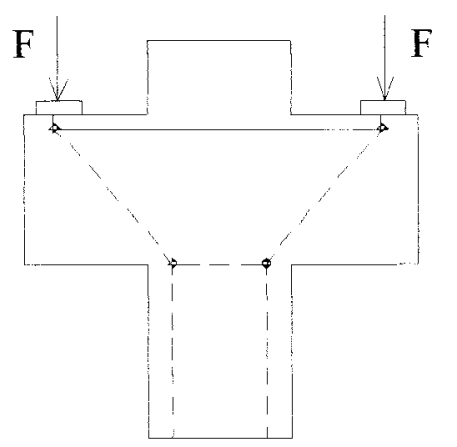

c) Modelo para dois consolos em um pilar
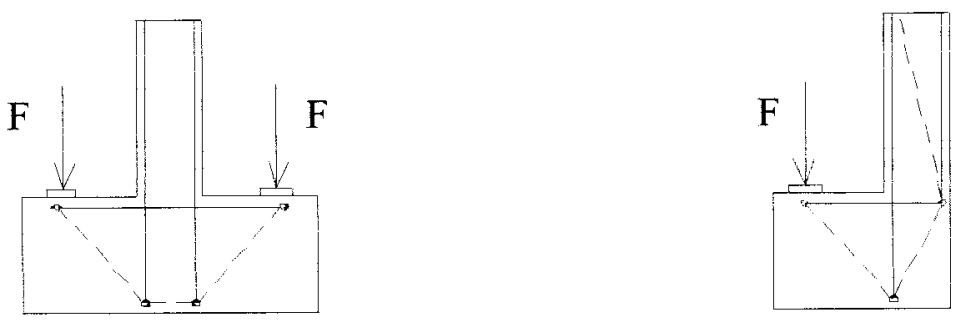

d) Modelos para consolos apoiados em vigas tirante biela

Figura 2.3 - Modelação das trajetórias de tensão existentes nos consolos 
Para consolos com força aplicada ao longo de toda a altura ou então carregados apenas na face inferior, conforme ilustra as figuras 2.4.a e 2.4.b, deve ser utilizada uma armadura de suspensão. Alguns autores, entre eles LEONHARD \& MÖNNIG (1978), recomendam que esta força deve ser integralmente suspensa através do uso de armadura vertical ou através do uso simultâneo de armadura de suspensão vertical e inclinada, que seguem o esquema apresentado na figura 2.5 . Quando se utiliza o detalhamento com armadura de suspensão vertical e inclinada, o cálculo da estrutura é feito adotando-se uma força correspondente a $60 \%$ da força total $\mathrm{F}$, aplicada tanto na face superior quanto na face inferior do consolo, conforme indicado na figura 2.4.c.

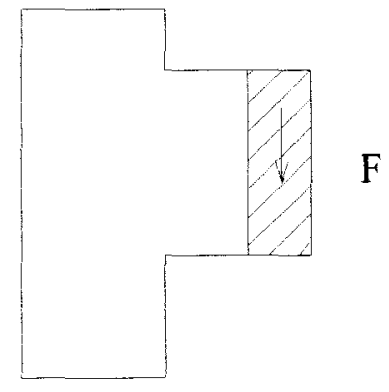

a) Carregamento ao longo da altura

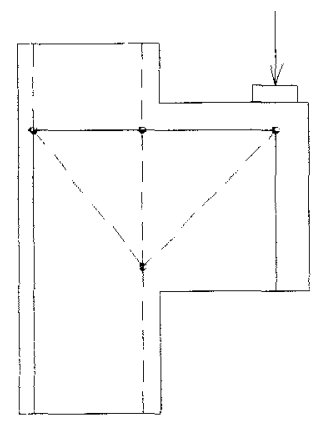

$0,6 \mathrm{~F}$

c) Modelo de cálculo para armadura de suspensão inclinada

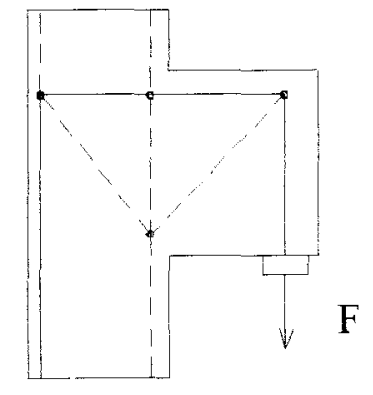

b) Carregamento na face inferior

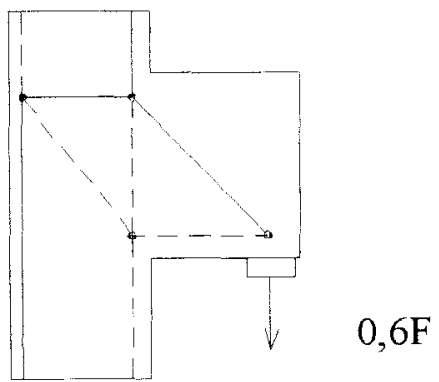

$0,6 \mathrm{~F}$

Figura 2.4 - Treliças idealizadas para carregamento indireto 

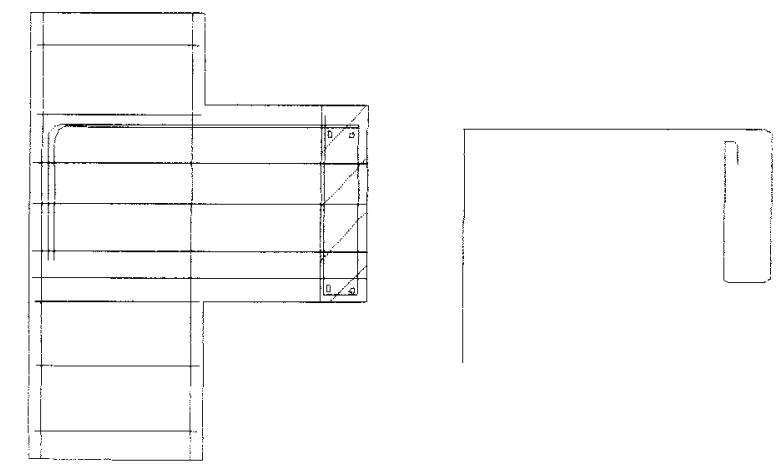

a) Detalhe para armadura de suspensão vertical
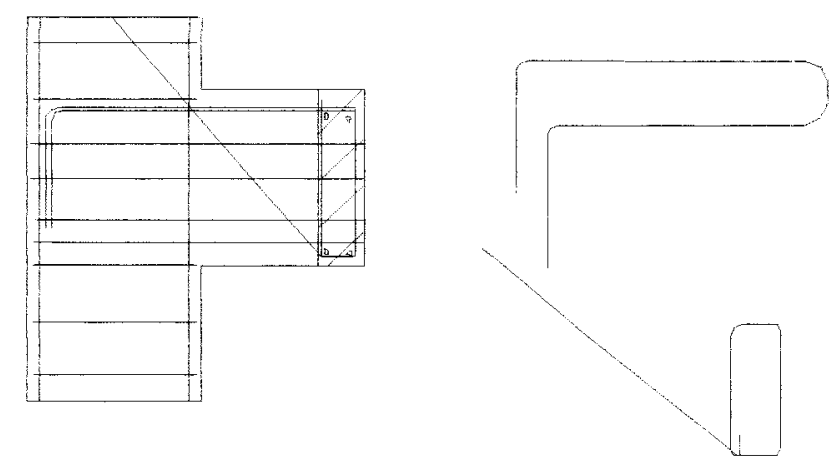

b) Detalhe para armadura de suspensão vertical e inclinada

Figura 2.5 - Armaduras de suspensão

\subsection{2 - Modelo de atrito-cisalhamento}

Os consolos muito curtos, ou seja, com relação $a / d<0,5$, devem ser analisados segundo a teoria de atrito-cisalhamento. Este método admite que existe uma tendência de deslocamento relativo entre as superficies adjacentes de concreto. A integridade das partes é garantida pela colocação de uma armadura cruzando esta superficie, que irá produzir força normal e, que consequentemente, mobilizará forças de atrito que equilibram o cisalhamento. A força vertical atuante é então transmitida do consolo para o pilar através das forças de atrito resultantes das forças de compressão e também pelo engrenamento dos agregados (ver figura 2.6). A ocorrência de força externa horizontal de tração, normal à fissura potencial, acarreta a 
necessidade de se determinar uma armadura adicional, que deve ser somada àquela necessária para resistir às tensões de cisalhamento.

Este modelo não fornece indicações com relação à posição da armadura, como ocorre no modelo descrito anteriormente. Portanto, o detalhamento deste tipo de consolo é feito seguindo o mesmo esquema de armação de consolos curtos. Além disto, a armadura principal para consolos muito curtos, calculada pelo modelo de atrito-cisalhamento, não deve ser menor do que a área de aço calculada pelo modelo de bielas e tirantes.

$F_{d}$

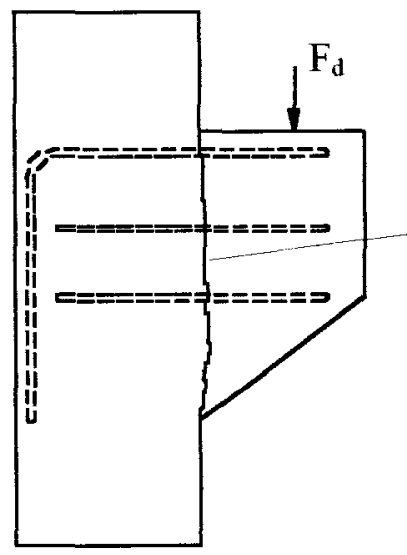

Fissura

Potencial
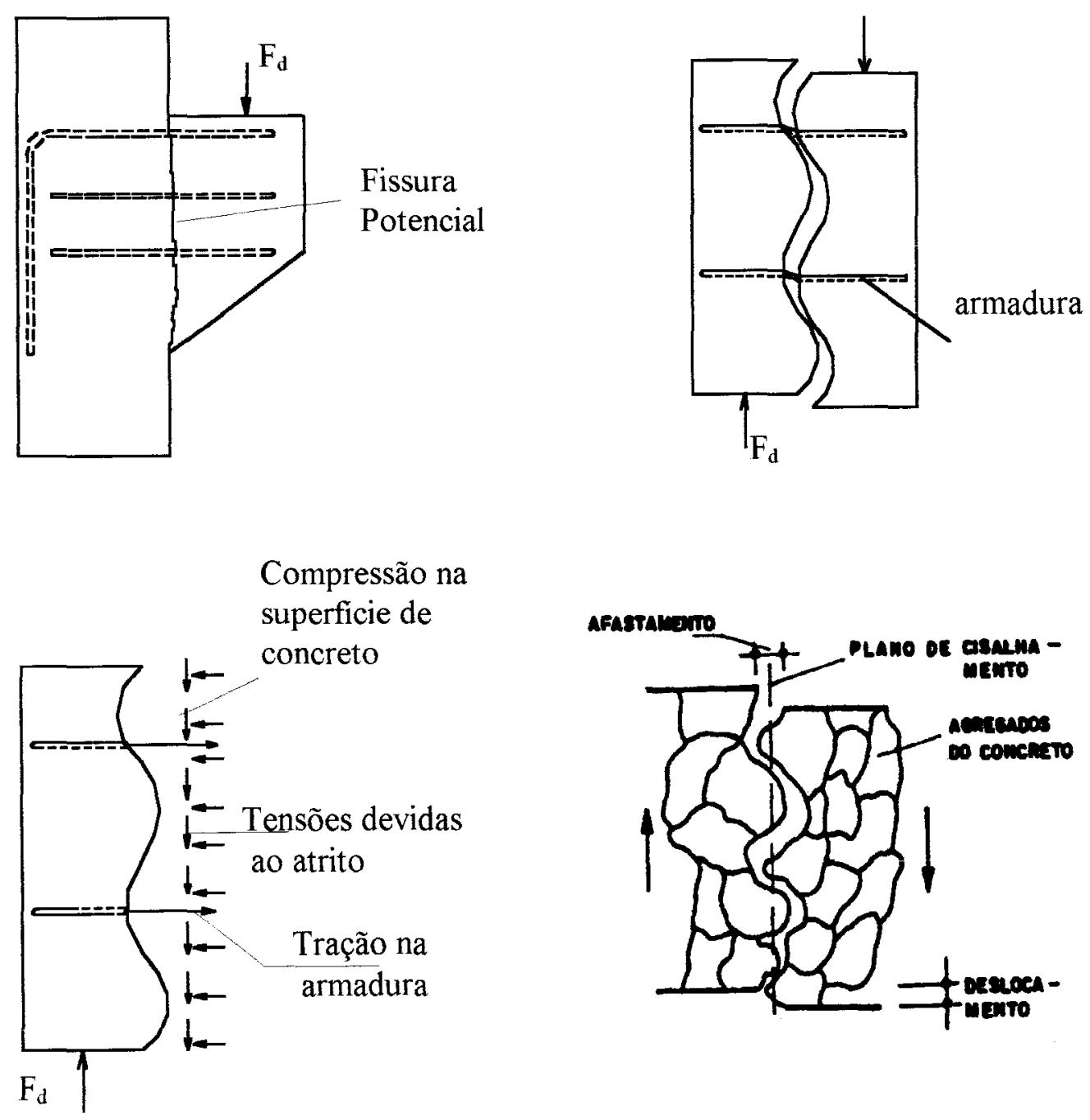

Figura 2.6 - Modelo atrito-cisalhamento 


\section{4 - CÁLCULO DE CONSOLOS DE ACORDO COM AS NORMAS}

Conhecer o comportamento de uma peça estrutural é extremamente importante, pois o dimensionamento e o detalhamento são feitos a partir de várias considerações de cálculo, baseadas nas distribuições de tensões e de esforços existentes na estrutura.

0 esquema principal de dimensionamento de consolos é baseado na simplificação adotada nos estudos de FRANZ \& NIEDENHOFF (1963), que consiste na substituição dos campos tracionados e comprimidos por suas resultantes. Praticamente todas as normas estudadas adotam esta simplificação, alterando apenas algumas considerações na forma de cálculo.

A seguir, serão apresentadas considerações de cálculo, tais como: as da Norma Americana ACI 318M-89, da Norma Canadense CAN3-A23.3-M1984, do CEB-Model Code-1991 e da Norma Brasileira, NBR-9062.

\subsection{1 - ACI 318M-1989}

O Código Americano ACI 318M-89 limita as recomendações apenas para consolos com relação $a / d<1$, sujeitos a um esforço horizontal de tração $H$, não maior que o esforço vertical $\mathrm{F}$, atuante na face do consolo e com altura do consolo, medida na face externa da placa de apoio do carregamento, não menor do que $0,5 \mathrm{~d}$.

Esta norma recomenda que a região de ligação entre o pilar e o consolo deve ser projetada para resistir a um esforço cisalhante $F$, a uma força de tração $H$, e a um momento $\mathrm{M}$ causado por estas forças no plano de cisalhamento. Para tal, esta norma recomenda que os consolos devem ser dimensionados segundo modelos de bielas e tirantes e de atrito-cisalhamento. $\mathrm{O}$ modelo de bielas e tirantes pode ser observado na figura 2.7 .

Para obter os valores de esforços para dimensionamento e os valores das tensões de cálculo dos materiais, a norma americana recomenda multiplicar os valores nominais por coeficientes de ponderação, que são apresentados a seguir: 
- Coeficientes majoradores de carga:

- $\gamma=1,4$ para cargas permanentes;

$\cdot \gamma=1,7$ para cargas variáveis.

- Coeficientes redutores de resistência:

- $\phi=0,85$ para todos os casos.

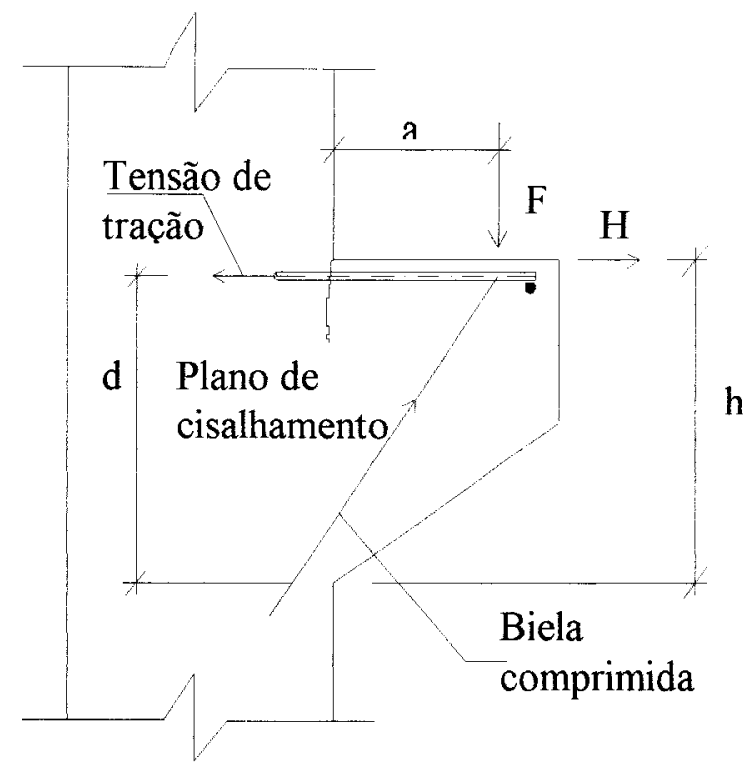

Figura 2.7 - Esquema estrutural de acordo com ACI 318M-89

$\mathrm{O}$ momento $\mathrm{M}$ é obtido pelo equilíbrio de momentos no centro de gravidade da armadura principal, na junção do consolo com o pilar, e o momento e a armadura para resisti-lo são dados por:

$$
\begin{aligned}
& M=F \cdot a+H \cdot(h-d) \\
& A_{f}=\frac{M_{d}}{\phi \cdot f_{y k} \cdot\left(d-\frac{x}{2}\right)}
\end{aligned}
$$

onde: $\quad x=\frac{A_{f} \cdot f_{y k}}{f_{c k} \cdot b}$

Como este processo é iterativo, alguns autores como NAWY (1990) e MACGREGOR (1988) recomendam adotar $\left(d-\frac{x}{2}\right)$ igual a $0,85 \cdot d$ e $0,90 \cdot d$, respectivamente. 
A armadura para resistir à força cortante F é obtida pelo cálculo através da teoria do atrito-cisalhamento e é dada por:

$$
A_{\mathrm{vf}}=\frac{F_{\mathrm{d}}}{\phi \cdot f_{\mathrm{yk}} \cdot \mu}
$$

Valores de $\mu$ :

$\mu=1,4 \lambda$ para concreto lançado monoliticamente;

$\mu=1,0 \lambda$ para concreto lançado sobre concreto endurecido com interface rugosa;

$\mu=0,6 \lambda$ para concreto lançado sobre concreto endurecido com interface lisa;

$\mu=0,7 \lambda$ para concreto sobre estrutura de aço, ancorado através de studs com cabeça ou barras de armadura

Os valores de $\lambda$ são:

$\lambda=1$ para concreto de peso normal;

$\lambda=0,85$ para concreto com agregado miúdo leve;

$\lambda=0,75$ para concreto com todo agregado leve.

Uma interpolação linear é permitida quando há uma substituição parcial do agregado graúdo

É importante ressaltar que a resistência de cálculo de escoamento da armadura deve ser menor ou igual a $422 \mathrm{MPa}$.

A armadura para resistir à força horizontal é dada por:

$$
A_{n}=\frac{H_{d}}{\phi \cdot f_{y k}}
$$

Para um concreto de densidade normal, a resistência ao cisalhamento, F, deve ser menor que $0,2 \cdot f_{\mathrm{c}} \cdot \mathrm{b} \cdot \mathrm{d}$ e que $5,5 \cdot \mathrm{b} \cdot \mathrm{d}$.

$\mathrm{A}$ área da armadura principal de tração, $\mathrm{A}_{\mathrm{S}}$, deve ser igual ou maior que os seguintes limites:

$$
\begin{aligned}
& \cdot\left(A_{f}+A_{n}\right) \\
& \cdot\left(2 A_{v f} / 3+A_{n}\right) .
\end{aligned}
$$


A taxa de armadura no consolo, $\rho=\mathrm{A}_{\mathrm{S}} / \mathrm{bd}$, não deve ser inferior a $0,04\left(\mathrm{f}_{\mathrm{ck}} / \mathrm{f}_{\mathrm{yk}}\right)$.

Além da armadura principal $A_{s}$, deve ser distribuida uniformemente, ao longo de $2 / 3$ da altura efetiva do consolo, uma área de aço não menor que $0,5 \cdot\left(A_{S}-A_{n}\right)$. Esta armadura pode ser colocada na forma de estribos ou ganchos paralelos à armadura principal.

\subsection{2 - CAN3-A23.3-M1984}

A Norma Canadense, CAN3-A23.3-M84, recomenda que o cálculo de consolos curtos seja feito através de modelos de treliças, que simulem o fluxo interno de forças atuantes na peça. Desta forma, as tensões unidirecionais podem ser modeladas como barras comprimidas (concreto) e barras tracionadas (aço). As regiões sujeitas a um estado multidirecional de tensões, ou seja, locais onde as barras comprimidas e tracionadas se encontram, são caracterizadas como zonas nodais.

Esta norma prescreve algumas condições para o cálculo de consolos:

- A relação $\frac{\mathrm{a}}{\mathrm{d}}$ não deve ser maior que a unidade;

- A altura do consolo, medida na face externa da placa de apoio, não deve ser inferior à metade da altura do consolo, medida na face do apoio;

- A força horizontal $\mathrm{H}$ não deve ser menor do que $0,2 \mathrm{~F}$;

- A armadura de costura deve ser distribuída em uma altura de dois terços de "d", adjacente à armadura principal, e não deve ter área inferior a $50 \%$ da área da armadura principal;

- A taxa de armadura $\rho=\frac{A_{s}}{b \cdot d}$, na face do apoio, não deve ser inferior a $0,04 \frac{f_{c}}{f_{y}}$ 
Para obter os valores de esforços para dimensionamento e os valores das tensões de cálculo dos materiais, a norma canadense recomenda multiplicar os valores nominais por coeficientes de ponderação, que são apresentados à seguir:

- Coeficientes majoradores de carga:

- $\gamma=1,25$ para cargas permanentes;

- $y=1,5$ para cargas variáveis.

- Coeficientes redutores de resistência:

- $\phi_{\mathrm{c}}=0,60$ para resistência do concreto;

- $\phi=0,85$ para resistência do aço

O dimensionamento de consolos, segundo esta norma, pode ser feito modelando as tensões de tração e de compressão por uma treliça e realizando o somatório de momentos em relação ao ponto $\mathrm{C}$, conforme a figura 2.8 .

$$
\Sigma \mathrm{M}_{\mathrm{C}}=0 ; \quad \text { então }: H \cdot d+\mathrm{F} \cdot\left(\mathrm{a}^{+} \mathrm{l}^{\prime}\right)=\mathrm{N}_{\mathrm{c}} \cdot\left(\mathrm{l}^{\prime}-\mathrm{a}^{\prime \prime} / 2\right)
$$

$$
\text { onde }: a^{\prime \prime}=\frac{N_{c}}{0,75 \cdot f_{c k} \cdot \phi_{c} \cdot b}
$$
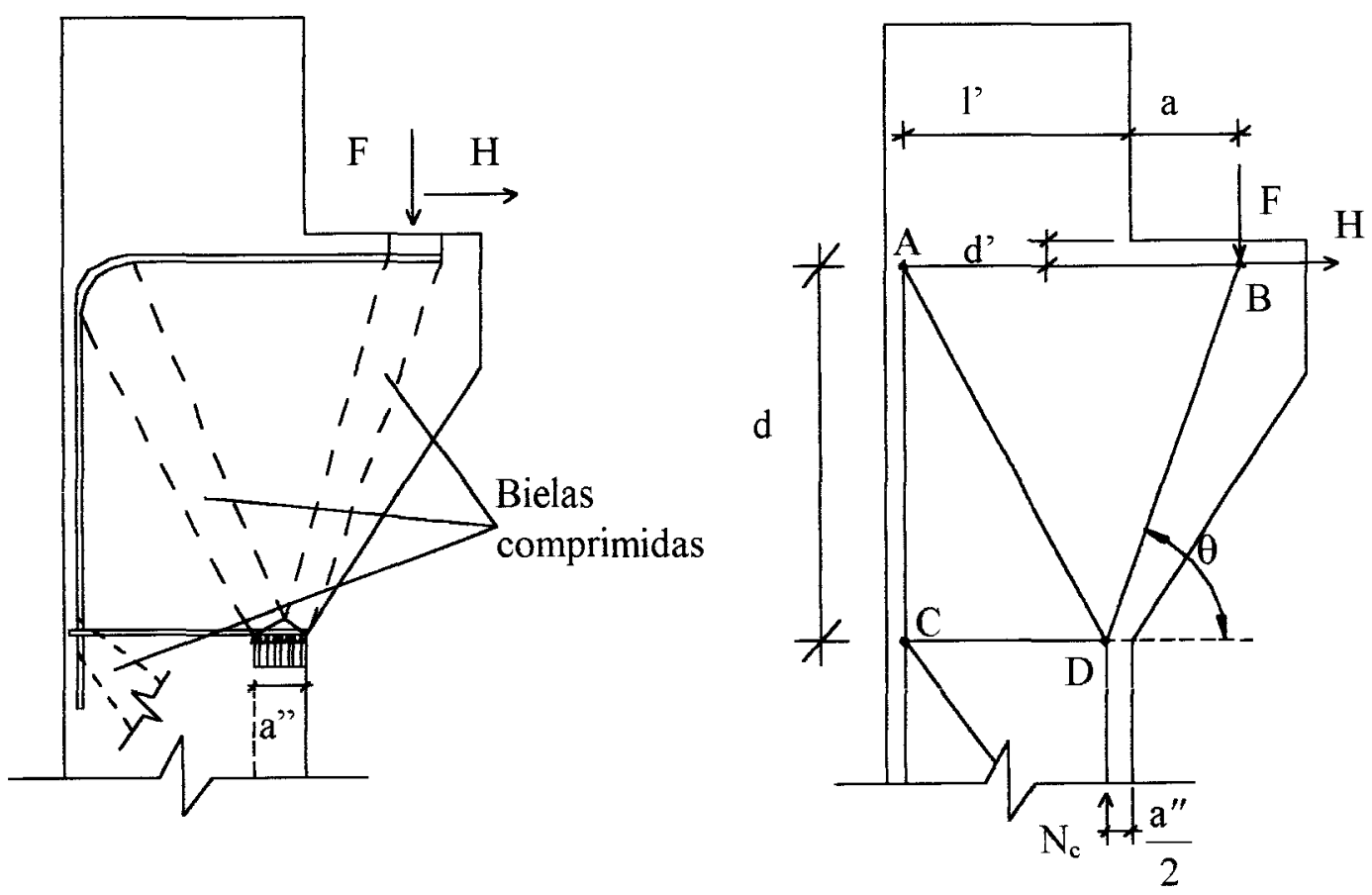

Figura 2.8 - Modelo estrutural de acordo com CAN3-A23.3-M1984 
Após obter $\mathrm{N}_{\mathrm{c}}$ e a", calculam-se os esforços nas barras da treliça, juntamente com as áreas de aço, e realiza-se a verificação da resistência do concreto nas zonas nodais e nas barras comprimidas.

As áreas de aço das barras são calculadas de acordo com as expressões:

- Armadura principal, armadura para resistir ao esforço atuante na barra $F_{A B}$.

$$
A_{s}=\frac{F_{A B}}{\phi \cdot f_{y k}}
$$

- Armadura para resistir ao esforço atuante na barra $\mathrm{F}_{\mathrm{CD}}$.

$$
A_{\mathrm{s} 2}=\frac{F_{C D}}{\phi \cdot f_{y k}}
$$

As barras tracionadas, que compõem a armadura, devem ser devidamente ancoradas para garantir a transferência dos esforços às zonas nodais.

A tensão de compressão $f_{2}$, atuante na barra comprimida de concreto, não pode ultrapassar uma tensão limite $\mathrm{f}_{2 \max }$. Estas tensões podem ser calculadas pelas expressões:

$$
\begin{aligned}
& \mathrm{f}_{2}=\left(\operatorname{tg} \theta+\frac{1}{\operatorname{tg} \theta}\right) \cdot\left(\frac{\mathrm{V}}{\mathrm{b} \cdot \mathrm{d}}\right) \\
& \mathrm{f}_{2 \max }=\frac{\lambda \phi_{\mathrm{c}} \mathrm{f}_{\mathrm{ck}}}{\left(0,8+170 \cdot \epsilon_{1}\right)}
\end{aligned}
$$

onde:

$\lambda=$ Fator relativo à baixa densidade do concreto;

$\phi_{\mathrm{c}}=$ Fator de resistência do concreto;

$\theta=$ Ângulo de inclinação da tensão da diagonal comprimida em relação à horizontal;

$\epsilon_{1}=$ Deformação principal no concreto. 
A tensão $f_{2 \operatorname{máx}}$ não deve ser superior a $\lambda \phi_{\mathrm{c}} \mathrm{f}_{\mathrm{ck}}$. Portanto, o denominador da expressão 2.11 fica limitado em $0,8+170 \epsilon_{1} \leq 1,0$. Entretanto, quando o concreto está comprimido triaxialmente, deve-se utilizar a expressão 2.12 .

$$
\epsilon_{1}=\epsilon_{\mathrm{x}}+\frac{\epsilon_{\mathrm{x}}+0,002}{\tan ^{2} \theta}
$$

$\epsilon_{\mathrm{x}}=$ Deformação longitudinal no meio da altura do elemento quando sujeito aos esforços M, V e H. Se não for possível obter valores mais precisos, pode-se adotar $\epsilon_{\mathrm{x}}=0,002$.

Caso não haja um confinamento especial, as tensões compressivas nas zonas nodais não devem exceder os seguintes limites:

$\cdot 0,85 \phi_{\mathrm{c}} \cdot \mathrm{f}_{\mathrm{ck}}$ nas zonas nodais delimitadas por tensões compressivas;

$\cdot 0,75 \phi_{\mathrm{c}} \cdot \mathrm{f}_{\mathrm{ck}}$ nas zonas nodais ancorando somente uma barra tracionada;

- $0,60 \phi_{\mathrm{c}} \cdot \mathrm{f}_{\mathrm{ck}}$ nas zonas nodais ancorando barras tracionadas em mais de uma direção.

Para que as zonas nodais suportem as tensões existentes, a armadura principal deve ser distribuída em uma área efetiva de concreto, no mínimo igual à força de tração divida pelos limites de tensão já definidos.

\subsection{3 - CEB-Model Code 1991}

De acordo com o CEB-Model Code 1991, os consolos podem ser projetados através do modelo de bielas e tirantes. Se a relação entre o vão de cisalhamento 'a' e o braço de alavanca ' $z$ ' for maior que a unidade, o consolo pode ser dimensionado como um elemento linear (viga).

Para obter os valores de esforços para dimensionamento e os valores das tensões de cálculo dos materiais, o CEB recomenda multiplicar os valores nominais 
dos esforços e dividir as tensões características por coeficientes de ponderação, que são apresentados a seguir:

- Coeficientes majoradores de carga:

- $y=1,35$ para cargas permanentes;

$\cdot \gamma=1,50$ para cargas variáveis.

- Coeficientes redutores de resistência:

- $\phi_{\mathrm{c}}=1,50$ para resistência do concreto;

- $\phi=1,15$ para resistência do aço.

$O$ braço de alavanca $z$, a força principal de tração $F_{1}$ e o nó 1 comprimido, ilustrados nos modelos estruturais da figura 2.9, podem ser calculados para os efeitos de ações axiais. A seção crítica de projeto é definida por :

$$
\mathrm{x}=\frac{\mathrm{F}_{\mathrm{v}}}{0,85 \cdot \mathrm{b} \cdot \mathrm{f}_{\mathrm{ed}}}
$$

Os nós sujeitos somente a forças de compressão podem ser limitados por um polígono, não necessariamente formando ângulos retos com as direções das forças atuantes. As tensões em cada superfície de nó podem ser consideradas como distribuídas.

No caso de nó sobre uma carga concentrada, a tensão de concreto deve ser verificada de acordo com a expressão:

$$
f_{\text {cdl }}=0,85\left[1-\left(\frac{f_{c k}}{250}\right)\right] f_{c d}
$$

$\mathrm{f}_{\mathrm{cd} 1}=$ Limite da tensão do concreto para nós submetidos apenas à compressão, $\mathrm{em} \mathrm{kgf} / \mathrm{cm}^{2}$. 

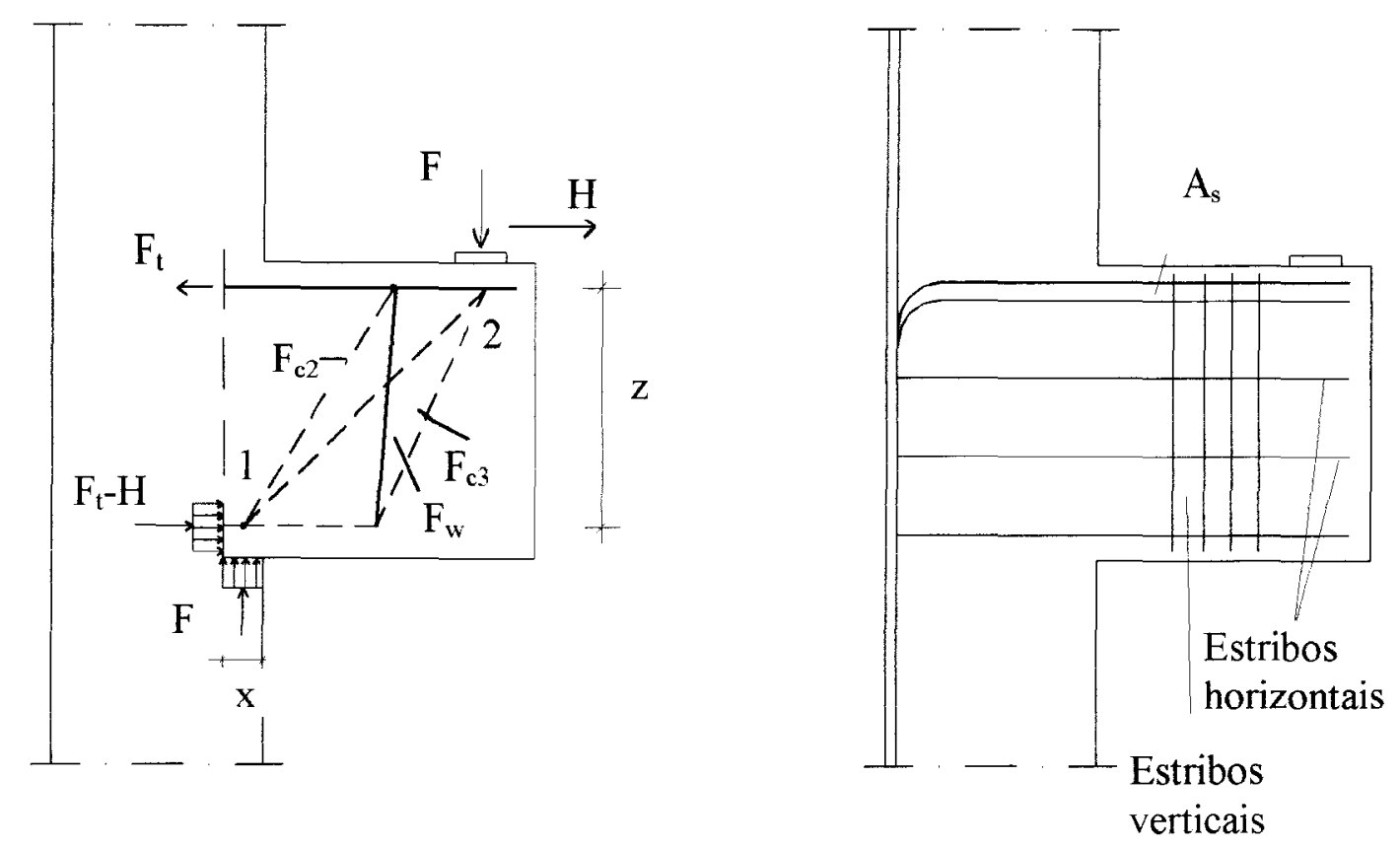

Figura 2.9-Modelo estrutural de consolos de acordo com CEB Model Code 1990

O nó 2 (nó com ancoragem de barras paralelas) pode ser verificado substituindo as componentes $F_{c 2}$ e $F_{c 3}$ pela correspondente resultante (ver figura 10). Esta resultante é inclinada de um ângulo $\theta$, obtido a partir da relação:

$$
\cot \theta=\frac{\mathrm{a}}{\mathrm{z}}\left(1-\frac{\mathrm{F}_{\mathrm{w}}}{2 \mathrm{~F}}\right)
$$

Recomenda-se, para a ancoragem da armadura principal do nó 2 , o uso de barras com pequeno diâmetro na forma de " $U$ ", dispostas horizontalmente e em diversas camadas. Podem ser usadas também placas de ancoragem ou barras transversais soldadas de igual diâmetro, posicionadas próximas à face externa do consolo.

Normalmente, em adição à armadura principal, podem ser usados estribos horizontais, se a relação $a / z$ for menor que 0,5 . No caso de $a>z / 2$, podem ser utilizados estribos verticais e quando $\mathrm{a}<\mathrm{z}$ pode-se adotar a combinação dos dois. 


\subsection{4 - NBR-9062}

A norma brasileira NBR-9062 - "Projeto e execução de estruturas prémoldadas de concreto" recomenda que os consolos curtos sejam dimensionados por modelos de bielas e tirantes e os consolos muito curtos através da teoria de atritocisalhamento.

Para obter os valores de esforços para dimensionamento, as normas brasileiras recomendam multiplicar os valores nominais por dois coeficientes de ponderação: o primeiro $\gamma$ provém da NBR-6118 e tem seu valor igual a 1,4 , e o outro $\gamma_{\mathrm{n}}$, provêm da NBR-9062 e seu valor é dado por:

Elementos pré-fabricados em usina: $\gamma_{\mathbf{n}}=1,0$ carga permanente predominante; $\gamma_{\mathrm{n}}=1,1$ caso contrário.

Demais casos: $\gamma_{\mathrm{n}}=1,1$ carga permanente predominante; $\gamma_{\mathrm{n}}=1,2$ caso contrário.

No caso dos materiais, para se obterem as resistências de cálculo, a norma brasileira recomenda dividir as resistências por coeficientes de segurança que são apresentados a seguir:

- Coeficientes redutores de resistência:

- $\gamma_{\mathrm{c}}=1,40$ para resitência do concreto;

- $\gamma_{\mathrm{s}}=1,15$ para resitência do aço.

\subsubsection{1 - Consolos curtos}

Para determinação dos esforços internos em consolos curtos com carregamento direto, será adotado o modelo de treliça recomendado por LEONHARDT \& MÖNNIG (1978), que está ilustrado na figura 2.10.

Neste modelo, as forças de tração são resistidas pelo tirante (armadura) e as forças de compressão são resistidas pela biela de concreto. Além disto, adota-se um valor de braço de alavanca $z=0,9 \mathrm{~d}$. As forças de cálculo $F_{d}$ e $H_{d}$ são obtidas 
multiplicando as forças características $\mathrm{F}$ e $\mathrm{H}$, aplicadas no consolo, pelos coeficientes de majoração das ações.

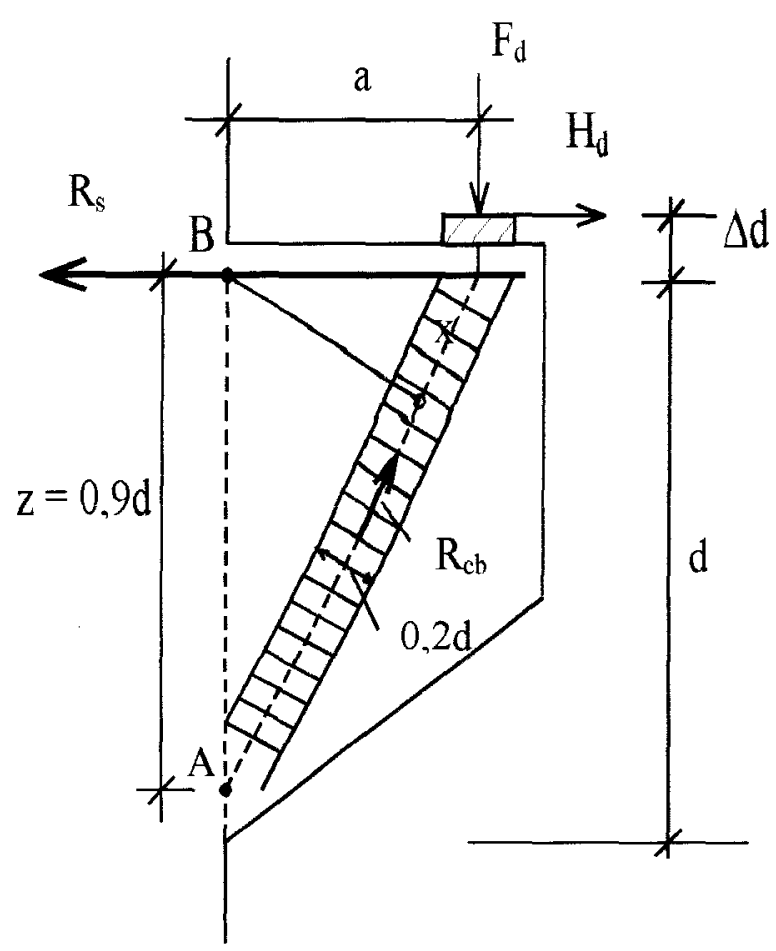

Figura 2.10 - Modelo estrutural NBR-9062 / LEONHARDT \& MÖNNIG (1978)

A partir desta modelação obtém-se as expressões de cálculo seguintes.

a) Força de tração

Fazendo o equilíbrio de momentos no ponto A, obtém-se o valor da força de tração no tirante através das seguintes expressões :

$$
\begin{aligned}
& \sum \mathrm{M}_{\mathrm{A}}=0 \Rightarrow \mathrm{R}_{\mathrm{s}} \cdot 0,9 \mathrm{~d}-\mathrm{F}_{\mathrm{d}} \cdot \mathrm{a}-\mathrm{H}_{\mathrm{d}}(\Delta \mathrm{d}+0,9 \mathrm{~d})=0 \\
& \mathrm{R}_{\mathrm{s}}=\mathrm{H}_{\mathrm{d}}\left[1+\frac{\Delta \mathrm{d}}{0,9 \mathrm{~d}}\right]+\frac{\mathrm{a}}{0,9 \mathrm{~d}} \mathrm{~F}_{\mathrm{d}}
\end{aligned}
$$


Adotando-se $\frac{\Delta \mathrm{d}}{0,9 \mathrm{~d}}=0,2$ e substituindo este valor na expressão (2.15), tem-se:

$$
\mathrm{R}_{\mathrm{s}}=1,2 \mathrm{H}_{\mathrm{d}}+\frac{\mathrm{a}}{0,9 \mathrm{~d}} \mathrm{~F}_{\mathrm{d}}
$$

\section{b) Força de compressão na biela}

Fazendo o equilíbrio de momentos no ponto B, calcula-se o valor da força de compressão atuante na biela de concreto pelas expressões:

$$
\begin{aligned}
& \sum M_{B}=0 \Rightarrow R_{c b} \cdot x-F_{d} \cdot a-H_{d} \cdot \Delta d=0 \\
& R_{c b}=\frac{1}{x}\left[H_{d} \cdot \Delta d+a \cdot F_{d}\right]
\end{aligned}
$$

onde x é calculado a partir da geometria da treliça, sendo dado pela expressão:

$$
x=\frac{0,9 d \cdot a}{\sqrt{(0,9 d)^{2}+a^{2}}}
$$

Substituindo a expressão (2.19) na (2.18) e desprezando o efeito da força horizontal, tem-se a expressão para cálculo da força de compressão na biela:

$$
\mathrm{R}_{\mathrm{cb}}=\frac{\mathrm{F}_{\mathrm{d}} \sqrt{0,9^{2}+\left(\begin{array}{l}
\mathrm{a} \\
\mathrm{d}
\end{array}\right)^{2}}}{0,9}
$$

c) Tensão de compressão na biela

A tensão de cálculo na biela comprimida é obtida dividindo a força de compressão pela área da seção transversal da biela. De acordo com LEONHARDT \& 
MÖNNIG (1978), esta área é dada por $0,2 \cdot b \cdot d$. A partir daí, têm-se as seguintes expressões de cálculo:

$$
\sigma_{\mathrm{cb}}=\frac{\mathrm{R}_{\mathrm{cb}}}{0,2 \mathrm{~b} \cdot \mathrm{d}}
$$

Desprezando a contribuição da força horizontal no cálculo da força na biela e substituindo a expressão (2.20) na (2.21), obtém-se :

$$
\sigma_{\mathrm{cb}}=\frac{\mathrm{F}_{\mathrm{d}} \sqrt{0,9^{2}+\left(\frac{\mathrm{a}}{\mathrm{d}}\right)^{2}}}{0,18 \mathrm{~b} \cdot \mathrm{d}}
$$

Para que não ocorra o esmagamento do concreto, esta tensão está limitada pelo valor da tensão de compressão de cálculo do concreto, $\mathrm{f}_{\mathrm{cd}}$. Sendo assim, tem-se que:

$$
\sigma_{\mathrm{cb}} \leq \mathrm{f}_{\mathrm{cd}}
$$

d) Armadura principal

O valor relativo à armadura principal é calculado dividindo-se a força de tração pela tensão de escoamento de cálculo no aço, resultando a expressão:

$$
A_{s}=\frac{R_{s}}{f_{y d}}
$$

Substituindo a expressão (2.16) na (2.24), tem-se:

$$
A_{s}=\frac{1}{f_{y d}} \cdot\left(\frac{a \cdot F_{d}}{0,9 d}+1,2 H_{d}\right)
$$




\subsubsection{2 - Consolos muito curtos}

O dimensionamento de consolos muito curtos é feito utilizando a teoria do atrito-cisalhamento. Entretanto, a NBR-9062 recomenda que a armadura principal utilizada não deve ser inferior à calculada através do modelo de bielas e tirantes. As expressões indicadas a seguir são as apresentadas diretamente na NBR-9062.

a) Armadura do tirante

$$
A_{s}=\frac{0,8 \cdot F_{d}}{f_{y d} \cdot \mu}+\frac{H_{d}}{f_{y d}}
$$

Valores de $\mu$ :

$$
\begin{aligned}
& \mu=1,4 \text { para concreto lançado monoliticamente; } \\
& \mu=1,0 \text { para concreto lançado sobre concreto endurecido com interface } \\
& \text { rugosa; } \\
& \mu=0,6 \text { para concreto lançado sobre concreto endurecido com interface } \\
& \text { lisa. }
\end{aligned}
$$

É importante ressaltar que o limite da tensão na armadura deve ser: $f_{y d} \leq 435$ MPa.

b) Tensão atuante no concreto

$$
\tau_{d}=\frac{F_{d}}{b \cdot d}<\tau_{w u}
$$

onde $\tau_{\mathrm{wu}} \leq\left\{\begin{array}{l}3,0+0,9 \rho \cdot \mathrm{f}_{\mathrm{yd}} \leq 0,3 \cdot \mathrm{f}_{\mathrm{cd}}(\mathrm{em} \mathrm{MPa}) \\ 6 \mathrm{MPa}\end{array}\right.$

e $\quad \rho=\frac{A_{s}}{b \cdot d}$ 
Além destas recomendações, a norma brasileira recomenda :

- 0 uso de armadura de costura com área não inferior a $0,4 \mathrm{~A}_{\mathrm{s}}$ para consolos curtos e $0,5 \mathrm{~A}_{\mathrm{s}}$ para consolos muito curtos. Esta armadura de costura deve ser distribuída em uma altura de dois terços de "d", adjacente à armadura principal;

- $O$ uso de uma taxa mecânica de armadura do tirante $\omega=\frac{A s \cdot f_{\mathrm{yk}}}{\mathrm{b} \cdot \mathrm{d} \cdot \mathrm{f}_{\mathrm{ck}}}$, não inferior 0,04 e nem superior a 0,15 ;

- 0 uso de armadura vertical em forma de estribos, com área não inferior a:

$$
A_{s, v e r t} \geq\left\{\begin{array}{l}
0,14 \cdot b \\
0,2 \cdot A_{s}
\end{array}\right.
$$

- Não se devem adotar valores para a tensão de cálculo na armadura superiores a $425 \mathrm{MPa}$.

\section{5 - ESTUDOS REALIZADOS POR OUTROS PESQUISADORES}

Com o intuito de situar este trabalho em relação aos estudos realizados até o momento, por outros pesquisadores, são descritos a seguir, de maneira resumida, os principais trabalhos encontrados na literatura.

Durante muitas décadas na Europa, o projeto de consolos foi baseado na analogia de viga proposta por RAUSCH (1931) apud HAGBERG (1983). NIEDENHOFF (1961) propôs uma teoria para cálculo baseada na analogia de treliça, formada pela armadura resistindo aos esforços de tração horizontal e pelo concreto atuando como um elemento comprimido e inclinado. Com esta nova teoria surgiu também uma nova maneira de armar e detalhar consolos, indicando principalmente um reforço na região do pilar acima do consolo.

RAUSCH, E. (1931). Direct shear in concrete structures. Der Bauiungeieur. v. 38, $\mathrm{n}$. 32/33 p.578-581. Apud HAGBERG, T. (1983). Design of concrete brackets: on the application of the truss analogy. Journal of the American Concrete Institute. v. 80, n. 1, p. $3-12$. 
FRANZ \& NIEDENHOFF (1963) realizaram ensaios de consolos não simétricos, sem carregamento axial no pilar, com diversas relações de a/d e carregados direta e indiretamente. Nesse estudo, através da fotoelasticidade, foram traçadas as trajetórias de tensão nos consolos, as quais estão explicadas no item 2.2 deste trabalho. O trabalho de FRANZ \& NIEDENHOFF (1963) reforçou ainda mais o modelo de cálculo proposto por NIEDENHOFF (1961).

Nos Estado Unidos, o dimensionamento de consolos era baseado em um critério de projeto empírico corriqueiro. KRIZ \& RATHS (1965) ensaiaram, no laboratório de pesquisa e desenvolvimento da Associação de Cimento Portland dos Estados Unidos, duas séries de consolos, uma contendo 124 consolos simétricos, sujeitos apenas a forças verticais, e outra contendo 71 consolos, sujeitos a combinação de forças verticais e horizontais. Estas duas séries foram compostas por consolos com várias relações $\mathrm{a} / \mathrm{d}$, consolos com e sem armadura de costura secundária e resistência do concreto variando de 15 a $46 \mathrm{MPa}$.

Com base nestes ensaios, eles propuseram um equacionamento para cálculo de consolos. Estes estudos, mais tarde, foram levados em conta na elaboração da Norma Americana ACI 318-71.

MAST (1968) apud HAGBERG (1983) propôs um método aproximado semiempírico, baseado nos estudos de KRIZ \& RATHS (1965). Este método é chamado de "shear-friction", ou seja, atrito-cisalhamento.

HERMANSEN \& CAWAN (1974) propuseram mudanças no modelo proposto por MAST (1968). Estas mudanças basearam-se, principalmente, na análise separada de três tipos de ruínas:

- Ruína por cisalhamento, a mais provável de acontecer em consolos;

- Ruína por flexão, que ocorre quando a armadura principal escoa ou quando há o esmagamento do concreto;

MAST, R.F. (1968). Auxiliary reinforced in concrete connections. Journal of de Structural Division, ASCE. v. 94, n. ST6, p.1485-1504. Apud HAGBERG, T. (1983). Design of concrete brackets: on the application of the truss analogy. Journal of the American Concrete Institute. v. 80, n. 1, p. 3-12. 
- Ruína por efeitos secundários, que ocorrem geralmente por falhas no detalhamento.

MATTOCK et all (1975) ensaiaram uma série de consolos simétricos, com e sem armadura de costura, consolos de concreto normal e de concreto com agregados leves, com várias relações a/d e utilizando combinações de carregamentos verticais e horizontais. Neste estudo, as forças de ruína dos consolos foram comparadas com forças de ruína teóricas obtidas pela análise do ACI 318-71 e ainda foram analisadas e propostas algumas modificações para esta Norma.

MATTOCK (1975) propôs um método de cálculo de consolos levando em conta as modificações propostas em MATTOCK et al. (1975). Tais propostas basearam-se praticamente em mudanças nos fatores de verificação do cisalhamento e na teoria do atrito-cisalhamento.

HAGBERG (1983) propôs um modelo teórico para cálculo de consolos, baseado na analogia de treliça proposta por FRANZ \& NIEDENHOFF (1963). Este modelo parte de algumas premissas, dentre as quais citam-se:

- As condições de equilíbrio de esforços internos e externos devem ser satisfeitas;

- As deformações elásticas foram negligenciadas quando comparadas com as deformações plásticas;

- Foram considerados critérios de ruína: o esmagamento do concreto e o escoamento do aço;

- A resistência dos materiais é determinada em testes uniaxiais e a resistência do concreto à tração é negligenciada;

- A geometria das peças deve seguir o modelo proposto;

- Deve-se assegurar que não haja ruína localizada da peça.

Tal modelo foi desenvolvido para consolos com carregamentos verticais e horizontais e para detalhamento de consolos com diversos tipos de estribos. Para verificar a precisão do modelo, foram calculadas as forças de ruína teórica e comparadas com os resultados experimentais de alguns consolos ensaiados por KRIZ 
\& RATHS (1965). Os resultados desta análise foram bastante satisfatórios, principalmente para consolos com ruína devida ao escoamento da armadura.

NAEGELI (1988) realizou um estudo experimental de consolos não simétricos com carregamento vertical. Neste estudo foram ensaiados consolos curtos e muito curtos ligados a pilares com e sem carregamento axial. Os resultados das forças de ruína foram comparados com os respectivos resultados previstos por normas. Além disto, neste trabalho, foram analisadas as forças de início de fissuração, a relação força aplicada x deformação na armadura principal do consolo e o efeito do carregamento axial no pilar, no controle de fissuração e na resistência final do consolo.

FATTUHI (1990) analisou o comportamento de consolos simétricos com carregamento axial no pilar e concluiu que esse carregamento no pilar não provocou nenhum aumento aparente na capacidade de carga do consolo.

SHEHATA et al. (1991) compararam os resultados experimentais da força de ruína dos consolos ensaiados por NAEGELI (1988), com valores teóricos obtidos através da análise plástica, teoremas dos limites inferior e superior, obtendo, desta análise, um erro percentual médio inferior a $4 \%$.

ZIELINSKI \& RIGOTTI (1995) analisaram consolos, dentes geber e vigasparede, buscando encontrar o valor da resistência máxima ao esforço cortante de peças dimensionadas pelo modelo de bielas e tirantes. Neste trabalho é indicado o limite máximo da tensão de cisalhamento, em função da resistência do concreto e da quantidade de armadura

REIS \& TORRES (1996) realizaram um estudo experimental de consolos simétricos muito curtos com carregamento vertical. Os resultados das forças de ruina foram comparados com os respectivos resultados teóricos previstos por normas. Além disto, neste trabalho, foram analisadas as forças de inicio de fissuração e a relação força aplicada x deformação na armadura principal do consolo.

Além dos trabalhos clássicos sobre consolos com concreto de resistência normal e armados de maneira convencional, podem-se destacar ainda duas linhas de pesquisa, apresentadas a seguir. 


\subsection{1 - Consolos de concreto com fibras}

O estudo de consolos com fibras teve um grande impulso a partir da década de 80. FATTUHI (1987) ensaiou uma série de consolos sem armadura de costura e utilizando concreto com e sem fibras. Os consolos com fibras apresentaram força de ruína cerca de $40 \%$ superior e força de início de fissuração cerca de $74 \%$ superior em relação aos consolos sem fibras. FATTUHI \& HUGHES (1989) analisaram consolos com e sem fibras e com armadura de costura. Seus estudos indicaram que consolos com fibras apresentaram um comportamento mais dúctil do que consolos sem fibras, tanto para cargas de serviço como na ruína.

Além destes, podem-se citar trabalhos que analisaram outros aspectos do comportamento e do dimensionamento de consolos com vários tipos de fibras. Entre eles, destacam-se: HUGHES \& FATTUHI (1989), FATTUHI \& HUGHES (1989), FATTUHI (1990), FATTUHI (1994) e YOUNG \& BALAGURU (1994).

\subsection{2 - Consolos de concreto de alta resistência}

O estudo de consolos de concreto de alta resistência é bastante recente e, nesta linha, destacam-se os trabalhos comentados a seguir.

YOUNG et al. (1985) ensaiaram consolos de concreto de alta resistência e compararam os resultados da força de ruína com os valores teóricos desta força, obtidos através dos modelos de bielas e tirantes propostos por HAGBERG(1983) e das recomendações da Norma Americana ACI. Os resultados destes estudos indicaram que, para concreto de alta resistência, a Norma Americana é muito conservativa e que a análise pelos modelos de bielas e tirantes apresentam resultados satisfatórios.

FOSTER et al. (1996) ensaiaram 30 consolos com resistência do concreto variando de 45 a $105 \mathrm{MPa}$ e com várias relações de a/d, chegando às seguintes conclusões: 
- Consolos de concreto de alta resistência apresentam comportamento similar a consolos de concreto de resistência normal;

- A armadura de costura faz com que haja redução na abertura das fissuras, aumenta a ductilidade e provoca mudanças no tipo de ruína. A quantidade mínima de armadura de costura é a mesma indicada para concreto de resistência normal;

- 0 ACI 318-89 não é recomendado para cálculo de consolos de concreto de alta resistência;

- O modelo indicado por HAGBERG (1983) é uma boa ferramenta para cálculo de consolos de concreto de alta resistência. 


\section{CAPÍTULO 3 - ANÁLISE DE CONSOLOS ENSAIADOS POR OUTROS PESQUISADORES}

Neste capítulo são apresentados e analisados consolos ensaiados por outros pesquisadores. Os consolos foram divididos em quatro grupos: consolos sem armadura de costura e carregamento vertical, consolos sem armadura de costura e carregamentos verticais e horizontais, consolos com armadura de costura e carregamento vertical e consolos com armadura de costura e carregamentos verticais e horizontais.

Para facilitar a análise, foram montadas tabelas que incluem as principais características dos consolos, a força de ruína e a relação entre força de ruína experimental e a força de ruína calculada utilizando normas ACI-318M-89, CAN3A23.3-M1984 e NBR-9062.

$\mathrm{Na}$ coluna de identificação dos consolos, usou-se o mesmo esquema adotado por NAEGELI (1997): as duas primeiras letra referem-se ao sobrenome dos autores/pesquisadores que ensaiaram os consolos ou o sobrenome do primeiro autor, quando havia mais de dois autores. As siglas utilizadas significam:

- KR - Kriz e Raths;

- HC - Hermansen e Cowam;

- MA - Mattock et al;

- YO - Young e Young \& Balagaru;

- $\mathrm{CH}$ - Chakrabarti \& Farahani e Chakrabarti et al; 
- $\mathrm{CO}-\mathrm{Cook}$

- NA - Naegeli;

- FA - Fattuhi e Fattuhi \& Hughes;

- ZE - Zeller;

- SE - Selim, Foster e Gowripalan;

- RT - Reis e Torres.

As demais letras e os números indicados referem-se à identificação utilizada pelos próprios autores.

\section{1 - CONSOLOS SEM ARMADURA DE COSTURA E CARREGAMENTO VERTICAL}

A tabela 3.1 apresenta as características destes consolos, o valor da relação entre a força horizontal e a força vertical aplicada no consolo $\left(F_{h} / F_{v}\right)$, que, neste caso, é igual a zero, e a relação entre a força de ruína experimental e a força de ruína calculada $\left(\mathrm{F}_{\mathrm{r}} / \mathrm{F}_{\mathrm{c}}\right)$. Esta tabela apresenta, ainda, a média e o desvio padrão dos valores $F_{\mathrm{r}} / \mathrm{F}_{\mathrm{c}}$, para a força de ruína calculada por cada uma das normas citadas.

Através da média e do desvio padrão da relação $F_{\mathrm{r}} / \mathrm{F}_{\mathrm{c}}$, nota-se que a norma que apresentou o valor desta relação mais próximo da unidade e com menor desvio foi a Norma Canadense. Entretanto, estes valores ficaram contra a segurança. Isto indica que, no caso de consolos sem armadura de costura, a norma canadense forneceu valores contra a segurança.

A norma que apresentou melhores resultados foi a Norma Brasileira. Entretanto, os valores da média e do desvio padrão da relação $F_{r} / F_{c}$ ficaram altos, indicando uma grande variabilidade dos resultados.

A Norma Americana foi a que apresentou os piores resultados, tanto na média da relação $F_{r} / F_{\mathfrak{c}}$, como no desvio padrão.

De maneira geral, os consolos que apresentaram os piores resultados da relação $F_{r} / F_{c}$ foram aqueles com a relação a/d muito pequena e com baixa taxa de 
armadura, consolos com baixa taxa de armadura e os consolos com a taxa de armadura muito elevada.

A verificação da teoria de atrito-cisalhamento utilizada pela Norma Americana indicou, na maioria dos casos, o valor da força de ruína calculada. Isto ocorreu principalmente para os consolos com baixa taxa de armadura. Para estes consolos o valor da relação $\mathrm{F}_{\mathrm{r}} / \mathrm{F}_{\mathrm{c}}$ ficou elevado. 
Tabela 3.1 - Consolos sem armadura de costura e com força vertical

\begin{tabular}{|c|c|c|c|c|c|c|c|c|c|c|c|c|c|c|}
\hline \multirow[b]{2}{*}{ Consolos } & \multicolumn{4}{|c|}{ Geometria } & \multirow{2}{*}{$\begin{array}{c}f_{c} \\
(\mathrm{MPa})\end{array}$} & \multicolumn{4}{|c|}{ Armadura } & \multirow{2}{*}{$\mathrm{F}_{\mathrm{h}} / \mathrm{F}_{\mathrm{v}}$} & \multirow{2}{*}{$\begin{array}{c}F_{r} \\
(k N)\end{array}$} & \multicolumn{3}{|c|}{ Relação $F_{r} / F_{c}$} \\
\hline & $a / d$ & $\begin{array}{c}\mathrm{a} \\
(\mathrm{mm})\end{array}$ & $\begin{array}{c}\mathrm{h} \\
(\mathrm{mm})\end{array}$ & $\begin{array}{c}\mathrm{b} \\
(\mathrm{mm})\end{array}$ & & $\begin{array}{c}\rho \\
(\%)\end{array}$ & $\begin{array}{c}A_{\mathrm{s}} \\
\left(\mathrm{mm}^{2}\right)\end{array}$ & $\begin{array}{c}f_{y} \\
(\mathrm{MPa})\end{array}$ & $\begin{array}{c}\mathrm{d} \\
(\mathrm{mm})\end{array}$ & & & $\mathrm{ACI}$ & $\mathrm{CAN}$ & NBR \\
\hline KR-1 & 0,14 & 70 & 559 & 203 & 26,1 & 0,38 & 396 & 312 & 513 & 0 & 445 & 2,57 & 0,84 & 2,05 \\
\hline KR-2 & 0,14 & 70 & 559 & 203 & 42,5 & 0,38 & 396 & 324 & 513 & 0 & 784 & 4,35 & 1,26 & 3,48 \\
\hline KR-3 & 0,11 & 70 & 660 & 203 & 26,3 & 0,32 & 400 & 312 & 615 & 0 & 485 & 2,77 & 0,80 & 2,22 \\
\hline KR-4 & 0,17 & 70 & 457 & 203 & 24,3 & 0,93 & 773 & 301 & 409 & 0 & 445 & 1,37 & 0,65 & 1,09 \\
\hline KR-5 & 0,14 & 70 & 559 & 203 & 26,5 & 0,75 & 778 & 299 & 511 & 0 & 607 & 1,87 & 0,75 & 1,50 \\
\hline KR-6 & 0,11 & 70 & 660 & 203 & 27,4 & 0,62 & 771 & 324 & 612 & 0 & 611 & 1,75 & 0,63 & 1,40 \\
\hline KR-7 & 0,17 & 70 & 457 & 203 & 22,5 & 1,86 & 1546 & 299 & 409 & 0 & 624 & 1,80 & 0,70 & 0,82 \\
\hline KR-8 & 0,14 & 70 & 559 & 203 & 28,8 & 1,49 & 1546 & 316 & 511 & 0 & 780 & 1,31 & 0,66 & 1,32 \\
\hline KR-9 & 0,14 & 70 & 559 & 203 & 44,8 & 1,49 & 1546 & 310 & 511 & 0 & 1180 & 1,76 & 0,75 & 1,41 \\
\hline KR-10 & 0,11 & 70 & 660 & 203 & 33,0 & 1,24 & 1542 & 324 & 612 & 0 & 770 & 1,10 & 0,55 & 0,94 \\
\hline KR-11 & 0,33 & 102 & 356 & 203 & 26,9 & 1,24 & 774 & 329 & 307 & 0 & 411 & 1,22 & 0,78 & 1,30 \\
\hline KR-12 & 0,37 & 152 & 457 & 203 & 29,2 & 0,31 & 259 & 352 & 411 & 0 & 314 & 2,45 & 1,43 & 1,96 \\
\hline KR-13 & 0,30 & 152 & 559 & 203 & 31,6 & 0,25 & 261 & 352 & 513 & 0 & 427 & 3,34 & 1,58 & 2,67 \\
\hline KR-14 & 0,25 & 152 & 660 & 203 & 31,3 & 0,21 & 262 & 352 & 615 & 0 & 374 & 2,90 & 1,17 & 2,32 \\
\hline KR-15 & 0,37 & 152 & 457 & 203 & 31,0 & 0,48 & 401 & 332 & 411 & 0 & 321 & 1,72 & 1,03 & 1,38 \\
\hline KR-16 & 0,37 & 152 & 457 & 203 & 23,6 & 0,48 & 401 & 331 & 411 & 0 & 349 & 1,88 & 1,17 & 1,51 \\
\hline KR-17 & 0,37 & 152 & 457 & 203 & 27,5 & 0,48 & 401 & 661 & 411 & 0 & 380 & 1,03 & 0,70 & 0,82 \\
\hline KR-18 & 0,37 & 152 & 457 & 203 & 29,0 & 0,48 & 401 & 326 & 411 & 0 & 360 & 1,97 & 1,19 & 1,57 \\
\hline KR-19 & 0,30 & 152 & 559 & 203 & 26,1 & 0,38 & 396 & 298 & 513 & 0 & 411 & 2,49 & 1,25 & 1,99 \\
\hline KR-20 & 0,30 & 152 & 559 & 203 & 24,5 & 0,38 & 396 & 661 & 513 & 0 & 383 & 1,05 & 0,61 & 0,84 \\
\hline KR-21 & 0,25 & 152 & 660 & 203 & 27,0 & 0,32 & 400 & 298 & 615 & 0 & 423 & 2,53 & 1,08 & 2,03 \\
\hline KR-22 & 0,25 & 152 & 660 & 203 & 25,8 & 0,32 & 400 & 661 & 615 & 0 & 467 & 1,26 & 0,64 & 1,01 \\
\hline KR-23 & 0,25 & 152 & 660 & 203 & 27,2 & 0,32 & 400 & 310 & 615 & 0 & 394 & 2,26 & 0,97 & 1,81 \\
\hline KR-24 & 0,37 & 152 & 457 & 203 & 29,3 & 0,93 & 773 & 326 & 409 & 0 & 396 & 1,12 & 0,75 & 0,90 \\
\hline
\end{tabular}


Tabela 3.1 - Continuação: Consolos sem armadura de costura e com força vertical

\begin{tabular}{|c|c|c|c|c|c|c|c|c|c|c|c|c|c|c|}
\hline \multirow[b]{2}{*}{ Consolos } & \multicolumn{4}{|c|}{ Geometria } & \multirow[b]{2}{*}{$\begin{array}{c}f_{\mathrm{c}} \\
(\mathrm{MPa})\end{array}$} & \multicolumn{4}{|c|}{ Armadura } & \multirow{2}{*}{$\mathrm{F}_{\mathrm{h}} / \mathrm{F}_{\mathrm{v}}$} & \multirow{2}{*}{$\begin{array}{c}\mathrm{Fr}_{\mathrm{r}} \\
(\mathrm{kN})\end{array}$} & \multicolumn{3}{|c|}{ Relação $F_{r} / F_{c}$} \\
\hline & $a / d$ & $\begin{array}{c}\mathrm{A} \\
(\mathrm{mm})\end{array}$ & $\begin{array}{c}\mathrm{h} \\
(\mathrm{mm})\end{array}$ & $\begin{array}{c}\mathrm{b} \\
(\mathrm{mm})\end{array}$ & & $\begin{array}{c}\rho \\
(\%)\end{array}$ & $\begin{array}{c}\mathrm{A}_{\mathrm{s}} \\
\left(\mathrm{mm}^{2}\right)\end{array}$ & $\begin{array}{c}f_{\mathrm{y}} \\
(\mathrm{MPa})\end{array}$ & $\begin{array}{c}\mathrm{d} \\
(\mathrm{mm})\end{array}$ & & & $\mathrm{ACI}$ & CAN & NBR \\
\hline KR-25 & 0,37 & 152 & 457 & 203 & 44,2 & 0,93 & 773 & 321 & 409 & 0 & 579 & 1,66 & 1,04 & 1,33 \\
\hline KR-26 & 0,37 & 152 & 457 & 203 & 29,5 & 0,93 & 773 & 367 & 409 & 0 & 492 & 1,24 & 0,85 & 0,99 \\
\hline KR-27 & 0,30 & 152 & 559 & 203 & 29,8 & 0,75 & 778 & 326 & 511 & 0 & 511 & 1,44 & 0,81 & 1,15 \\
\hline KR-28 & 0,25 & 152 & 660 & 203 & 31,9 & 0,62 & 771 & 326 & 612 & 0 & 556 & 1,58 & 0,76 & 1,26 \\
\hline KR-29 & 0,25 & 152 & 660 & 203 & 25,7 & 0,62 & 771 & 328 & 612 & 0 & 549 & 1,55 & 0,78 & 1,24 \\
\hline KR-30 & 0,30 & 152 & 559 & 203 & 29,4 & 0,99 & 1022 & 314 & 508 & 0 & 601 & 1,33 & 0,79 & 1,07 \\
\hline KR-31 & 0,25 & 152 & 660 & 203 & 27,9 & 0,82 & 1016 & 321 & 610 & 0 & 668 & 1,46 & 0,77 & 1,17 \\
\hline KR-32 & 0,25 & 152 & 660 & 203 & 30,3 & 0,82 & 1016 & 321 & 610 & 0 & 623 & 1,36 & 0,70 & 1,09 \\
\hline KR-33 & 0,37 & 152 & 457 & 203 & 26,4 & 1,86 & 1546 & 326 & 409 & 0 & 507 & 1,15 & 0,58 & 0,63 \\
\hline KR-34 & 0,37 & 152 & 457 & 203 & 28,1 & 1,86 & 1546 & 367 & 409 & 0 & 549 & 1,18 & 0,56 & 0,64 \\
\hline KR-35 & 0,30 & 152 & 559 & 203 & 26,3 & 1,49 & 1546 & 326 & 511 & 0 & 588 & 1,02 & 0,57 & 0,67 \\
\hline KR-36 & 0,25 & 152 & 660 & 203 & 27,3 & 1,24 & 1542 & 326 & 612 & 0 & 690 & 1,02 & 0,45 & 0,78 \\
\hline KR-37 & 0,25 & 152 & 660 & 203 & 26,0 & 1,24 & 1542 & 374 & 612 & 0 & 694 & 1,07 & 0,54 & 0,67 \\
\hline KR-38 & 0,59 & 241 & 457 & 203 & 32,4 & 0,93 & 773 & 365 & 409 & 0 & 380 & 0,96 & 0,90 & 0,88 \\
\hline KR-39 & 0,59 & 241 & 457 & 203 & 31,0 & 0,93 & 773 & 376 & 409 & 0 & 386 & 0,83 & 0,90 & 0,90 \\
\hline KR-40 & 0,59 & 241 & 457 & 203 & 29,9 & 0,93 & 773 & 305 & 409 & 0 & 387 & 1,17 & 1,08 & 1,07 \\
\hline KR-41 & 0,59 & 241 & 457 & 203 & 29,0 & 0,93 & 773 & 306 & 409 & 0 & 347 & 1,05 & 0,98 & 0,96 \\
\hline KR-42 & 0,39 & 241 & 660 & 203 & 33,4 & 0,62 & 771 & 362 & 612 & 0 & 667 & 1,71 & 1,11 & 1,36 \\
\hline KR-43 & 0,39 & 241 & 660 & 203 & 28,5 & 0,62 & 771 & 315 & 612 & 0 & 533 & 1,57 & 1,03 & 1,26 \\
\hline KR-44 & 0,39 & 241 & 660 & 203 & 26,5 & 0,62 & 771 & 313 & 612 & 0 & 498 & 1,47 & 0,97 & 1,18 \\
\hline KR-45 & 0,59 & 241 & 457 & 203 & 29,5 & 1,86 & 1546 & 348 & 409 & 0 & 534 & 1,09 & 0,73 & 1,30 \\
\hline KR-46 & 0,59 & 241 & 457 & 203 & 26,5 & 1,86 & 1546 & 305 & 409 & 0 & 466 & 1,06 & 0,73 & 1,27 \\
\hline KR-47 & 0,59 & 241 & 457 & 203 & 28,0 & 1,86 & 1546 & 306 & 409 & 0 & 465 & 1,00 & 0,72 & 1,19 \\
\hline $\mathrm{KR}-48$ & 0,39 & 241 & 660 & 203 & 33,9 & 1,24 & 1542 & 313 & 612 & 0 & 616 & 0,91 & 0,65 & 0,73 \\
\hline
\end{tabular}


Tabela 3.1 - Continuação: Consolos sem armadura de costura e com força vertical

\begin{tabular}{|c|c|c|c|c|c|c|c|c|c|c|c|c|c|c|}
\hline \multirow[b]{2}{*}{ Consolos } & \multicolumn{4}{|c|}{ Geometria } & \multirow[b]{2}{*}{$\begin{array}{c}f_{c} \\
(\mathrm{MPa})\end{array}$} & \multicolumn{4}{|c|}{ Armadura } & \multirow{2}{*}{$F_{h} / F_{v}$} & \multirow[b]{2}{*}{$\begin{array}{c}\mathrm{F}_{\mathrm{r}} \\
(\mathrm{kN})\end{array}$} & \multicolumn{3}{|c|}{ Relação $F_{r} / F_{c}$} \\
\hline & $a / d$ & $\begin{array}{c}\mathrm{a} \\
(\mathrm{mm})\end{array}$ & $\begin{array}{c}\mathrm{h} \\
(\mathrm{mm})\end{array}$ & $\begin{array}{c}\mathrm{b} \\
(\mathrm{mm})\end{array}$ & & $\begin{array}{c}\rho \\
(\%)\end{array}$ & $\begin{array}{c}\mathrm{A}_{\mathrm{s}} \\
\left(\mathrm{mm}^{2}\right)\end{array}$ & $\begin{array}{c}f_{y} \\
(\mathrm{MPa})\end{array}$ & $\begin{array}{c}\mathrm{d} \\
(\mathrm{mm})\end{array}$ & & & $\mathrm{ACI}$ & $\mathrm{CAN}$ & NBR \\
\hline KR-49 & 0,39 & 241 & 660 & 203 & 28,8 & 1,24 & 1542 & 331 & 612 & 0 & 614 & 0,86 & 0,64 & 0,69 \\
\hline KR-50 & 0,39 & 241 & 660 & 203 & 30,3 & 1,24 & 1542 & 313 & 612 & 0 & 409 & 0,61 & 0,44 & 0,48 \\
\hline KR-51 & 0,39 & 241 & 660 & 203 & 31,0 & 1,24 & 1542 & 315 & 612 & 0 & 483 & 0,71 & 0,51 & 0,57 \\
\hline KR-52 & 0,62 & 254 & 457 & 203 & 27,3 & 0,48 & 401 & 305 & 411 & 0 & 213 & 1,24 & 1,15 & 1,19 \\
\hline KR-53 & 0,62 & 254 & 457 & 203 & 43,8 & 0,48 & 401 & 305 & 411 & 0 & 242 & 1,41 & 1,27 & 1,35 \\
\hline KR-54 & 0,62 & 254 & 457 & 203 & 27,2 & 0,48 & 401 & 310 & 411 & 0 & 200 & 1,15 & 1,06 & 1,10 \\
\hline KR-55 & 0,50 & 254 & 559 & 203 & 27,6 & 0,38 & 396 & 312 & 513 & 0 & 269 & 1,55 & 1,16 & 1,24 \\
\hline KR-56 & 0,41 & 254 & 660 & 203 & 26,0 & 0,32 & 400 & 312 & 615 & 0 & 259 & 1,48 & 0,95 & 1,19 \\
\hline KR-57 & 0,41 & 254 & 660 & 203 & 28,5 & 0,32 & 400 & 328 & 615 & 0 & 375 & 2,05 & 1,30 & 1,64 \\
\hline KR-58 & 0,62 & 254 & 457 & 203 & 25,6 & 0,93 & 773 & 308 & 409 & 0 & 249 & 0,75 & 0,74 & 0,72 \\
\hline KR-59 & 0,62 & 254 & 457 & 203 & 24,2 & 0,93 & 773 & 299 & 409 & 0 & 243 & 0,75 & 0,74 & 0,73 \\
\hline KR-60 & 0,62 & 254 & 457 & 203 & 26,3 & 0,93 & 773 & 305 & 409 & 0 & 355 & 1,08 & 1,05 & 1,04 \\
\hline KR-61 & 0,62 & 254 & 457 & 203 & 28,3 & 0,93 & 773 & 374 & 409 & 0 & 334 & 0,82 & 0,82 & 0,86 \\
\hline KR-62 & 0,50 & 254 & 559 & 203 & 22,5 & 0,75 & 778 & 301 & 511 & 0 & 312 & 0,95 & 0,78 & 0,76 \\
\hline KR-63 & 0,42 & 254 & 660 & 203 & 23,6 & 0,62 & 771 & 301 & 612 & 0 & 291 & 0,89 & 0,62 & 0,72 \\
\hline KR-64 & 0,42 & 254 & 660 & 203 & 45,1 & 0,62 & 771 & 321 & 612 & 0 & 423 & 1,22 & 0,79 & 0,97 \\
\hline KR-65 & 0,42 & 254 & 660 & 203 & 25,2 & 0,62 & 771 & 367 & 612 & 0 & 445 & 1,12 & 0,79 & 0,90 \\
\hline KR-66 & 0,42 & 254 & 660 & 203 & 27,9 & 0,62 & 771 & 304 & 612 & 0 & 413 & 1,26 & 0,85 & 1,01 \\
\hline KR-67 & 0,42 & 254 & 660 & 203 & 28,0 & 0,62 & 771 & 364 & 612 & 0 & 393 & 1,00 & 0,69 & 0,80 \\
\hline KR-68 & 0,62 & 254 & 457 & 203 & 23,3 & 1,86 & 1546 & 296 & 409 & 0 & 239 & 0,62 & 0,40 & 0,75 \\
\hline KR-69 & 0,62 & 254 & 457 & 203 & 25,4 & 1,86 & 1546 & 305 & 409 & 0 & 383 & 0,91 & 0,62 & 1,10 \\
\hline KR-70 & 0,62 & 254 & 457 & 203 & 27,6 & 1,86 & 1546 & 367 & 409 & 0 & 356 & 0,78 & 0,49 & 0,94 \\
\hline KR-71 & 0,50 & 254 & 559 & 203 & 30,4 & 1,49 & 1546 & 314 & 511 & 0 & 351 & 0,56 & 0,45 & 0,41 \\
\hline KR-72 & 0,42 & 254 & 660 & 203 & 28,3 & 1,24 & 1542 & 314 & 612 & 0 & 336 & 0,50 & 0,38 & 0,40 \\
\hline
\end{tabular}


Tabela 3.1 - Continuação: Consolos sem armadura de costura e com força vertical

\begin{tabular}{|c|c|c|c|c|c|c|c|c|c|c|c|c|c|c|}
\hline \multirow[b]{2}{*}{ Consolos } & \multicolumn{4}{|c|}{ Geometria } & \multirow[b]{2}{*}{$\begin{array}{c}f_{\mathrm{c}} \\
(\mathrm{MPa})\end{array}$} & \multicolumn{4}{|c|}{ Armadura } & \multirow{2}{*}{$\mathrm{F}_{\mathrm{h}} / \mathrm{F}_{\mathrm{v}}$} & \multirow{2}{*}{$\begin{array}{c}\mathrm{F}_{\mathrm{r}} \\
(\mathrm{kN})\end{array}$} & \multicolumn{3}{|c|}{ Relação $F_{r} / F_{c}$} \\
\hline & $a / d$ & $\begin{array}{c}\mathrm{a} \\
(\mathrm{mm})\end{array}$ & $\begin{array}{c}\mathrm{h} \\
(\mathrm{mm})\end{array}$ & $\begin{array}{c}\mathrm{b} \\
(\mathrm{mm})\end{array}$ & & $\begin{array}{c}\rho \\
(\%)\end{array}$ & $\begin{array}{c}\mathrm{A}_{\mathrm{s}} \\
\left(\mathrm{mm}^{2}\right)\end{array}$ & $\begin{array}{c}\mathrm{f}_{\mathrm{y}} \\
(\mathrm{MPa})\end{array}$ & $\begin{array}{c}\mathrm{d} \\
(\mathrm{mm})\end{array}$ & & & $\mathrm{ACI}$ & CAN & NBR \\
\hline KR-73 & 0,42 & 254 & 660 & 203 & 27,9 & 1,24 & 1542 & 304 & 612 & 0 & 489 & 0,74 & 0,56 & 0,60 \\
\hline KR-74 & 0,42 & 254 & 660 & 203 & 30,1 & 1,24 & 1542 & 363 & 612 & 0 & 514 & 0,69 & 0,51 & 0,52 \\
\hline KR-75 & 0,30 & 318 & 1143 & 203 & 28,3 & 0,95 & 2045 & 313 & 1059 & 0 & 951 & 1,06 & 0,63 & 0,85 \\
\hline KR-76 & 0,30 & 318 & 1143 & 203 & 28,2 & 0,95 & 2045 & 322 & 1059 & 0 & 1111 & 1,21 & 0,72 & 0,96 \\
\hline KR-77 & 0,14 & 89 & 660 & 203 & 15,2 & 0,48 & 600 & 312 & 615 & 0 & 408 & 1,56 & 0,67 & 1,24 \\
\hline KR-78 & 0,15 & 89 & 660 & 203 & 15,2 & 0,93 & 1157 & 305 & 612 & 0 & 484 & 1,28 & 0,61 & 0,78 \\
\hline KR-79 & 0,15 & 89 & 660 & 203 & 16,5 & 1,24 & 1542 & 326 & 612 & 0 & 443 & 1,08 & 0,47 & 0,50 \\
\hline KR-80 & 0,30 & 152 & 559 & 203 & 16,8 & 0,49 & 511 & 300 & 513 & 0 & 370 & 1,72 & 0,98 & 1,38 \\
\hline KR-81 & 0,30 & 152 & 559 & 203 & 17,7 & 0,94 & 975 & 308 & 511 & 0 & 481 & 1,31 & 0,76 & 0,92 \\
\hline KR-82 & 0,30 & 121 & 457 & 203 & 14,5 & 1,23 & 1016 & 311 & 406 & 0 & 375 & 1,56 & 0,64 & 0,68 \\
\hline KR-83 & 0,53 & 216 & 457 & 203 & 15,9 & 0,48 & 401 & 316 & 411 & 0 & 229 & 1,29 & 1,09 & 1,05 \\
\hline KR-84 & 0,53 & 216 & 457 & 203 & 15,8 & 0,93 & 773 & 326 & 409 & 0 & 311 & 1,19 & 0,83 & 0,72 \\
\hline KR-85 & 0,53 & 216 & 457 & 203 & 15,0 & 1,23 & 1016 & 308 & 406 & 0 & 282 & 1,14 & 0,64 & 0,53 \\
\hline KR-86 & 0,14 & 89 & 660 & 203 & 28,8 & 0,48 & 600 & 319 & 615 & 0 & 756 & 2,82 & 0,99 & 2,26 \\
\hline KR-87 & 0,15 & 89 & 660 & 203 & 26,8 & 0,93 & 1157 & 305 & 612 & 0 & 690 & 1,39 & 0,61 & 1,12 \\
\hline KR-88 & 0,15 & 89 & 660 & 203 & 26,3 & 1,24 & 1542 & 328 & 612 & 0 & 664 & 1,01 & 0,52 & 0,75 \\
\hline KR-89 & 0,30 & 152 & 559 & 203 & 27,6 & 0,49 & 511 & 309 & 513 & 0 & 490 & 2,22 & 1,15 & 1,77 \\
\hline KR-90 & 0,30 & 152 & 559 & 203 & 29,2 & 0,94 & 975 & 321 & 511 & 0 & 692 & 1,58 & 0,93 & 1,26 \\
\hline KR-91 & 0,30 & 121 & 457 & 203 & 28,0 & 1,23 & 1016 & 322 & 406 & 0 & 547 & 1,19 & 0,76 & 0,96 \\
\hline KR-92 & 0,53 & 216 & 457 & 203 & 28,7 & 0,48 & 401 & 316 & 411 & 0 & 287 & 1,62 & 1,29 & 1,32 \\
\hline KR-93 & 0,53 & 216 & 457 & 203 & 27,4 & 0,93 & 773 & 328 & 409 & 0 & 400 & 1,13 & 0,98 & 1,02 \\
\hline KR-94 & 0,53 & 216 & 457 & 203 & 27,2 & 1,23 & 1016 & 322 & 406 & 0 & 506 & 1,01 & 1,00 & 1,31 \\
\hline KR-95 & 0,14 & 89 & 660 & 203 & 43,5 & 0,48 & 600 & 312 & 615 & 0 & 845 & 3,22 & 1,00 & 2,58 \\
\hline KR-96 & 0,15 & 89 & 660 & 203 & 44,3 & 0,93 & 1157 & 321 & 612 & 0 & 1115 & 2,15 & 0,81 & 1,72 \\
\hline
\end{tabular}


Tabela 3.1 - Continuação: Consolos sem armadura de costura e com força vertical

\begin{tabular}{|c|c|c|c|c|c|c|c|c|c|c|c|c|c|c|}
\hline \multirow[b]{2}{*}{ Consolos } & \multicolumn{4}{|c|}{ Geometria } & \multirow[b]{2}{*}{$\begin{array}{c}\mathrm{f}_{\mathrm{c}} \\
(\mathrm{MPa})\end{array}$} & \multicolumn{4}{|c|}{ Armadura } & \multirow{2}{*}{$\mathrm{F}_{\mathrm{h}} / \mathrm{F}_{\mathrm{v}}$} & \multirow[b]{2}{*}{$\begin{array}{c}F_{\mathrm{r}} \\
(\mathrm{kN})\end{array}$} & \multicolumn{3}{|c|}{ Relação $F_{r} / F_{c}$} \\
\hline & $a / d$ & $\begin{array}{c}\mathrm{a} \\
(\mathrm{mm})\end{array}$ & $\begin{array}{c}\mathrm{h} \\
(\mathrm{mm})\end{array}$ & $\begin{array}{c}\mathrm{b} \\
(\mathrm{mm})\end{array}$ & & $\begin{array}{c}\rho \\
(\%)\end{array}$ & $\begin{array}{c}\mathrm{A}_{\mathrm{s}} \\
\left(\mathrm{mm}^{2}\right)\end{array}$ & $\begin{array}{c}f_{y} \\
(\mathrm{MPa})\end{array}$ & $\begin{array}{c}\mathrm{d} \\
(\mathrm{mm})\end{array}$ & & & ACI & CAN & NBR \\
\hline KR-97 & 0,15 & 89 & 660 & 203 & 44,3 & 1,24 & 1542 & 305 & 612 & 0 & 952 & 1,44 & 0,59 & 1,16 \\
\hline KR-98 & 0,30 & 152 & 559 & 203 & 45,6 & 0,49 & 511 & 307 & 513 & 0 & 566 & 2,58 & 1,24 & 2,06 \\
\hline KR-99 & 0,30 & 152 & 559 & 203 & 45,3 & 0,94 & 975 & 321 & 511 & 0 & 823 & 1,88 & 1,01 & 1,50 \\
\hline KR-100 & 0,30 & 121 & 457 & 203 & 44,3 & 1,23 & 1016 & 328 & 406 & 0 & 763 & 1,64 & 0,94 & 1,31 \\
\hline KR-101 & 0,53 & 216 & 457 & 203 & 43,9 & 0,48 & 401 & 319 & 411 & 0 & 347 & 1,94 & 1,51 & 1,55 \\
\hline KR-102 & 0,53 & 216 & 457 & 203 & 46,1 & 0,93 & 773 & 321 & 409 & 0 & 432 & 1,24 & 1,02 & 1,02 \\
\hline KR-103 & 0,53 & 216 & 457 & 203 & 45,4 & 1,23 & 1016 & 328 & 406 & 0 & 525 & 1,13 & 0,95 & 0,93 \\
\hline HC-H19 & 0,30 & 111 & 406 & 228 & 46,5 & 0,46 & 393 & 344 & 375 & 0 & 498 & 2,63 & 1,27 & 2,11 \\
\hline $\mathrm{HC}-\mathrm{H} 27$ & 0,30 & 111 & 406 & 228 & 37,3 & 2,01 & 1705 & 338 & 372 & 0 & 743 & 1,17 & 0,63 & 0,85 \\
\hline $\mathrm{HC}-\mathrm{H} 28$ & 0,30 & 111 & 406 & 228 & 40,3 & 0,44 & 376 & 346 & 375 & 0 & 467 & 2,57 & 1,26 & 2,06 \\
\hline $\mathrm{HC}-\mathrm{H} 29$ & 0,30 & 111 & 406 & 228 & 17,6 & 0,44 & 376 & 346 & 375 & 0 & 462 & 2,54 & 1,43 & 2,04 \\
\hline HC-HM1 & 0,50 & 121 & 254 & 228 & 48,5 & 1,00 & 508 & 346 & 223 & 0 & 395 & 1,59 & 1,35 & 1,35 \\
\hline HC-HM7 & 0,50 & 121 & 254 & 228 & 40,3 & 0,75 & 381 & 345 & 223 & 0 & 265 & 1,44 & 1,20 & 1,22 \\
\hline HC-HM8 & 0,50 & 121 & 254 & 228 & 47,6 & 0,75 & 381 & 345 & 223 & 0 & 255 & 1,39 & 1,14 & 1,17 \\
\hline HC-HS3 & 0,32 & 76 & 268 & 152 & 46,5 & 0,79 & 285 & 341 & 237 & 0 & 263 & 1,93 & 1,07 & 1,55 \\
\hline FA-T1 & 0,74 & 89 & 150 & 150 & 40,2 & 0,87 & 157 & 558 & 120 & 0 & 93 & 0,84 & 0,87 & 0,88 \\
\hline FA-T6 & 0,74 & 89 & 150 & 150 & 42,0 & 1,27 & 227 & 491 & 120 & 0 & 136 & 0,98 & 1,01 & 1,01 \\
\hline FA-C1 & 1,04 & 125 & 150 & 150 & 38,6 & 0,87 & 157 & 558 & 120 & 0 & 80 & 1,01 & 1,00 & 1,05 \\
\hline FA-C8 & 0,44 & 53 & 150 & 150 & 32,2 & 0,87 & 157 & 558 & 120 & 0 & 144 & 1,24 & 0,94 & 1,38 \\
\hline FA-C9 & 1,04 & 125 & 150 & 150 & 32,2 & 0,87 & 157 & 558 & 120 & 0 & 74 & 0,95 & 0,94 & 0,97 \\
\hline FA-C21 & 0,44 & 53 & 150 & 150 & 37,8 & 0,56 & 100 & 495 & 120 & 0 & 114 & 1,65 & 1,18 & 1,31 \\
\hline FA-C22 & 0,74 & 89 & 150 & 150 & 40,1 & 0,56 & 100 & 495 & 120 & 0 & 82 & 1,28 & 1,30 & 1,37 \\
\hline FA-C23 & 1,04 & 125 & 150 & 150 & 40,1 & 0,56 & 100 & 495 & 120 & 0 & 47 & 1,02 & 1,02 & 1,09 \\
\hline FA-C24 & 0,44 & 53 & 150 & 150 & 37,8 & 0,87 & 157 & 558 & 120 & 0 & 115 & 0,93 & 0,73 & 0,75 \\
\hline
\end{tabular}


Tabela 3.1 - Continuação: Consolos sem armadura de costura e com força vertical

\begin{tabular}{|c|c|c|c|c|c|c|c|c|c|c|c|c|c|c|}
\hline \multirow[b]{2}{*}{ Consolos } & \multicolumn{4}{|c|}{ Geometria } & \multirow{2}{*}{$\begin{array}{c}f_{\mathrm{c}} \\
(\mathrm{MPa})\end{array}$} & \multicolumn{4}{|c|}{ Armadura } & \multirow{2}{*}{$\mathrm{F}_{\mathrm{h}} / \mathrm{F}_{\mathrm{v}}$} & \multirow{2}{*}{$\begin{array}{c}F_{\mathrm{r}} \\
(\mathrm{kN})\end{array}$} & \multicolumn{3}{|c|}{ Relação $F_{r} / F_{c}$} \\
\hline & $a / d$ & $\begin{array}{c}\mathrm{a} \\
(\mathrm{mm})\end{array}$ & $\begin{array}{c}\mathrm{h} \\
(\mathrm{mm})\end{array}$ & $\begin{array}{c}\mathrm{b} \\
(\mathrm{mm})\end{array}$ & & $\begin{array}{c}\rho \\
(\%)\end{array}$ & $\begin{array}{c}\mathrm{A}_{\mathrm{s}} \\
\left(\mathrm{mm}^{2}\right)\end{array}$ & $\begin{array}{c}f_{\mathrm{y}} \\
(\mathrm{MPa})\end{array}$ & $\underset{(\mathrm{mm})}{\mathrm{d}}$ & & & ACI & CAN & NBR \\
\hline FA-C 25 & 0,54 & 65 & 150 & 150 & 39,8 & 1,25 & 226 & 491 & 120 & 0 & 151 & 1,06 & 0,90 & 1,23 \\
\hline FA-C26 & 1,04 & 125 & 150 & 150 & 38,6 & 1,25 & 226 & 491 & 120 & 0 & 90 & 0,92 & 0,90 & 0,99 \\
\hline FA-17 & 0,74 & 89 & 150 & 150 & 24,6 & 1,26 & 226 & 450 & 120 & 0 & 109 & 1,22 & 0,94 & 1,60 \\
\hline FA-25 & 0,93 & 111 & 150 & 150 & 29,8 & 1,26 & 226 & 450 & 120 & 0 & 109 & 1,09 & 1,09 & 1,45 \\
\hline FA-26 & 0,67 & 80 & 150 & 150 & 29,8 & 0,87 & 157 & 450 & 120 & 0 & 113 & 1,14 & 1,20 & 1,31 \\
\hline FA-33 & 0,63 & 75 & 150 & 150 & 32,0 & 0,56 & 100 & 450 & 120 & 0 & 91 & 1,44 & 1,38 & 1,40 \\
\hline FA-34 & 1,14 & 137 & 150 & 150 & 32,0 & 1,88 & 339 & 450 & 120 & 0 & 114 & 0,99 & 0,93 & 1,61 \\
\hline FA-41 & 1,14 & 137 & 150 & 150 & 28,7 & 1,53 & 276 & 450 & 120 & 0 & 98 & 0,95 & 0,98 & 1,53 \\
\hline FA-42 & 1,13 & 135 & 150 & 150 & 28,7 & 2,83 & 509 & 450 & 120 & 0 & 112 & 1,09 & 0,63 & 1,72 \\
\hline FA-65 & 1,20 & 110 & 150 & 150 & 27,6 & 1,64 & 226 & 450 & 92 & 0 & 74 & 1,00 & 0,95 & 1,61 \\
\hline FA-66 & 1,45 & 135 & 150 & 150 & 27,6 & 2,43 & 339 & 450 & 93 & 0 & 74 & 0,95 & 0,76 & 1,79 \\
\hline FA-67 & 0,83 & 110 & 150 & 150 & 29,3 & 1,14 & 226 & 450 & 132 & 0 & 101 & 0,91 & 0,92 & 1,19 \\
\hline FA-68 & 0,98 & 110 & 150 & 150 & 29,3 & 1,35 & 226 & 450 & 112 & 0 & 96 & 1,03 & 1,02 & 1,43 \\
\hline FA-69 & 1,10 & 135 & 150 & 150 & 25,6 & 1,84 & 339 & 450 & 123 & 0 & 94 & 0,99 & 0,75 & 1,56 \\
\hline FA-70 & 1,46 & 135 & 150 & 150 & 25,6 & 2,46 & 339 & 450 & 92 & 0 & 67 & 0,95 & 0,71 & 1,82 \\
\hline FA-71 & 0,91 & 110 & 150 & 150 & 27,6 & 1,51 & 276 & 450 & 122 & 0 & 117 & 1,15 & 0,95 & 1,64 \\
\hline FA-72 & 0,89 & 110 & 150 & 150 & 27,6 & 1,22 & 226 & 450 & 123 & 0 & 101 & 0,99 & 0,99 & 1,40 \\
\hline FA-73 & 0,60 & 75 & 150 & 150 & 27,6 & 0,54 & 100 & 450 & 124 & 0 & 88 & 1,39 & 1,31 & 1,31 \\
\hline FA-74 & 0,80 & 75 & 150 & 150 & 27,6 & 0,71 & 100 & 450 & 94 & 0 & 74 & 1,40 & 1,43 & 1,46 \\
\hline FA-116 & 0,76 & 160 & 237 & 150 & 40,7 & 0,49 & 157 & 450 & 212 & 0 & 115 & 1,26 & 1,27 & 1,36 \\
\hline FA-117 & 0,80 & 175 & 246 & 152 & 70,7 & 0,68 & 226 & 450 & 220 & 0 & 153 & 1,22 & 1,23 & 1,33 \\
\hline SE-A3 & 0,34 & 250 & 800 & 150 & 92,0 & 0,57 & 628 & 430 & 740 & 0 & 860 & 2,28 & 1,19 & 1,82 \\
\hline SE-A4 & 0,34 & 250 & 800 & 150 & 92,0 & 1,71 & 1885 & 430 & 740 & 0 & 1500 & 1,32 & 0,80 & 1,06 \\
\hline SE-C12 & 0,50 & 300 & 700 & 125 & 90,0 & 2,37 & 1885 & 430 & 600 & 0 & 950 & 0,84 & 0,70 & 0,81 \\
\hline
\end{tabular}


Tabela 3.1 - Continuação: Consolos sem armadura de costura e com força vertical

\begin{tabular}{|c|c|c|c|c|c|c|c|c|c|c|c|c|c|c|}
\hline \multirow[b]{2}{*}{ Consolos } & \multicolumn{4}{|c|}{ Geometria } & \multirow{2}{*}{$\begin{array}{c}f_{\mathrm{c}} \\
(\mathrm{MPa})\end{array}$} & \multicolumn{4}{|c|}{ Armadura } & \multirow{2}{*}{$F_{h} / F_{v}$} & \multirow{2}{*}{$\begin{array}{c}\mathbf{F}_{\mathbf{r}} \\
(\mathrm{kN})\end{array}$} & \multicolumn{3}{|c|}{ Relação $F_{r} / F_{c}$} \\
\hline & $\mathrm{a} / \mathrm{d}$ & $\begin{array}{c}\mathrm{a} \\
(\mathrm{mm})\end{array}$ & $\begin{array}{c}\mathrm{h} \\
(\mathrm{mm})\end{array}$ & $\begin{array}{c}\mathrm{b} \\
(\mathrm{mm})\end{array}$ & & $\begin{array}{c}\rho \\
(\%)\end{array}$ & $\begin{array}{c}A_{\mathrm{s}} \\
\left(\mathrm{mm}^{2}\right)\end{array}$ & $\begin{array}{c}f_{y} \\
(\mathrm{MPa})\end{array}$ & $\underset{(\mathrm{mm})}{\mathrm{d}}$ & & & ACI & CAN & NBR \\
\hline SE-C14 & 0,55 & 300 & 700 & 125 & 90,0 & 0,83 & 679 & 430 & 600 & 0 & 470 & 1,16 & 0,87 & 0,92 \\
\hline SE-C22 & 0,50 & 300 & 700 & 125 & 62,0 & 2,37 & 1885 & 430 & 600 & 0 & 700 & 0,75 & 0,55 & 0,86 \\
\hline SE-C24 & 0,50 & 300 & 700 & 125 & 62,0 & 0,83 & 679 & 430 & 600 & 0 & 490 & 1,20 & 0,93 & 0,96 \\
\hline SE-PA1 & 0,60 & 300 & 600 & 150 & 53,0 & 2,51 & 1885 & 430 & 500 & 0 & 550 & 0,69 & 0,50 & 0,83 \\
\hline SE-PB1 & 0,60 & 300 & 600 & 150 & 105,0 & 4,93 & 3695 & 495 & 500 & 0 & 1180 & 0,75 & 0,49 & 0,90 \\
\hline SE-PC1 & 0,30 & 150 & 600 & 150 & 53,0 & 0,98 & 1256 & 420 & 500 & 0 & 650 & 0,88 & 0,55 & 1,10 \\
\hline SE-PD1 & 0,40 & 200 & 600 & 150 & 71,0 & 2,47 & 1847 & 450 & 500 & 0 & 540 & 0,51 & 0,35 & 0,51 \\
\hline SE-PE1 & 1,00 & 450 & 600 & 150 & 71,0 & 4,52 & 3054 & 480 & 450 & 0 & 680 & 0,71 & 0,53 & 1,06 \\
\hline SE-PF1 & 0,30 & 150 & 600 & 150 & 105,0 & 0,98 & 1256 & 420 & 500 & 0 & 750 & 1,01 & 0,55 & 1,26 \\
\hline RT-C1 & 0,37 & 225 & 653 & 150 & 36,1 & 0,16 & 158 & 530 & 638 & 0 & 245 & 2,09 & 1,12 & 1,67 \\
\hline RT-C2 & 0,37 & 225 & 653 & 150 & 36,1 & 0,48 & 474 & 530 & 608 & 0 & 500 & 1,42 & 0,90 & 1,14 \\
\hline RT-C3 & 0,38 & 225 & 653 & 150 & 29,6 & 0,48 & 474 & 570 & 608 & 0 & 470 & 1,24 & 0,83 & 0,99 \\
\hline & & & & & & & & & & & & 1,37 & 0,87 & 1,22 \\
\hline
\end{tabular}




\section{2 - CONSOLOS SEM ARMADURA DE COSTURA E COM CARREGAMENTOS VERTICAIS E HORIZONTAIS}

A tabela 3.2 apresenta as características destes consolos, o valor da relação entre força horizontal e a força vertical aplicada no consolo $\left(F_{h} / F_{v}\right)$ e a relação entre a força de ruína experimental e a força de ruína calculada $\left(\mathrm{F}_{\mathrm{r}} / \mathrm{F}_{\mathrm{c}}\right)$. Esta tabela apresenta, ainda, a média e o desvio padrão dos valores $F_{\mathrm{r}} / \mathrm{F}_{\mathrm{c}}$, para a força de ruína calculada segundo cada uma das normas citadas.

Através da média e do desvio padrão da relação $\mathrm{F}_{\mathrm{r}} / \mathrm{F}_{\mathrm{c}}$, nota-se que a norma que apresentou o valor desta relação mais próximo da unidade e com menor desvio foi a Norma Canadense, seguida pela Norma Brasileira e pela Norma Americana. Os valores da média e do desvio padrão da relação $\mathrm{F}_{\mathrm{r}} / \mathrm{F}_{\mathrm{c}}$, para as Normas Brasileira e Americana, ficaram altos.

De maneira geral, os consolos que apresentaram os piores resultados da relação $F_{r} / F_{c}$ foram aqueles com a relação a/d muito pequena e com baixa taxa de armadura, consolos com baixa taxa de armadura e consolos com taxa de armadura muito elevada. Neste caso, é importante ressaltar que a relação entre a taxa de armadura e a força horizontal aplicada influencia de maneira significativa na relação $\mathrm{F}_{\mathrm{r}} / \mathrm{F}_{\mathrm{e}}$.

Para o consolos com baixa taxa de armadura, a relação $\mathrm{F}_{\mathrm{r}} / \mathrm{F}_{\mathrm{c}}$ ficou muito elevada, e para os consolos com taxa de armadura muito alta, a relação $F_{r} / F_{c}$ ficou muito baixa.

Com base na observação da tabela 3.2, nota-se que quanto mais elevados os valores da relação $F_{h} / F_{v}$, mais discrepantes foram os valores da relação $F_{r} / F_{c}$.

É importante ressaltar que, dentro de certos limites, quanto maior o valor do carregamento horizontal, maior deve ser o valor da taxa de armadura. 
Tabela 3.2 - Consolos sem armadura de costura e com forças verticais e horizontais

\begin{tabular}{|c|c|c|c|c|c|c|c|c|c|c|c|c|c|c|}
\hline \multirow[b]{2}{*}{ Consolos } & \multicolumn{4}{|c|}{ Geometria } & \multirow[b]{2}{*}{$\begin{array}{c}\mathrm{f}_{\mathrm{c}} \\
(\mathrm{MPa})\end{array}$} & \multicolumn{4}{|c|}{ Armadura } & \multirow{2}{*}{$\mathrm{F}_{\mathrm{h}} / \mathrm{F}_{\mathrm{v}}$} & \multirow{2}{*}{$\underset{(\mathrm{kN})}{\mathrm{F}_{\mathrm{r}}}$} & \multicolumn{3}{|c|}{ Relação $\mathrm{F}_{\mathrm{r}} / \mathrm{F}_{\mathrm{c}}$} \\
\hline & $\mathrm{a} / \mathrm{d}$ & $\begin{array}{c}\mathrm{a} \\
(\mathrm{mm})\end{array}$ & $\begin{array}{c}\mathrm{h} \\
(\mathrm{mm})\end{array}$ & $\begin{array}{c}\mathrm{b} \\
(\mathrm{mm})\end{array}$ & & $\begin{array}{c}\rho \\
(\%)\end{array}$ & $\begin{array}{c}\mathrm{A}_{\mathrm{s}} \\
\left(\mathrm{mm}^{2}\right)\end{array}$ & $\begin{array}{c}\mathrm{f}_{\mathrm{y}} \\
(\mathrm{MPa})\end{array}$ & $\begin{array}{c}\mathrm{d} \\
(\mathrm{mm})\end{array}$ & & & $\mathrm{ACI}$ & CAN & NBR \\
\hline KR-104 & 0,17 & 70 & 457 & 203 & 29,0 & 0,48 & 401 & 315 & 411 & 0,5 & 250 & 2,40 & 1,40 & 1,92 \\
\hline KR-105 & 0,14 & 70 & 559 & 203 & 26,6 & 0,38 & 396 & 315 & 513 & 0,5 & 276 & 2,69 & 1,48 & 2,15 \\
\hline KR-106 & 0,11 & 70 & 660 & 203 & 27,9 & 0,32 & 400 & 326 & 615 & 0,5 & 308 & 2,87 & 1,52 & 2,30 \\
\hline KR-107 & 0,17 & 70 & 457 & 203 & 28,1 & 0,93 & 773 & 334 & 409 & 0,5 & 356 & 1,67 & 1,03 & 1,34 \\
\hline KR-108 & 0,14 & 70 & 559 & 203 & 26,6 & 0,75 & 778 & 329 & 511 & 0,5 & 368 & 1,75 & 1,01 & 1,40 \\
\hline KR-109 & 0,11 & 70 & 660 & 203 & 29,2 & 0,62 & 771 & 332 & 612 & 0,5 & 445 & 2,11 & 1,16 & 1,69 \\
\hline KR-110 & 0,17 & 70 & 457 & 203 & 29,3 & 1,86 & 1546 & 328 & 409 & 0,5 & 534 & 1,28 & 0,84 & 1,02 \\
\hline KR-111 & 0,14 & 70 & 559 & 203 & 26,9 & 1,49 & 1546 & 336 & 511 & 0,5 & 567 & 1,32 & 0,83 & 1,06 \\
\hline KR-112 & 0,11 & 70 & 660 & 203 & 29,7 & 1,24 & 1542 & 336 & 612 & 0,5 & 623 & 1,46 & 0,86 & 1,17 \\
\hline KR-113 & 0,37 & 152 & 457 & 203 & 30,3 & 0,47 & 393 & 321 & 411 & 0,5 & 217 & 2,09 & 1,54 & 1,68 \\
\hline KR-114 & 0,30 & 152 & 559 & 203 & 29,8 & 0,38 & 396 & 315 & 513 & 0,5 & 240 & 2,34 & 1,58 & 1,87 \\
\hline KR-115 & 0,25 & 152 & 660 & 203 & 34,1 & 0,32 & 400 & 315 & 615 & 0,5 & 292 & 2,81 & 1,78 & 2,25 \\
\hline KR-116 & 0,37 & 152 & 457 & 203 & 26,7 & 0,93 & 773 & 333 & 409 & 0,5 & 277 & 1,31 & 1,01 & 1,05 \\
\hline KR-117 & 0,30 & 152 & 559 & 203 & 26,8 & 0,75 & 778 & 308 & 511 & 0,5 & 323 & 1,63 & 1,14 & 1,31 \\
\hline KR-118 & 0,25 & 152 & 660 & 203 & 29,2 & 0,62 & 771 & 334 & 612 & 0,5 & 389 & 1,84 & 1,20 & 1,47 \\
\hline KR-119 & 0,37 & 152 & 457 & 203 & 29,0 & 1,86 & 1546 & 334 & 409 & 0,5 & 467 & 1,10 & 0,89 & 0,88 \\
\hline KR-120 & 0,30 & 152 & 559 & 203 & 28,5 & 1,49 & 1546 & 329 & 511 & 0,5 & 511 & 1,22 & 0,90 & 0,98 \\
\hline KR-121 & 0,29 & 152 & 660 & 203 & 27,4 & 1,24 & 1542 & 332 & 612 & 0,5 & 509 & 1,20 & 0,83 & 0,96 \\
\hline KR-122 & 0,62 & 254 & 457 & 203 & 23,3 & 0,48 & 401 & 321 & 411 & 0,5 & 122 & 1,15 & 1,08 & 1,18 \\
\hline KR-123 & 0,50 & 254 & 559 & 203 & 29,2 & 0,38 & 396 & 321 & 513 & 0,5 & 150 & 1,44 & 1,20 & 1,30 \\
\hline KR-124 & 0,41 & 254 & 660 & 203 & 29,2 & 0,32 & 400 & 321 & 615 & 0,5 & 178 & 1,69 & 1,30 & 1,39 \\
\hline KR-125 & 0,62 & 254 & 457 & 203 & 22,4 & 0,93 & 773 & 330 & 409 & 0,5 & 135 & 0,64 & 0,62 & 0,67 \\
\hline KR-126 & 0,62 & 254 & 457 & 203 & 30,9 & 0,93 & 773 & 368 & 409 & 0,5 & 197 & 0,84 & 0,81 & 0,87 \\
\hline KR-127 & 0,50 & 254 & 559 & 203 & 22,8 & 0,75 & 778 & 330 & 511 & 0,5 & 155 & 0,73 & 0,63 & 0,67 \\
\hline
\end{tabular}


Tabela 3.2 - Continuação: Consolos sem armadura de costura e com forças verticais e horizontais

\begin{tabular}{|c|c|c|c|c|c|c|c|c|c|c|c|c|c|c|}
\hline \multirow[b]{2}{*}{ Consolos } & \multicolumn{4}{|c|}{ Geometria } & \multirow{2}{*}{$\begin{array}{c}f_{\mathrm{c}} \\
(\mathrm{MPa})\end{array}$} & \multicolumn{4}{|c|}{ Armadura } & \multirow{2}{*}{$F_{h} / F_{v}$} & \multirow{2}{*}{$\begin{array}{c}\mathrm{F}_{\mathrm{r}} \\
(\mathrm{kN})\end{array}$} & \multicolumn{3}{|c|}{ Relação $\mathrm{F}_{\mathrm{r}} / \mathrm{F}_{\mathrm{c}}$} \\
\hline & $\mathrm{a} / \mathrm{d}$ & $\begin{array}{c}\mathrm{a} \\
(\mathrm{mm})\end{array}$ & $\begin{array}{c}\mathrm{h} \\
(\mathrm{mm})\end{array}$ & $\begin{array}{c}\mathrm{b} \\
(\mathrm{mm})\end{array}$ & & $\begin{array}{c}\rho \\
(\%)\end{array}$ & $\begin{array}{c}A_{s} \\
\left(\mathrm{~mm}^{2}\right)\end{array}$ & $\begin{array}{c}\mathrm{f}_{\mathrm{y}} \\
(\mathrm{MPa})\end{array}$ & $\begin{array}{c}\mathrm{d} \\
(\mathrm{mm})\end{array}$ & & & ACI & CAN & NBR \\
\hline KR-128 & 0,42 & 254 & 660 & 203 & 24,9 & 0,62 & 771 & 331 & 612 & 0,5 & 209 & 1,00 & 0,79 & 0,82 \\
\hline KR-129 & 0,42 & 254 & 660 & 203 & 28,4 & 0,62 & 771 & 324 & 612 & 0,5 & 289 & 1,40 & 1,10 & 1,16 \\
\hline KR-130 & 0,62 & 254 & 457 & 203 & 27,1 & 1,86 & 1546 & 329 & 409 & 0,5 & 186 & 0,44 & 0,44 & 0,46 \\
\hline KR-131 & 0,62 & 254 & 457 & 203 & 29,1 & 1,86 & 1546 & 310 & 409 & 0,5 & 244 & 0,62 & 0,61 & 0,64 \\
\hline KR-132 & 0,50 & 254 & 559 & 203 & 28,4 & 1,49 & 1546 & 308 & 511 & 0,5 & 200 & 0,51 & 0,45 & 0,46 \\
\hline KR-133 & 0,42 & 254 & 660 & 203 & 28,8 & 1,24 & 1542 & 334 & 612 & 0,5 & 239 & 0,56 & 0,46 & 0,47 \\
\hline KR-134 & 0,42 & 254 & 660 & 203 & 29,6 & 1,24 & 1542 & 303 & 612 & 0,5 & 393 & 1,02 & 0,82 & 0,84 \\
\hline KR-135 & 0,25 & 76 & 356 & 203 & 44,3 & 1,24 & 774 & 323 & 307 & 0,75 & 334 & 1,96 & 1,39 & 1,56 \\
\hline KR-136 & 0,17 & 70 & 457 & 203 & 26,7 & 0,48 & 401 & 324 & 411 & 1 & 145 & 1,91 & 1,33 & 1,53 \\
\hline KR-137 & 0,14 & 70 & 559 & 203 & 31,8 & 0,38 & 396 & 305 & 513 & 1 & 161 & 2,28 & 1,53 & 1,82 \\
\hline KR-138 & 0,11 & 70 & 660 & 203 & 26,7 & 0,32 & 400 & 323 & 615 & 1 & 183 & 2,44 & 1,61 & 1,95 \\
\hline KR-139 & 0,17 & 70 & 457 & 203 & 30,5 & 0,93 & 773 & 305 & 409 & 1 & 288 & 2,09 & 1,48 & 1,67 \\
\hline KR-140 & 0,14 & 70 & 559 & 203 & 26,8 & 0,75 & 778 & 305 & 511 & 1 & 267 & 1,92 & 1,32 & 1,54 \\
\hline KR-141 & 0,11 & 70 & 660 & 203 & 27,6 & 0,62 & 771 & 312 & 612 & 1 & 289 & 2,06 & 1,37 & 1,65 \\
\hline KR-142 & 0,17 & 70 & 457 & 203 & 29,4 & 1,86 & 1546 & 305 & 409 & 1 & 378 & 1,37 & 1,00 & 1,10 \\
\hline KR-143 & 0,14 & 70 & 559 & 203 & 28,3 & 1,49 & 1546 & 325 & 511 & 1 & 411 & 1,40 & 0,99 & 1,12 \\
\hline KR-144 & 0,11 & 70 & 660 & 203 & 29,3 & 1,24 & 1542 & 336 & 612 & 1 & 456 & 1,51 & 1,03 & 1,21 \\
\hline KR-145 & 0,37 & 152 & 457 & 203 & 25,6 & 0,48 & 401 & 310 & 411 & 1 & 122 & 1,68 & 1,37 & 1,51 \\
\hline KR-146 & 0,30 & 152 & 559 & 203 & 29,6 & 0,38 & 396 & 310 & 513 & 1 & 119 & 1,66 & 1,27 & 1,39 \\
\hline KR-147 & 0,25 & 152 & 660 & 203 & 27,9 & 0,32 & 400 & 310 & 615 & 1. & 211 & 2,92 & 2,15 & 2,33 \\
\hline KR-148 & 0,37 & 152 & 457 & 203 & 29,3 & 0,93 & 773 & 301 & 409 & 1 & 222 & 1,64 & 1,35 & 1,48 \\
\hline KR-149 & 0,30 & 152 & 559 & 203 & 29,8 & 0,75 & 778 & 301 & 511 & 1 & 250 & 1,83 & 1,42 & 1,53 \\
\hline KR-150 & 0,25 & 152 & 660 & 203 & 27,9 & 0,62 & 771 & 301 & 612 & 1 & 267 & 1,97 & 1,47 & 1,58 \\
\hline KR-151 & 0,37 & 152 & 457 & 203 & 29,2 & 1,86 & 1546 & 312 & 409 & 1 & 311 & 1,10 & 0,93 & 1,00 \\
\hline
\end{tabular}


Tabela 3.2 - Continuação: Consolos sem armadura de costura e com forças verticais e horizontais

\begin{tabular}{|c|c|c|c|c|c|c|c|c|c|c|c|c|c|c|}
\hline \multirow[b]{2}{*}{ Consolos } & \multicolumn{4}{|c|}{ Geometria } & \multirow[b]{2}{*}{$\begin{array}{c}f_{\mathrm{c}} \\
(\mathrm{MPa})\end{array}$} & \multicolumn{4}{|c|}{ Armadura } & \multirow{2}{*}{$\mathrm{F}_{\mathrm{h}} / \mathrm{F}_{\mathrm{v}}$} & \multirow[b]{2}{*}{$\begin{array}{c}\mathrm{F}_{\mathrm{r}} \\
(\mathrm{kN})\end{array}$} & \multicolumn{3}{|c|}{ Relação $F_{r} / F_{c}$} \\
\hline & $a / d$ & $\begin{array}{c}\mathrm{a} \\
(\mathrm{mm})\end{array}$ & $\begin{array}{c}\mathrm{h} \\
(\mathrm{mm})\end{array}$ & $\begin{array}{c}\mathrm{b} \\
(\mathrm{mm})\end{array}$ & & $\begin{array}{c}\rho \\
(\%)\end{array}$ & $\begin{array}{c}\mathrm{A}_{\mathrm{s}} \\
\left(\mathrm{mm}^{2}\right)\end{array}$ & $\begin{array}{c}\mathrm{f}_{\mathrm{y}} \\
(\mathrm{MPa})\end{array}$ & $\begin{array}{c}\mathrm{d} \\
(\mathrm{mm})\end{array}$ & & & ACI & CAN & NBR \\
\hline KR-152 & 0,30 & 152 & 559 & 203 & 28,5 & 1,49 & 1546 & 334 & 511 & 1 & 367 & 1,22 & 0,97 & 1,02 \\
\hline KR-153 & 0,25 & 152 & 660 & 203 & 27,3 & 1,24 & 1542 & 312 & 612 & 1 & 346 & 1,23 & 0,94 & 0,99 \\
\hline KR-154 & 0,62 & 254 & 457 & 203 & 32,7 & 0,48 & 401 & 334 & 411 & 1 & 73 & 0,94 & 0,89 & 0,99 \\
\hline KR-155 & 0,50 & 254 & 559 & 203 & 28,4 & 0,38 & 396 & 334 & 513 & 1 & 87 & 1,13 & 0,99 & 1,09 \\
\hline KR-156 & 0,41 & 254 & 660 & 203 & 25,3 & 0,32 & 400 & 334 & 615 & 1 & 95 & 1,22 & 1,01 & 1,09 \\
\hline KR-157 & 0,62 & 254 & 457 & 203 & 28,6 & 0,93 & 773 & 312 & 409 & 1 & 111 & 0,79 & 0,76 & 0,84 \\
\hline KR-158 & 0,62 & 254 & 457 & 203 & 29,6 & 0,93 & 773 & 314 & 409 & 1 & 116 & 0,82 & 0,79 & 0,87 \\
\hline KR-159 & 0,62 & 254 & 457 & 203 & 31,3 & 0,93 & 773 & 314 & 409 & 1 & 116 & 0,82 & 0,79 & 0,87 \\
\hline KR-160 & 0,50 & 254 & 559 & 203 & 29,0 & 0,75 & 778 & 312 & 511 & 1 & 111 & 0,78 & 0,70 & 0,75 \\
\hline KR-161 & 0,41 & 254 & 660 & 203 & 28,2 & 0,62 & 771 & 312 & 612 & 1 & 122 & 0,87 & 0,73 & 0,78 \\
\hline KR-162 & 0,41 & 254 & 660 & 203 & 30,8 & 0,62 & 771 & 298 & 612 & 1 & 134 & 1,00 & 0,84 & 0,90 \\
\hline KR-163 & 0,41 & 254 & 660 & 203 & 30,0 & 0,62 & 771 & 322 & 612 & 1 & 156 & 1,08 & 0,90 & 0,98 \\
\hline KR-164 & 0,62 & 254 & 457 & 203 & 28,1 & 1,86 & 1546 & 333 & 409 & 1 & 156 & 0,52 & 0,51 & 0,55 \\
\hline KR-165 & 0,62 & 254 & 457 & 203 & 31,2 & 1,86 & 1546 & 313 & 409 & 1 & 193 & 0,68 & 0,67 & 0,73 \\
\hline KR-166 & 0,50 & 254 & 559 & 203 & 28,3 & 1,49 & 1546 & 293 & 511 & 1 & 152 & 0,57 & 0,52 & 0,56 \\
\hline KR-167 & 0,41 & 254 & 660 & 203 & 30,6 & 1,24 & 1542 & 293 & 612 & 1 & 165 & 0,62 & 0,53 & 0,56 \\
\hline KR-168 & 0,41 & 254 & 660 & 203 & 31,4 & 1,24 & 1542 & 322 & 612 & 1 & 253 & 0,87 & 0,74 & 0,79 \\
\hline KR-169 & 0,25 & 76 & 356 & 203 & 45,8 & 2,48 & 1549 & 323 & 307 & 1,25 & 423 & 1,66 & 1,32 & 1,47 \\
\hline & & & & & & & & & & Média & & 1,42 & 1,04 & 1,20 \\
\hline & & & & & & & & & & Desvio & drão & 0,63 & 0,36 & 0,47 \\
\hline
\end{tabular}




\section{3 - CONSOLOS COM ARMADURA DE COSTURA, SUJEITOS A CARREGAMENTO VERTICAL}

A tabela 3.3 apresenta as características destes consolos, o valor da relação entre a força horizontal e a força vertical aplicada no consolo $\left(F_{h} / F_{v}\right)$, que, neste caso, é igual a zero, e a relação entre a força de ruína experimental e a força de ruína calculada $\left(\mathrm{F}_{\mathrm{r}} / \mathrm{F}_{\mathrm{c}}\right)$. Esta tabela apresenta, ainda, a média e o desvio padrão dos valores $\mathrm{F}_{\mathrm{r}} / \mathrm{F}_{\mathrm{c}}$, para a força de ruína calculada segundo cada uma das normas citadas.

Através da média e do desvio padrão da relação $F_{r} / F_{c}$, nota-se que a norma que apresentou o valor desta relação mais próximo da unidade foi a Norma Canadense. Entretanto, o maior desvio padrão foi apresentado por esta norma. Em seguida, vieram os valores das normas Americana e Brasileira. Os valores da média e do desvio padrão da relação de $F_{r} / F_{c}$, para todas as normas, ficaram altos.

De maneira geral, os consolos que apresentaram os piores resultados da relação $F_{r} / F_{c}$ foram os consolos com a relação a/d muito pequena e com baixa taxa de armadura, consolos com baixa taxa de armadura e consolos com taxa de armadura muito elevada. Observou-se, também, que os consolos com a relação entre a taxa de armadura de costura e a taxa de armadura principal muito diferente de 0,5 apresentaram resultados da relação $\mathrm{F}_{\mathrm{r}} / \mathrm{F}_{\mathrm{c}}$ um pouco discrepantes.

Para o consolos com baixas taxas de armadura, a relação $F_{r} / F_{c}$ fícou muito elevada, e para os consolos com taxa de armadura muito alta, a relação $F_{r} / F_{c}$ ficou muito baixa.

Nesta capítulo foi feito ainda um estudo paramétrico, no qual foi traçado um gráfico, que está ilustrado nas figura 3.1. O gráfico foi montado para analisar a relação $\frac{F_{r}}{f_{c} b d}$ versus a taxa de armadura de costura dos consolos.

Com base no gráfico da figura 3.1, pode-se afirmar, observando a linha de tendência, que, dentro de certos limites, quanto maior a taxa de armadura de costura, melhor é o aproveitamento do concreto. Isto, tomando o cuidado para que a peça não venha a ruir antes por escoamento da armadura principal. 
Com base nestas observações, pode-se afirmar que, dentro de certos limites, quanto maior a taxa de armadura de costura e maior a resistência do concreto, melhor será 0 aproveitamento da armadura principal

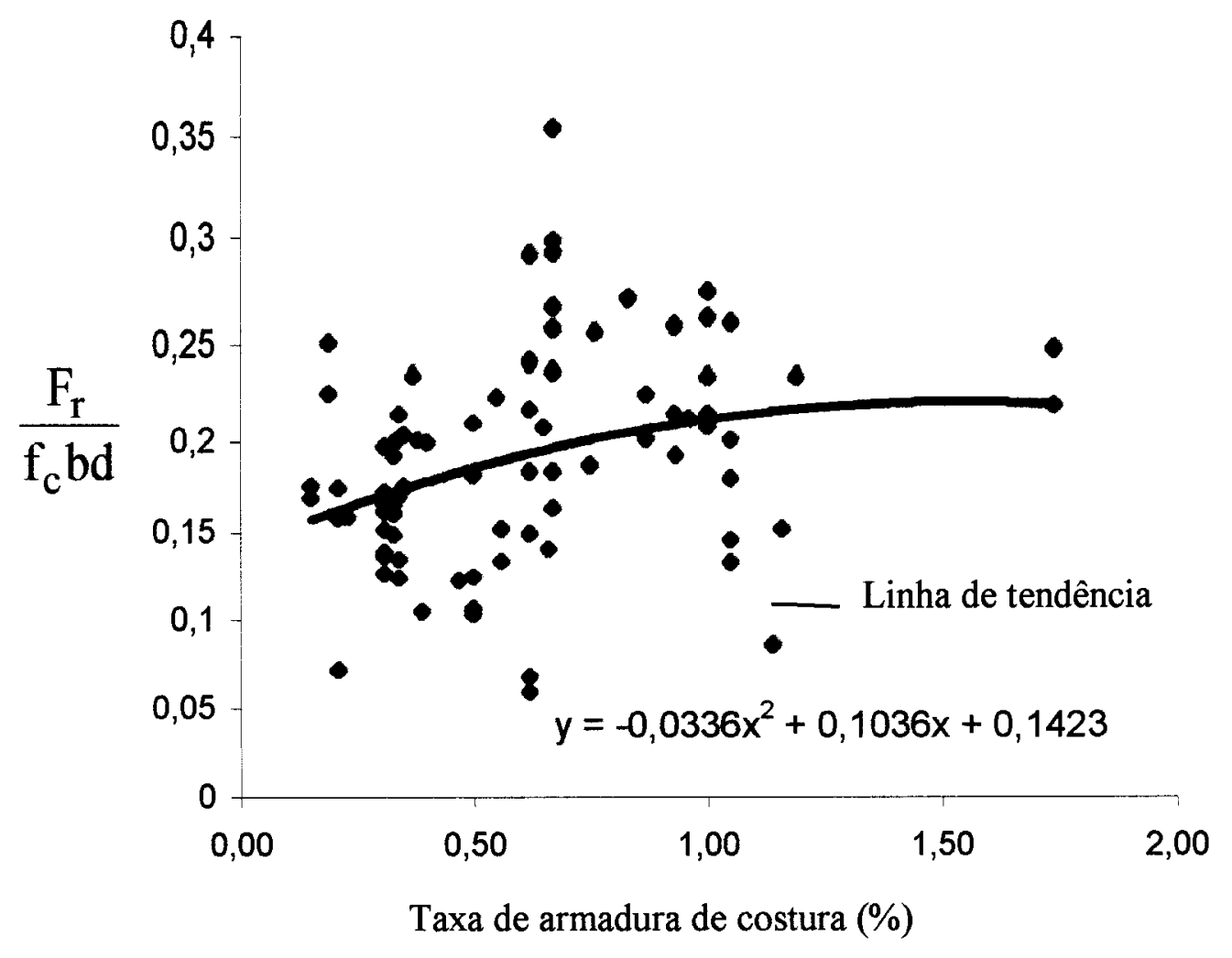

Figura 3.1 - Gráfico $\frac{F_{r}}{f_{c} b d}$ versus taxa de armadura de costura 
Tabela 3.3 - Consolos com armadura de costura e com força vertical

\begin{tabular}{|c|c|c|c|c|c|c|c|c|c|c|c|c|c|c|c|c|c|}
\hline \multirow[b]{2}{*}{ Consolos } & \multicolumn{4}{|c|}{ Geometria } & \multirow[b]{2}{*}{$\begin{array}{c}f_{\mathrm{c}} \\
(\mathrm{MPa})\end{array}$} & \multicolumn{7}{|c|}{ Armadura } & \multirow{2}{*}{$F_{h} / F_{v}$} & \multirow{2}{*}{$\begin{array}{c}F_{\mathbf{r}} \\
(\mathrm{kN})\end{array}$} & \multicolumn{3}{|c|}{ Relação $F_{r} / F_{c}$} \\
\hline & $\mathrm{a} / \mathrm{d}$ & $\begin{array}{c}a \\
(\mathrm{~mm})\end{array}$ & $\underset{(\mathrm{mm})}{\mathbf{h}}$ & $\begin{array}{c}\mathrm{b} \\
(\mathrm{mm})\end{array}$ & & $\begin{array}{c}\rho \\
(\%)\end{array}$ & $\begin{array}{c}A_{\mathrm{s}} \\
\left(\mathrm{mm}^{2}\right)\end{array}$ & $\begin{array}{c}f_{y} \\
(\mathrm{MPa})\end{array}$ & $\begin{array}{c}\mathrm{d} \\
(\mathrm{mm})\end{array}$ & $\begin{array}{c}\rho_{\mathrm{c}} \\
(\%)\end{array}$ & $\begin{array}{c}A_{\mathrm{sc}} \\
\left(\mathrm{mm}^{2}\right)\end{array}$ & $\begin{array}{c}f_{\mathrm{yc}} \\
(\mathrm{MPa})\end{array}$ & & & ACI & CAN & NBR \\
\hline KR-1S & 0,59 & 242 & 458 & 203 & 29,9 & 0,93 & 775 & 303 & 410 & 0,34 & 283 & 345 & 0 & 426 & 1,12 & 1,20 & 1,19 \\
\hline KR-2S & 0,59 & 242 & 458 & 203 & 31,7 & 0,93 & 775 & 303 & 410 & 0,62 & 517 & 319 & 0 & 487 & 1,28 & 1,36 & 1,36 \\
\hline KR-3S & 0,59 & 242 & 458 & 203 & 30,5 & 0,93 & 775 & 310 & 410 & 0,93 & 775 & 323 & 0 & 490 & 1,26 & 1,35 & 1,34 \\
\hline KR-4S & 0,37 & 153 & 458 & 203 & 29,9 & 0,93 & 782 & 305 & 414 & 0,34 & 286 & 392 & 0 & 543 & 1,11 & 1,07 & 0,93 \\
\hline KR-5S & 0,37 & 153 & 458 & 203 & 29,9 & 0,93 & 782 & 305 & 414 & 0,62 & 522 & 341 & 0 & 611 & 1,21 & 1,20 & 1,05 \\
\hline KR-6S & 0,37 & 153 & 458 & 203 & 30,9 & 0,93 & 782 & 305 & 414 & 0,93 & 782 & 339 & 0 & 676 & 1,30 & 1,32 & 1,16 \\
\hline KR-7S & 0,39 & 242 & 662 & 203 & 28,3 & 0,93 & 1174 & 310 & 621 & 0,34 & 429 & 384 & 0 & 722 & 1,01 & 0,98 & 0,86 \\
\hline KR-8S & 0,39 & 242 & 662 & 203 & 29,7 & 0,93 & 1174 & 310 & 621 & 0,62 & 782 & 345 & 0 & 820 & 1,09 & 1,10 & 0,98 \\
\hline KR-9S & 0,39 & 242 & 662 & 203 & 29,2 & 0,93 & 1174 & 319 & 621 & 0,93 & 1174 & 355 & 0 & 797 & 1,08 & 1,05 & 0,92 \\
\hline KR-10S & 0,30 & 121 & 458 & 203 & 28,6 & 0,93 & 762 & 328 & 403 & 0,62 & 508 & 339 & 0 & 686 & 1,47 & 1,17 & 1,21 \\
\hline $\mathrm{HC}-\mathrm{Hl}$ & 0,32 & 121 & 406 & 228 & 39,8 & 0,59 & 504 & 341 & 375 & 0,15 & 130 & 380 & 0 & 600 & 1,94 & 1,35 & 1,55 \\
\hline $\mathrm{HC}-\mathrm{H} 2$ & 0,32 & 121 & 406 & 228 & 35,8 & 0,59 & 504 & 341 & 375 & 0,15 & 130 & 380 & 0 & 520 & 1,68 & 1,19 & 1,34 \\
\hline $\mathrm{HC}-\mathrm{H} 3$ & 0,32 & 121 & 406 & 228 & 37,8 & 0,59 & 504 & 341 & 375 & 0,35 & 299 & 303 & 0 & 570 & 1,55 & 1,29 & 1,24 \\
\hline $\mathrm{HC}-\mathrm{H} 4$ & 0,32 & 121 & 406 & 228 & 38,7 & 0,59 & 504 & 341 & 375 & 0,35 & 299 & 303 & 0 & 580 & 1,58 & 1,31 & 1,26 \\
\hline HC-H5 & 0,30 & 111 & 406 & 228 & 33,6 & 1,35 & 1145 & 359 & 372 & 0,67 & 568 & 342 & 0 & 680 & 1,19 & 0,76 & 0,94 \\
\hline $\mathrm{HC}-\mathrm{H} 6$ & 0,46 & 172 & 406 & 228 & 36,6 & 1,35 & 1145 & 359 & 372 & 0,67 & 568 & 342 & 0 & 510 & 0,82 & 0,72 & 0,70 \\
\hline $\mathrm{HC}-\mathrm{H} 7$ & 0,30 & 111 & 406 & 228 & 36,1 & 1,35 & 1145 & 350 & 372 & 0,67 & 568 & 342 & 0 & 900 & 1,47 & 1,00 & 1,26 \\
\hline $\mathrm{HC}-\mathrm{H} 8$ & 0,30 & 111 & 406 & 228 & 30,4 & 1,35 & 1145 & 350 & 372 & 0,67 & 568 & 342 & 0 & 915 & 1,77 & 1,06 & 1,28 \\
\hline $\mathrm{HC}-\mathrm{H} 9$ & 0,30 & 111 & 406 & 228 & 37,6 & 0,76 & 646 & 350 & 373 & 1,00 & 850 & 342 & 0 & 885 & 1,38 & 1,52 & 1,58 \\
\hline HC-H10 & 0,30 & 111 & 406 & 228 & 33,9 & 1,35 & 1145 & 350 & 372 & 0,67 & 568 & 342 & 0 & 860 & 1,50 & 0,97 & 1,20 \\
\hline HC-H11 & 0,30 & 111 & 406 & 228 & 29,6 & 1,35 & 1145 & 350 & 372 & 0,67 & 568 & 342 & 0 & 675 & 1,34 & 0,79 & 0,94 \\
\hline $\mathrm{HC}-\mathrm{H} 13$ & 0,30 & 111 & 406 & 228 & 36,7 & 1,35 & 1145 & 336 & 372 & 0,67 & 568 & 342 & 0 & 805 & 1,29 & 0,92 & 1,15 \\
\hline HC-H14 & 0,32 & 121 & 406 & 228 & 40,0 & 0,62 & 530 & 349 & 375 & 0,35 & 299 & 249 & 0 & 698 & 1,92 & 1,48 & 1,54 \\
\hline HC-H15 & 0,30 & 111 & 406 & 228 & 48,5 & 0,29 & 248 & 348 & 375 & 0,50 & 428 & 340 & 0 & 757 & 2,63 & 2,88 & 2,89 \\
\hline HC-H16 & 0,30 & 111 & 406 & 228 & 45,3 & 0,44 & 376 & 348 & 375 & 0,76 & 650 & 332 & 0 & 994 & 2,29 & 2,62 & 2,50 \\
\hline $\mathrm{HC}-\mathrm{H} 17$ & 0,30 & 111 & 406 & 228 & 49,2 & 0,46 & 393 & 343 & 375 & 0,23 & 197 & 296 & 0 & 670 & 2,48 & 1,70 & 1,98 \\
\hline
\end{tabular}


Tabela 3.3 - Continuação: Consolos com armadura de costura e com força vertical

\begin{tabular}{|c|c|c|c|c|c|c|c|c|c|c|c|c|c|c|c|c|c|}
\hline \multirow[b]{2}{*}{ Consolos } & \multicolumn{4}{|c|}{ Geometria } & \multirow[b]{2}{*}{$\begin{array}{c}f_{\mathrm{c}} \\
(\mathrm{MPa})\end{array}$} & \multicolumn{7}{|c|}{ Armadura } & \multirow{2}{*}{$F_{b} / F_{v}$} & \multirow{2}{*}{$\begin{array}{c}F_{r} \\
(k N)\end{array}$} & \multicolumn{3}{|c|}{ Relação $F_{r} / F_{c}$} \\
\hline & $a / d$ & $\begin{array}{c}\mathrm{a} \\
(\mathrm{mm})\end{array}$ & $\begin{array}{c}\mathrm{h} \\
(\mathrm{mm})\end{array}$ & $\begin{array}{c}\mathrm{b} \\
(\mathrm{mm})\end{array}$ & & $\begin{array}{c}\rho \\
(\%)\end{array}$ & $\begin{array}{c}A_{\mathrm{s}} \\
\left(\mathrm{mm}^{2}\right)\end{array}$ & $\begin{array}{c}f_{y} \\
(\mathrm{MPa})\end{array}$ & $\begin{array}{c}\mathrm{d} \\
(\mathrm{mm})\end{array}$ & $\begin{array}{c}\rho_{\mathrm{c}} \\
(\%)\end{array}$ & $\begin{array}{c}A_{\mathrm{sc}} \\
\left(\mathrm{mm}^{2}\right)\end{array}$ & $\begin{array}{c}f_{\mathrm{yc}} \\
(\mathrm{MPa})\end{array}$ & & & ACI & CAN & NBR \\
\hline HC-H18 & 0,30 & 111 & 406 & 228 & 46,7 & 0,76 & 646 & 317 & 373 & 0,40 & 340 & 230 & 0 & 794 & 2,01 & 1,43 & 1,60 \\
\hline $\mathrm{HC}-\mathrm{H} 20$ & 0,30 & 111 & 406 & 228 & 44,7 & 0,29 & 248 & 348 & 375 & 1,19 & 1017 & 328 & 0 & 903 & 3,14 & 3,46 & 3,45 \\
\hline $\mathrm{HC}-\mathrm{H} 21$ & 0,30 & 111 & 406 & 228 & 30,4 & 0,76 & 646 & 326 & 373 & 1,00 & 850 & 256 & 0 & 682 & 1,32 & 1,29 & 1,25 \\
\hline $\mathrm{HC}-\mathrm{H} 22$ & 0,30 & 111 & 406 & 228 & 47,3 & 0,76 & 646 & 326 & 373 & 1,00 & 850 & 256 & 0 & 870 & 1,45 & 1,52 & 1,59 \\
\hline $\mathrm{HC}-\mathrm{H} 23$ & 0,30 & 111 & 406 & 228 & 41,4 & 0,76 & 646 & 326 & 373 & 1,00 & 850 & 256 & 0 & 739 & 1,23 & 1,32 & 1,35 \\
\hline $\mathrm{HC}-\mathrm{H} 24$ & 0,30 & 111 & 406 & 228 & 40,8 & 0,76 & 646 & 326 & 373 & 1,00 & 850 & 256 & 0 & 726 & 1,21 & 1,30 & 1,33 \\
\hline HC-HT1 & 0,98 & 121 & 406 & 228 & 45,0 & 0,59 & 504 & 346 & 375 & 0,33 & 282 & 342 & 0 & 640 & 1,69 & 1,40 & 1,24 \\
\hline $\mathrm{HC}-\mathrm{HM} 2$ & 0,50 & 121 & 254 & 228 & 45,3 & 1,29 & 656 & 310 & 223 & 0,67 & 341 & 291 & 0 & 425 & 1,26 & 1,28 & 1,26 \\
\hline HC-HM3 & 0,50 & 121 & 254 & 228 & 44,7 & 1,91 & 997 & 328 & 229 & 0,96 & 501 & 303 & 0 & 498 & 1,07 & 0,97 & 1,24 \\
\hline HC-HM4 & 0,50 & 121 & 254 & 228 & 44,7 & 0,42 & 214 & 343 & 223 & 0,56 & 285 & 262 & 0 & 304 & 2,29 & 2,38 & 2,51 \\
\hline HC-HM5 & 0,50 & 121 & 254 & 228 & 37,2 & 0,75 & 381 & 347 & 223 & 1,00 & 508 & 346 & 0 & 447 & 1,90 & 2,03 & 2,04 \\
\hline HC-HM6 & 0,50 & 121 & 254 & 228 & 45,0 & 0,42 & 214 & 343 & 223 & 0,56 & 285 & 343 & 0 & 349 & 2,62 & 2,73 & 2,88 \\
\hline $\mathrm{HC}-\mathrm{HS} 1$ & 0,32 & 76 & 268 & 152 & 36,0 & 1,06 & 382 & 343 & 237 & 0,55 & 198 & 253 & 0 & 292 & 1,15 & 0,97 & 1,20 \\
\hline $\mathrm{HC}-\mathrm{HS} 2$ & 0,32 & 76 & 268 & 152 & 32,0 & 1,06 & 382 & 343 & 237 & 0,83 & 299 & 251 & 0 & 315 & 1,36 & 1,08 & 1,45 \\
\hline MA-B1 & 0,44 & 102 & 255 & 153 & 25,0 & 0,73 & 258 & 334 & 231 & 0,37 & 131 & 448 & 0 & 209 & 1,12 & 1,29 & 1,19 \\
\hline MA-B2 & 0,67 & 153 & 255 & 153 & 23,8 & 1,15 & 401 & 231 & 228 & 0,65 & 227 & 462 & 0 & 173 & 1,33 & 1,39 & 1,40 \\
\hline MA-B3A & 1,01 & 229 & 255 & 153 & 28,7 & 1,84 & 639 & 370 & 227 & 0,75 & 260 & 452 & 0 & 187 & 0,94 & 0,88 & 1,41 \\
\hline MA-G4 & 0,99 & 229 & 255 & 127 & 25,9 & 1,47 & 431 & 441 & 231 & 0,66 & 194 & 465 & 0 & 107 & 0,70 & 0,62 & 1,05 \\
\hline YO-B1 & 0,39 & 140 & 406 & 254 & 49,8 & 0,43 & 389 & 420 & 356 & 0,31 & 280 & 420 & 0 & 778 & 1,98 & 2,07 & 2,08 \\
\hline YO-B2 & 0,39 & 140 & 406 & 254 & 48,6 & 0,43 & 389 & 420 & 356 & 0,31 & 280 & 420 & 0 & 667 & 1,70 & 1,78 & 1,78 \\
\hline YO-Cl & 0,39 & 140 & 406 & 254 & 63,3 & 0,57 & 515 & 420 & 356 & 0,31 & 280 & 420 & 0 & 796 & 1,70 & 1,61 & 1,61 \\
\hline YO-C2 & 0,39 & 140 & 406 & 254 & 55,5 & 0,57 & 515 & 420 & 356 & 0,31 & 280 & 420 & 0 & 836 & 1,79 & 1,71 & 1,69 \\
\hline YO-D1 & 0,39 & 140 & 406 & 254 & 39,2 & 0,66 & 597 & 420 & 356 & 0,31 & 280 & 420 & 0 & 701 & 1,36 & 1,31 & 1,22 \\
\hline YO-D2 & 0,39 & 140 & 406 & 254 & 54,5 & 0,66 & 597 & 420 & 356 & 0,31 & 280 & 420 & 0 & 801 & 1,55 & 1,44 & 1,40 \\
\hline YO-E1 & 0,25 & 140 & 406 & 254 & 62,1 & 0,88 & 796 & 420 & 356 & 0,31 & 280 & 420 & 0 & 712 & 1,12 & 0,98 & 0,93 \\
\hline YO-E2 & 0,25 & 140 & 406 & 254 & 64,9 & 0,88 & 796 & 420 & 356 & 0,31 & 280 & 420 & 0 & 801 & 1,27 & 1,09 & 1,05 \\
\hline
\end{tabular}


Tabela 3.3 - Continuação: Consolos com armadura de costura e com força vertical

\begin{tabular}{|c|c|c|c|c|c|c|c|c|c|c|c|c|c|c|c|c|c|}
\hline \multirow[b]{2}{*}{ Consolos } & \multicolumn{4}{|c|}{ Geometria } & \multirow{2}{*}{$\begin{array}{c}f_{c} \\
(\mathrm{MPa})\end{array}$} & \multicolumn{7}{|c|}{ Armadura } & \multirow{2}{*}{$F_{h} / F_{v}$} & \multirow{2}{*}{$\begin{array}{c}F_{\mathrm{r}} \\
(\mathrm{kN})\end{array}$} & \multicolumn{3}{|c|}{ Relação $F_{r} / F_{c}$} \\
\hline & $a / d$ & $\begin{array}{c}\mathrm{a} \\
(\mathrm{mm})\end{array}$ & $\begin{array}{c}\mathrm{h} \\
(\mathrm{mm})\end{array}$ & $\begin{array}{c}\mathrm{b} \\
(\mathrm{mm})\end{array}$ & & $\begin{array}{c}\rho \\
(\%) \\
\end{array}$ & $\begin{array}{c}\mathbf{A}_{\mathbf{s}} \\
\left(\mathrm{mm}^{2}\right)\end{array}$ & $\begin{array}{c}f_{\mathrm{y}} \\
(\mathrm{MPa})\end{array}$ & $\begin{array}{c}\mathrm{d} \\
(\mathrm{mm})\end{array}$ & $\begin{array}{c}\rho_{c} \\
(\%)\end{array}$ & $\begin{array}{c}\mathrm{A}_{\mathrm{sc}} \\
\left(\mathrm{mm}^{2}\right)\end{array}$ & $\begin{array}{c}f_{\mathrm{yc}} \\
(\mathrm{MPa})\end{array}$ & & & $\mathrm{ACI}$ & CAN & NBR \\
\hline YO-E3 & 0,25 & 140 & 406 & 254 & 79,5 & 1,44 & 1302 & 420 & 356 & 0,62 & 561 & 420 & 0 & 1079 & 0,99 & 0,93 & 0,86 \\
\hline YO-F1 & 0,50 & 140 & 406 & 254 & 82,2 & 1,11 & 1004 & 420 & 356 & 0,47 & 425 & 420 & 0 & 912 & 1,09 & 0,99 & 0,95 \\
\hline YO-F2 & 0,50 & 140 & 406 & 254 & 62,5 & 1,81 & 1637 & 420 & 356 & 0,62 & 561 & 420 & 0 & 845 & 0,75 & 0,63 & 0,82 \\
\hline YO-G1 & 0,75 & 140 & 406 & 254 & 61,4 & 1,43 & 1293 & 420 & 356 & 0,62 & 561 & 420 & 0 & 334 & 0,31 & 0,30 & 0,33 \\
\hline YO-G2 & 0,75 & 140 & 406 & 254 & 66,2 & 1,43 & 1293 & 420 & 356 & 0,62 & 561 & 420 & 0 & 411 & 0,38 & 0,37 & 0,37 \\
\hline YO-G3 & 0,75 & 140 & 406 & 254 & 70,8 & 2,12 & 1917 & 420 & 356 & 1,14 & 1031 & 420 & 0 & 556 & 0,43 & 0,36 & 0,47 \\
\hline NA-C1 & 0,75 & 300 & 430 & 250 & 33,4 & 0,21 & 200 & 821 & 380 & 0,21 & 200 & 600 & 0 & 230 & 1,14 & 1,15 & 1,23 \\
\hline NA-C2 & 0,75 & 300 & 430 & 250 & 24,0 & 0,42 & 399 & 608 & 380 & 0,21 & 200 & 891 & 0 & 400 & 1,37 & 1,40 & 1,44 \\
\hline NA-C $2 B$ & 0,75 & 300 & 430 & 250 & $22, \overline{6}$ & 0,42 & 399 & 614 & 380 & 0,21 & 200 & 614 & 0 & 340 & 1,16 & 1,19 & 1,22 \\
\hline NA-C3 & 0,25 & 100 & 430 & 250 & 34,7 & 0,34 & 302 & 746 & 355 & 0,19 & 169 & 1201 & 0 & 700 & 1,17 & 1,18 & 1,22 \\
\hline NA-C $3 A$ & 0,25 & 100 & 430 & 250 & 30,0 & 0,34 & 302 & 733 & 355 & 0,19 & 169 & 790 & 0 & 670 & 1,35 & 1,18 & 1,32 \\
\hline ZE-K1 & 0,50 & 300 & 690 & 300 & 24,5 & 0,86 & 1651 & 500 & 640 & 0,38 & 730 & 500 & 0 & 948 & 1,01 & 0,70 & 1,78 \\
\hline ZE-K3 & 1,00 & 600 & 690 & 300 & 22,5 & 0,86 & 1651 & 500 & 640 & 0,39 & 749 & 500 & 0 & 455 & 0,57 & 0,57 & 0,76 \\
\hline FA-T1 & 0,74 & 89 & 150 & 150 & 40,2 & 0,87 & 157 & 558 & 120 & 0,87 & 157 & 558 & 0 & 146 & 1,32 & 1,36 & 1,38 \\
\hline FA-T7 & 0,74 & 89 & 150 & 150 & 38,5 & 0,87 & 157 & 491 & 120 & 0,87 & 157 & 558 & 0 & 157 & 1,60 & 1,65 & 1,69 \\
\hline FA-T8 & 0,74 & 89 & 150 & 150 & 42,0 & 0,87 & 157 & 491 & 120 & 1,74 & 313 & 558 & 0 & 188 & 1,92 & 1,97 & 2,02 \\
\hline FA-T9 & 0,74 & 89 & 150 & 150 & 38,5 & 0,87 & 157 & 491 & 120 & 1,74 & 313 & 558 & 0 & 153 & 1,56 & 1,61 & 1,65 \\
\hline SE-A1 & 0,34 & 250 & 800 & 150 & 87,0 & 1,71 & 1898 & 430 & 740 & 0,34 & 377 & 430 & 0 & 1200 & 0,88 & 0,64 & 1,00 \\
\hline SE-A2 & 0,34 & 250 & 800 & 150 & 87,0 & 1,71 & 1898 & 430 & 740 & 0,34 & 377 & 430 & 0 & 1300 & 0,95 & 0,69 & 1,08 \\
\hline SE-B1 & 0,34 & 250 & 800 & 150 & 56,0 & 1,12 & 1243 & 430 & 740 & 0,33 & 366 & 430 & 0 & 1000 & 1,03 & 0,82 & 1,06 \\
\hline SE-B2 & 0,34 & 250 & 800 & 150 & 56,0 & 1,12 & 1243 & 430 & 740 & 0,33 & 366 & 430 & 0 & 1200 & 1,72 & 0,98 & 1,27 \\
\hline SE-C11 & 0,50 & 300 & 700 & 125 & 90,0 & 2,37 & 1885 & 430 & 600 & 0,50 & 375 & 430 & 0 & 720 & 0,53 & 0,53 & 0,61 \\
\hline SE-C13 & 0,50 & 300 & 700 & 125 & 90,0 & 0,91 & 683 & 430 & 600 & 0,50 & 375 & 430 & 0 & 700 & 1,22 & 1,29 & 1,33 \\
\hline SE-C21 & 0,50 & 300 & 700 & 125 & 62,0 & 2,37 & 1885 & 430 & 600 & 0,50 & 375 & 430 & 0 & 980 & 1,05 & 0,77 & 1,21 \\
\hline SE-C23 & 0,50 & 300 & 700 & 125 & 62,0 & 0,90 & 675 & 430 & 600 & 0,50 & 375 & 430 & 0 & 580 & 1,03 & 1,11 & 1,11 \\
\hline SE-PA2 & 0,60 & 300 & 600 & 150 & 53,0 & 2,51 & 1883 & 450 & 500 & 1,05 & 788 & 450 & 0 & 800 & 1,01 & 0,70 & 1,21 \\
\hline
\end{tabular}


Tabela 3.3 - Continuação: Consolos com armadura de costura e com força vertical

\begin{tabular}{|c|c|c|c|c|c|c|c|c|c|c|c|c|c|c|c|c|c|}
\hline \multirow[b]{2}{*}{ Consolos } & \multicolumn{4}{|c|}{ Geometria } & \multirow[b]{2}{*}{$\begin{array}{c}\mathbf{f}_{\mathrm{c}} \\
(\mathrm{MPa})\end{array}$} & \multicolumn{7}{|c|}{ Armadura } & \multirow{2}{*}{$F_{h} / F_{v}$} & \multirow{2}{*}{$\begin{array}{c}F_{r} \\
(k N)\end{array}$} & \multicolumn{3}{|c|}{ Relação $\mathbf{F}_{x} / \mathbf{F}_{c}$} \\
\hline & $a / d$ & $\begin{array}{c}\mathrm{a} \\
(\mathrm{mm})\end{array}$ & $\begin{array}{c}\mathrm{h} \\
(\mathrm{mm})\end{array}$ & $\begin{array}{c}\mathrm{b} \\
(\mathrm{mm})\end{array}$ & & $\begin{array}{c}\rho \\
(\%)\end{array}$ & $\begin{array}{c}\mathrm{A}_{\mathrm{s}} \\
\left(\mathrm{mm}^{2}\right)\end{array}$ & $\begin{array}{c}\mathbf{f}_{\mathrm{y}} \\
(\mathrm{MPa})\end{array}$ & $\begin{array}{c}\mathrm{d} \\
(\mathrm{mm})\end{array}$ & $\begin{array}{c}\rho_{\mathrm{c}} \\
(\%)\end{array}$ & $\begin{array}{c}\mathrm{A}_{\mathrm{sc}} \\
\left(\mathrm{mm}^{2}\right)\end{array}$ & $\begin{array}{c}f_{y c} \\
(\mathrm{MPa})\end{array}$ & & & $\mathrm{ACI}$ & CAN & NBR \\
\hline SE-PB2 & 0,60 & 300 & 600 & 150 & 105,0 & 4,93 & 3698 & 495 & 500 & 1,05 & 788 & 495 & 0 & 1150 & $0,7 \overline{3}$ & 0,47 & 0,88 \\
\hline SE-PC2 & 0,30 & 150 & 600 & 150 & 53,0 & 1,68 & 1260 & 420 & 500 & 1,05 & 788 & 420 & 0 & 1040 & 1,31 & 0,88 & 1,31 \\
\hline SE-PD2 & 0,40 & 200 & 600 & 150 & 71,0 & 2,47 & 1853 & 450 & 500 & 1,05 & 788 & 450 & 0 & 960 & 0,90 & 0,63 & 0,99 \\
\hline SE-PE2 & 1,00 & 450 & 600 & 150 & 71,0 & 4,52 & 3051 & 480 & 450 & 1,16 & 783 & 450 & 0 & 730 & 0,76 & 0,57 & 1,14 \\
\hline SE-PF2 & 0,30 & 150 & 600 & 150 & 105,0 & 1,67 & 1253 & 420 & 500 & 1,05 & 788 & 450 & 0 & 1050 & 0,85 & 0,77 & 1,33 \\
\hline SE-PG1 & 0,60 & 300 & 600 & 150 & 45,0 & 2,51 & 1883 & 415 & 500 & 0,33 & 248 & 415 & 0 & 674 & 1,00 & 0,65 & 1,22 \\
\hline SE-PG2 & 0,60 & 300 & 600 & 150 & 94,0 & 2,51 & 1883 & 415 & 500 & 0,33 & 248 & 415 & 0 & 1050 & 0,85 & 0,92 & 1,03 \\
\hline & & & & & & & & & & & & \multicolumn{3}{|c|}{ Média } & 1,33 & 1,21 & 1,33 \\
\hline & & & & & & & & & & & & \multicolumn{3}{|c|}{ Desvio padrão } & 0,51 & 0,56 & 0,51 \\
\hline
\end{tabular}




\section{4 - CONSOLOS COM ARMADURA DE COSTURA SUJEITOS A CARREGAMENTOS VERTICAIS E HORIZONTAIS}

A tabela 3.4 apresenta as características destes consolos, o valor da força horizontal dividida pela força vertical aplicada no consolo $\left(\mathrm{F}_{\mathrm{h}} / \mathrm{F}_{\mathrm{v}}\right)$ e a força de ruína experimental dividida pela força de ruína calculada $\left(\mathrm{F}_{\mathrm{r}} / \mathrm{F}_{\mathrm{c}}\right)$. Esta tabela apresenta, ainda, a média e o desvio padrão dos valores $\mathrm{F}_{\mathrm{r}} / \mathrm{F}_{\mathrm{c}}$, para a força de ruína calculada segundo cada uma das normas citadas.

Através da média e do desvio padrão da relação $F_{\mathrm{r}} / \mathrm{F}_{\mathrm{c}}$, nota-se que a norma que apresentou o valor desta relação mais próximo da unidade foi a Norma Canadense; em seguida vieram os valores das normas Americana e Brasileira. Os valores do desvio padrão da relação de $\mathrm{F}_{\mathrm{r}} / \mathrm{F}_{\mathrm{c}}$, para todas as normas, ficaram altos. Entretanto, os valores das médias ficaram muito próximos do ideal.

De maneira geral, os consolos que apresentaram os piores resultados da relação $F_{r} / F_{c}$ foram os consolos com baixa taxa de armadura e com uma relação $F_{h} / F_{v}$ alta e consolos com taxa de armadura muito elevada e com baixa relação $F_{h} / F_{v}$.

Em geral os consolos sujeitos a carregamentos horizontais devem ter a taxa de armadura principal um pouco elevada. Entretanto, consolos com taxas exageradas de armadura principal apresentam a relação $\mathrm{F}_{\mathrm{r}} / \mathrm{F}_{\mathrm{c}}$ contra a segurança. Isto indica que, para aumentar a resistência final do consolos, em certos casos, não basta somente aumentar a taxa de armadura. 
Tabela 3.4-Consolos com armadura de costura e forças verticais e horizontais

\begin{tabular}{|c|c|c|c|c|c|c|c|c|c|c|c|c|c|c|c|c|c|}
\hline \multirow[b]{2}{*}{ Consolos } & \multicolumn{4}{|c|}{ Geometria } & \multirow[b]{2}{*}{$\begin{array}{c}f_{\mathrm{c}} \\
(\mathrm{MPa})\end{array}$} & \multicolumn{7}{|c|}{ Armadura } & \multirow{2}{*}{$F_{h} / F_{v}$} & \multirow{2}{*}{$\begin{array}{c}\mathbf{F}_{\mathbf{r}} \\
(\mathrm{kN})\end{array}$} & \multicolumn{3}{|c|}{ Relação $\mathbf{F}_{r} / \mathbf{F}_{c}$} \\
\hline & $\mathrm{a} / \mathrm{d}$ & $\begin{array}{c}\mathrm{a} \\
(\mathrm{mm})\end{array}$ & $\begin{array}{c}\mathrm{h} \\
(\mathrm{mm})\end{array}$ & $\begin{array}{c}\mathrm{b} \\
(\mathrm{mm})\end{array}$ & & $\begin{array}{c}\rho \\
(\%) \\
\end{array}$ & $\begin{array}{c}A_{s} \\
\left(\mathrm{~mm}^{2}\right)\end{array}$ & $\begin{array}{c}f_{y} \\
(\mathrm{MPa})\end{array}$ & $\begin{array}{c}\mathrm{d} \\
(\mathrm{mm})\end{array}$ & $\begin{array}{c}\rho_{\mathrm{c}} \\
(\%)\end{array}$ & $\begin{array}{c}A_{\mathrm{sc}} \\
\left(\mathrm{mm}^{2}\right)\end{array}$ & $\begin{array}{c}\mathrm{f}_{\mathrm{yc}} \\
(\mathrm{MPa})\end{array}$ & & & $\mathrm{ACI}$ & $\mathrm{CAN}$ & NBR \\
\hline KR-13S & 0,62 & 255 & 458 & 204 & 26,9 & 0,59 & 495 & 328 & 411 & 0,34 & 285 & 338 & 1 & 150 & 0,99 & 1,52 & 1,69 \\
\hline $\mathrm{HC}-\mathrm{H} 25$ & 0,30 & 111 & 406 & 228 & 38,5 & 1,43 & 1216 & 331 & 373 & 1,00 & 850 & 256 & 0,28 & 711 & 1,14 & 1,18 & 1,13 \\
\hline $\mathrm{HC}-\mathrm{H} 26$ & 0,30 & 111 & 406 & 228 & 39,1 & 2,10 & 1786 & 332 & 373 & 1,00 & 850 & 256 & 0,57 & 691 & 1,10 & 1,12 & 1,11 \\
\hline $\mathrm{MA}-\mathrm{C} 1$ & 0,45 & 102 & 255 & 153 & 27,6 & 2,02 & 698 & 339 & 226 & 0,38 & 131 & 414 & 0,75 & 196 & 1,03 & 1,07 & 1,13 \\
\hline MA-C2 & 0,68 & 153 & 255 & 153 & 25,6 & 2,48 & 854 & 348 & 225 & 0,38 & 131 & 465 & $0,7 \overline{5}$ & 178 & 1,01 & 0,92 & 1,26 \\
\hline $\mathrm{MA}-\mathrm{C} 2 \mathrm{~A}$ & 0,68 & 153 & 255 & 153 & 25,5 & 2,24 & 771 & 336 & 225 & 0,38 & 131 & 452 & 0,75 & 180 & 1,02 & 1,06 & 1,29 \\
\hline MA-C3 & 1,02 & 229 & 255 & 153 & 30,2 & 3,08 & 1060 & 345 & 225 & 0,76 & 262 & 452 & 0,75 & 167 & 0,80 & 0,85 & 0,91 \\
\hline MA-D1 & 0,45 & 102 & 255 & $15 \overline{3}$ & 27,0 & 1,66 & 571 & 346 & 225 & 0,19 & 65 & 483 & 1 & 125 & 0,93 & 0,96 & 1,04 \\
\hline MA-D2 & 0,68 & 153 & 255 & 153 & 26,2 & 2,03 & 699 & 328 & 225 & 0,38 & 131 & 441 & 1 & 151 & 0,90 & 1,15 & 1,26 \\
\hline MA-D3 & 1,01 & 229 & 255 & 153 & 25,5 & 2,48 & 861 & 334 & 227 & 0,55 & 191 & 466 & 1 & 146 & 0,82 & 1,06 & 1,26 \\
\hline MA-E1 & 0,22 & 51 & 255 & 127 & 28,1 & 1,89 & 554 & 436 & 231 & 0,33 & 97 & 441 & 1 & 245 & 1,48 & 1,35 & 1,38 \\
\hline MA-E2 & 0,45 & 102 & 255 & 127 & 30,9 & 2,10 & 603 & 437 & 226 & 0,33 & 95 & 462 & 1 & 205 & 1,16 & 1,20 & 1,28 \\
\hline MA-E3 & 0,68 & 153 & 255 & 127 & 29,1 & 2,43 & 694 & 436 & 225 & 0,67 & 191 & 448 & 1 & 216 & 1,30 & 1,27 & 1,62 \\
\hline MA-E4 & 1,01 & 229 & 255 & 127 & 28,0 & 2,97 & 856 & 431 & 227 & 0,79 & 228 & 462 & 1 & 160 & 0,99 & 0,92 & 1,50 \\
\hline MA-F2 & 0,45 & 102 & 255 & 127 & 25,6 & 2,10 & 603 & 440 & 226 & 0,34 & 98 & 470 & 1 & 162 & 1,10 & 0,96 & 1,01 \\
\hline MA-F3 & 0,68 & 153 & 255 & 127 & 25,7 & 2,43 & 694 & 435 & 225 & 0,67 & 191 & 441 & 1 & 107 & 0,73 & 0,64 & 0,91 \\
\hline MA-F4 & 1,01 & 229 & 255 & 127 & 27,8 & 2,97 & 856 & 436 & 227 & 0,79 & 228 & 470 & 1 & 107 & 0,67 & 0,61 & 1,00 \\
\hline MA-F4A & 1,01 & 229 & 255 & 127 & 25,6 & 2,97 & 856 & 437 & 227 & 0,79 & 228 & 469 & 1 & 105 & 0,71 & 0,60 & 0,63 \\
\hline MA-H1 & 0,23 & 51 & 255 & 127 & 27,0 & 2,10 & 589 & 459 & 221 & 0,46 & 129 & 441 & 1 & 298 & 1,96 & 1,50 & 1,57 \\
\hline $\mathrm{MA}-\mathrm{H} 2$ & $0, \overline{45}$ & 102 & 255 & 127 & 27,1 & 2,43 & 697 & 436 & 226 & 0,67 & 192 & 441 & 1 & 222 & 1,42 & 1,15 & 1,20 \\
\hline MA-H3 & 0,68 & 153 & 255 & 127 & 26,6 & 2,97 & 849 & 436 & 225 & 0,80 & 229 & 462 & 1 & 211 & 1,39 & 1,03 & 1,74 \\
\hline MA-H3A & 0,68 & 153 & 255 & 127 & 27,3 & 2,97 & 849 & 442 & 225 & 0,80 & 229 & 473 & 1 & 176 & 1,13 & 0,85 & 1,42 \\
\hline MA-H3B & 0,68 & 153 & 255 & 127 & 26,3 & 2,97 & 849 & 439 & 225 & 0,80 & 229 & 469 & 1 & 205 & 1,37 & 1,00 & 1,71 \\
\hline MA-J4 & 1,01 & 229 & 255 & 127 & 25,1 & 1,98 & 571 & 447 & 227 & 0,67 & 193 & 441 & 1 & 96 & 0,66 & 0,79 & 1,00 \\
\hline YO-E3 & 0,25 & 90 & 406 & 254 & 79,5 & 1,44 & 1302 & 420 & 356 & 0,62 & 561 & 420 & 0,2 & 1079 & 1,26 & 1,04 & 1,24 \\
\hline YO-F1 & 0,50 & 178 & 406 & 254 & 82,2 & 1,11 & 1004 & 420 & 356 & 0,47 & 425 & 420 & 0,2 & 912 & 1,18 & 1,60 & 1,70 \\
\hline
\end{tabular}


Tabela 3.4 - Continuação: Consolos com armadura de costura e forças verticais e horizontais

\begin{tabular}{|c|c|c|c|c|c|c|c|c|c|c|c|c|c|c|c|c|c|}
\hline \multirow[b]{2}{*}{ Consolos } & \multicolumn{4}{|c|}{ Geometria } & \multirow[b]{2}{*}{$\begin{array}{c}f_{\mathrm{c}} \\
(\mathrm{MPa})\end{array}$} & \multicolumn{7}{|c|}{ Armadura } & \multirow{2}{*}{$F_{h} / F_{v}$} & \multirow{2}{*}{$\begin{array}{c}F_{\mathbf{r}} \\
(\mathbf{k N})\end{array}$} & \multicolumn{3}{|c|}{ Relação $F_{r} / F_{c}$} \\
\hline & $a / d$ & $\begin{array}{c}\mathrm{a} \\
(\mathrm{mm})\end{array}$ & $\begin{array}{c}\mathrm{h} \\
(\mathrm{mm})\end{array}$ & $\begin{array}{c}\mathrm{b} \\
(\mathrm{mm})\end{array}$ & & $\begin{array}{c}\rho \\
(\%) \\
\end{array}$ & $\begin{array}{c}A_{\mathrm{s}} \\
\left(\mathrm{mm}^{2}\right)\end{array}$ & $\begin{array}{c}f_{y} \\
(\mathrm{MPa})\end{array}$ & $\begin{array}{c}\mathrm{d} \\
(\mathrm{mm})\end{array}$ & $\begin{array}{c}\rho_{\mathrm{c}} \\
(\%)\end{array}$ & $\begin{array}{c}A_{\mathrm{sc}} \\
\left(\mathrm{mm}^{2}\right)\end{array}$ & $\begin{array}{c}f_{y c} \\
(\mathrm{MPa})\end{array}$ & & & ACI & CAN & NBR \\
\hline YO-F2 & 0,50 & 178 & 406 & 254 & 62,5 & 1,81 & 1637 & 420 & 356 & 0,62 & 561 & 420 & 0,2 & 845 & 0,84 & 0,96 & 0,97 \\
\hline YO-G1 & 0,75 & 267 & 406 & 254 & 61,4 & 1,43 & 1293 & 420 & 356 & 0,62 & 561 & 420 & 0,2 & 334 & 0,50 & 0,61 & 0,65 \\
\hline YO-G2 & 0,75 & 267 & 406 & 254 & 66,2 & 1,43 & 1293 & 420 & 356 & 0,62 & 561 & 420 & 0,2 & 411 & 0,62 & 0,75 & 0,81 \\
\hline YO-G3 & 0,75 & 267 & 406 & 254 & 70,8 & 2,12 & 1917 & 420 & 356 & $1, \overline{14}$ & 1031 & 420 & 0,2 & 556 & 0,57 & 0,70 & 0,74 \\
\hline & & & & & & & & & & & & \multicolumn{3}{|l|}{ Média } & 1,03 & 1,01 & 1,20 \\
\hline & & & & & & & & & & & & \multicolumn{3}{|c|}{ Desvio Padrão } & 0,32 & 0,27 & 0,32 \\
\hline
\end{tabular}




\section{5 - CONSIDERAÇÕES GERAIS}

A Norma Canadense apresentou os melhores resultados para a relação $F_{r} / F_{c}$. Entretanto, para o caso de consolos sem armadura de costura e carregamento apenas vertical, os resultados foram contra a segurança. Isto se deve principalmente ao fato de que, nos cálculos, esta norma já considera a existência da armadura de costura.

Os cálculos dos consolos através das normas, de maneira geral, foram bastante satisfatórios, apresentando discrepância nos resultados dos consolos com taxas de armadura muito altas ou muito baixas.

No caso de consolos com a resistência do concreto variando de 15 a $50 \mathrm{MPa}$, a resistência do concreto não influenciou de maneira significativa a relação $F_{\mathrm{r}} / \mathrm{F}_{\mathrm{c}}$. Entretanto, consolos com resistência do concreto superior a $50 \mathrm{MPa}$ e sem uma taxa adequada de armadura apresentaram a relação $\mathrm{F}_{\mathrm{r}} / \mathrm{F}_{\mathrm{c}}$ baixa, indicando resultados contra a segurança.

A relação taxa de armadura de costura/taxa de armadura principal é de fundamental importância para um bom desempenho do consolo e um bom desempenho do cálculo, de acordo com as normas analisadas. 


\section{CAPÍTULO 4 - DESCRIÇÃO DOS ENSAIOS}

Neste capítulo, serão apresentadas as dimensões dos consolos, o detalhamento das armaduras, as características dos materiais empregados, os procedimentos utilizados na concretagem e na cura, a instrumentação utilizada nos consolos, bem como o esquema e os procedimentos de ensaio.

\section{1 - DIMENSÕES}

As dimensões dos consolos estão indicadas na figura 4.1.
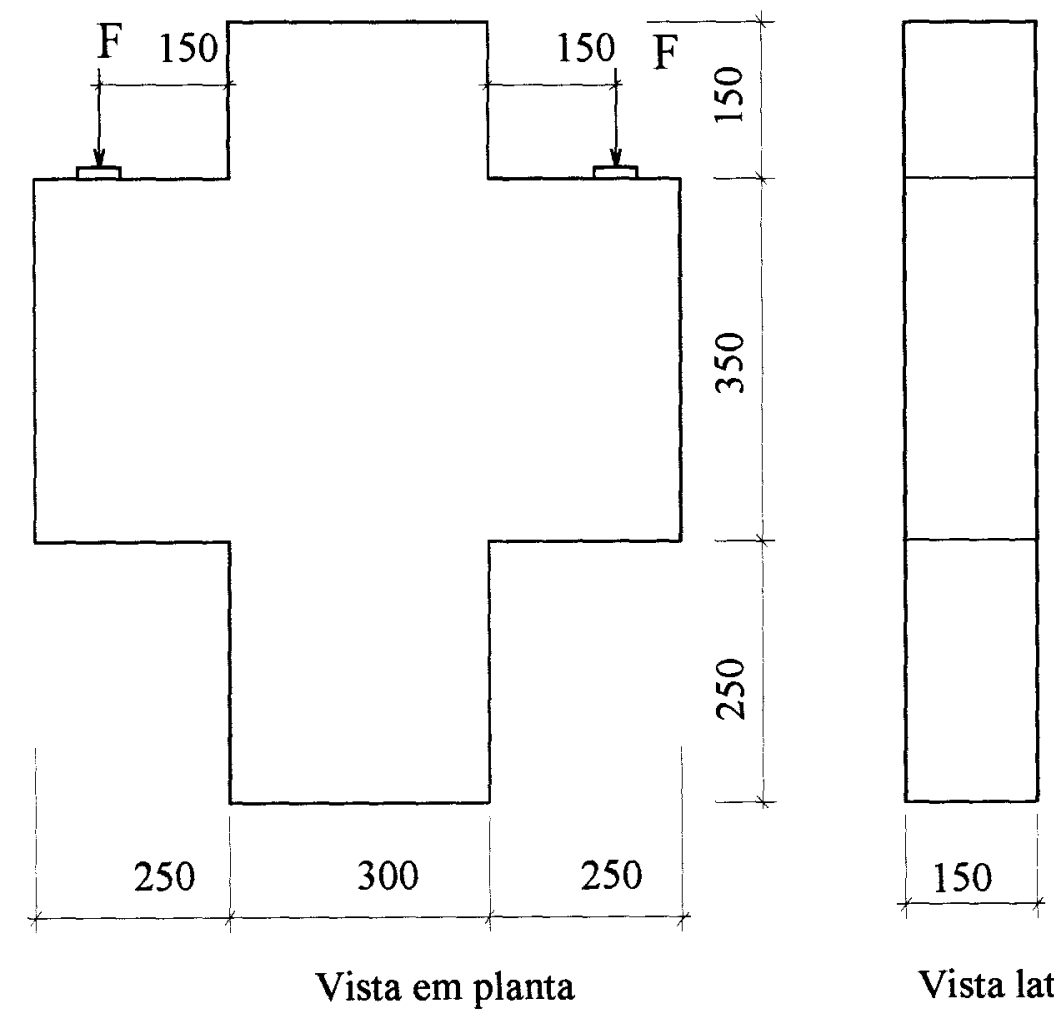

Figura 4.1 - Dimensões dos consolos

Vista lateral 


\section{2 - ARMADURA DOS CONSOLOS}

Neste item, serão descritos os esquema de armação dos consolos.

As peças ensaiadas tiveram esquemas de armação conforme ilustrados nas figuras 4.2 e 4.3 ;

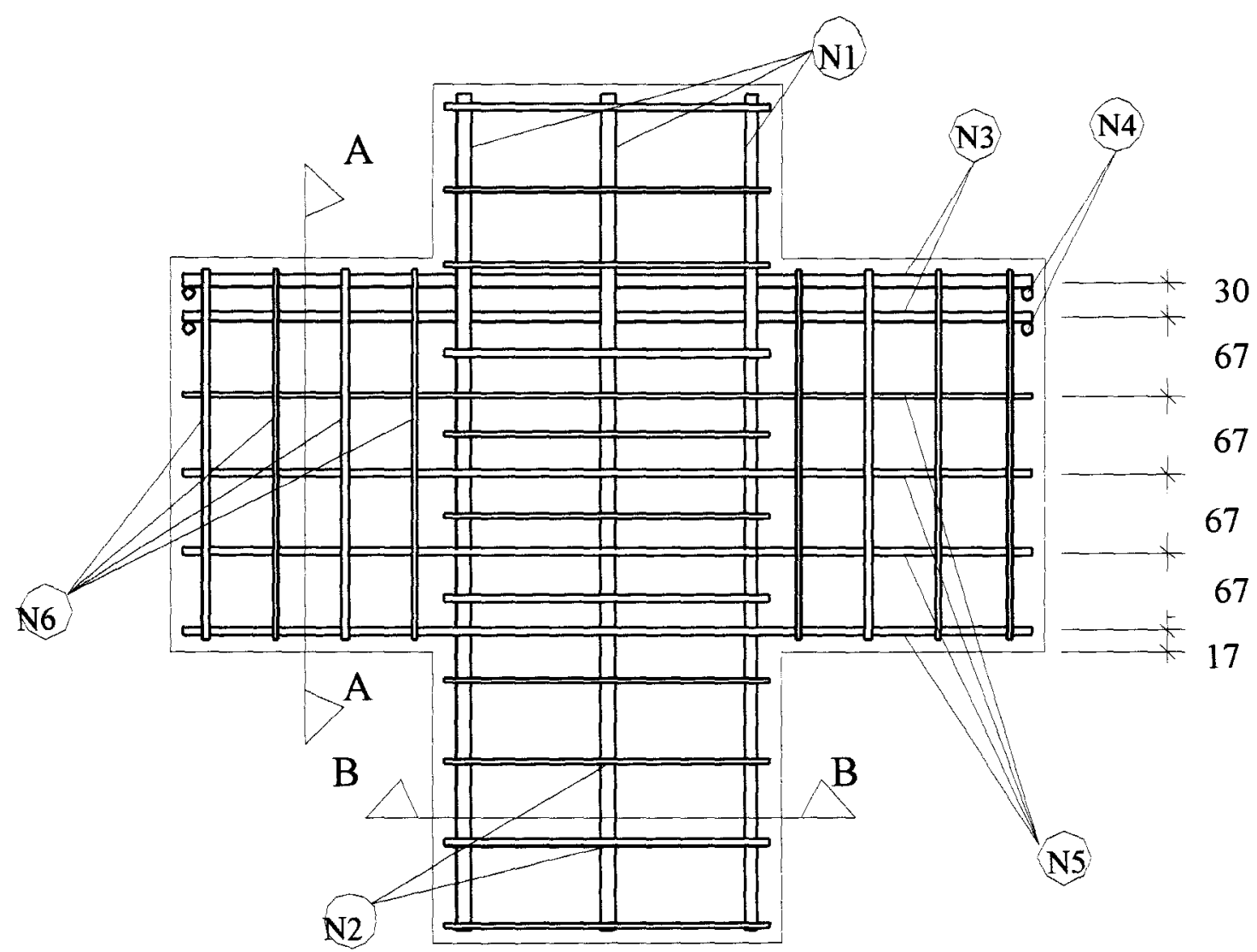

Figura 4.2 - Esquema geral de armadura dos consolos 
Corte AA

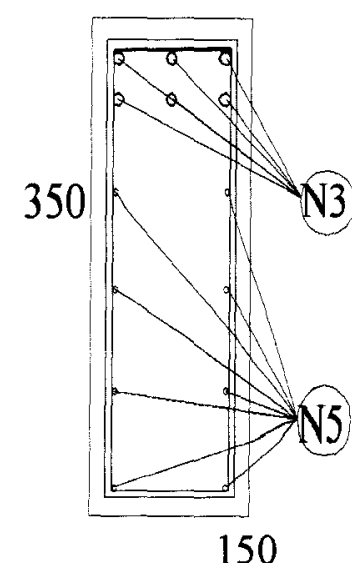

150

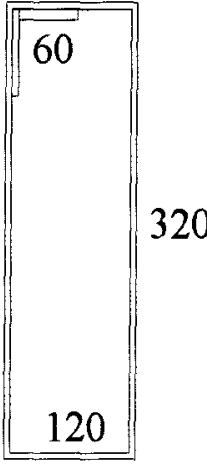

$8 \mathrm{~N} 6 \phi$ var. $\mathrm{L}=980 \mathrm{~mm}$

\section{Corte BB}

150
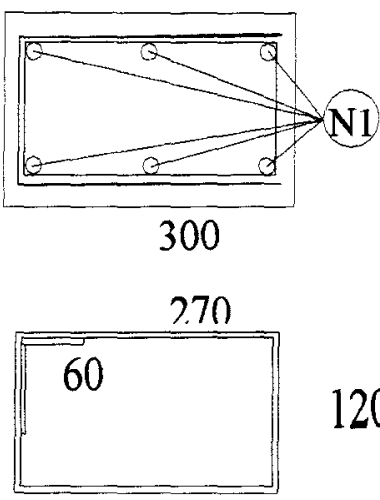

120

$11 \mathrm{~N} 2 \phi 5 \mathrm{~L}=900 \mathrm{~mm}$
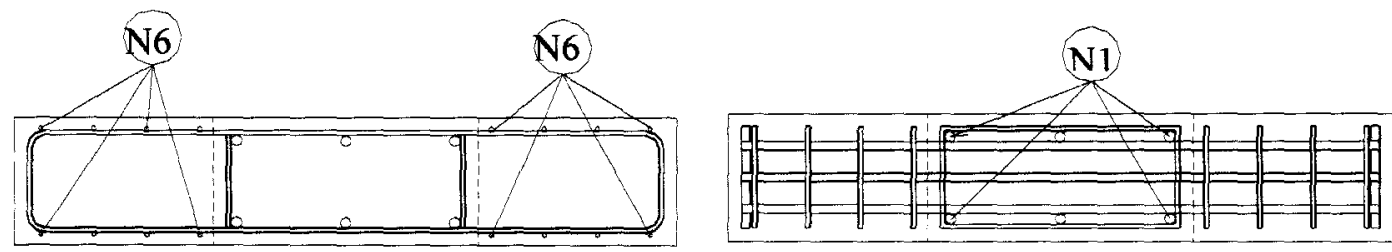

$6 \mathrm{~N} 1 \phi 12.5 \mathrm{~L}=720 \mathrm{~mm}$

$4 \mathrm{~N} 3 \phi 12,5 \mathrm{~L}=770 \mathrm{~mm}$

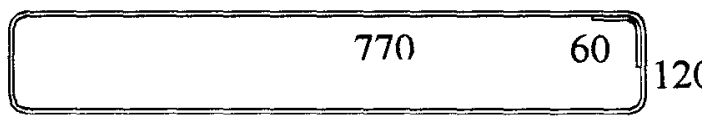

$4 \mathrm{~N} 5 \phi$ var. $\mathrm{L}=1900 \mathrm{~mm}$

$4 \mathrm{~N} 4 \phi 12,5 \mathrm{~L}=120 \mathrm{~mm}$

Figura 4.3 - Detalhe da armadura

A quantidade e a bitola de cada armadura estão indicadas na tabela 4.1; os nomes dos consolos foram adotados na forma " $\mathrm{CH} \phi \mathrm{V} \phi$ ", onde $\mathrm{C}$ significa consolo, $\mathrm{H} \phi$ representa a bitola dos estribos horizontais e $\mathrm{V} \phi$ bitola dos estribos verticais; 
Tabela 4.1 - Quantidade e diâmetro da armadura usada em cada consolo

\begin{tabular}{|c|c|c|c|c|c|c|c|}
\hline \multirow{2}{*}{ Série } & \multirow{2}{*}{ Consolo } & \multicolumn{7}{|c|}{ Armadura (em mm) } \\
\cline { 3 - 9 } & & $\mathrm{N} 1$ & $\mathrm{~N} 2$ & $\mathrm{~N} 3$ & $\mathrm{~N} 4$ & $\mathrm{~N} 5$ & N6 \\
\hline \multirow{2}{*}{$1^{\mathrm{a}}$} & CH0V0 & $6 \phi 12,5$ & $11 \phi 5$ & $4 \phi 12,5$ & $4 \phi 12,5$ & - & - \\
\cline { 2 - 8 } & CH5V5 & $"$ & $"$ & $"$ & $"$ & $4 \phi 5,0$ & - \\
\hline \multirow{2}{*}{$2^{\mathrm{a}}$} & CH5V0 & $"$ & $"$ & $"$ & $"$ & $4 \phi 5,0$ & - \\
\cline { 2 - 8 } & CH0V5 & $"$ & $"$ & $"$ & $"$ & - & $8 \phi 5,0$ \\
\hline \multirow{2}{*}{$3^{\mathrm{a}}$} & CH4V0 & $"$ & $"$ & $"$ & $"$ & - & $8 \phi 4,2$ \\
\cline { 2 - 8 } & CH4V4 & $"$ & $"$ & $"$ & $"$ & $4 \phi 4,2$ & $8 \phi 4,2$ \\
\hline \multirow{2}{*}{$4^{\mathrm{a}}$} & CH6V0 & $"$ & $"$ & $"$ & $"$ & $4 \phi 6,3$ & - \\
\cline { 2 - 8 } & CH4V4* & $"$ & $"$ & $"$ & $"$ & $4 \phi 4,2$ & - \\
\hline
\end{tabular}

\section{3 - CARACTERÍSTICAS DOS MATERIAIS}

Neste item, serão descritas as características do aço e do concreto utilizados para a confecção dos consolos.

\subsection{1 - Características do aço utilizado}

Para obtenção do módulo de elasticidade, tensão de escoamento e tensão de ruptura do aço, foram ensaiadas pelo menos duas amostras de cada bitola; estas amostras foram ensaiadas à tração, com extensômetros colados em suas laterais. Estes extensômetros foram colados ao pares nas barras de $\phi 12,5 \mathrm{~mm}$ e apenas um em cada barra com diâmetro inferior a $6,3 \mathrm{~mm}$.

$\mathrm{Na}$ tabela 4.2, estão apresentadas as características das barras de aço utilizadas e, na figura 4.4, estão indicados os diagramas tensão versus deformação da armadura. 
Tabela 4.2 - Características do aço das armaduras utilizadas

\begin{tabular}{|c|c|c|c|c|}
\hline Bitola & $\begin{array}{c}\text { Tensão de } \\
\text { escoamento }\end{array}$ & $\begin{array}{c}\text { Tipo de } \\
\text { aço }\end{array}$ & $\begin{array}{c}\text { Tensão de } \\
\text { ruptura }\end{array}$ & $\begin{array}{c}\text { Mod. de } \\
\text { elasticidade }\end{array}$ \\
\hline 4,2 & $695,0 \mathrm{MPa}$ & CA-60 & $776,0 \mathrm{MPa}$ & $210 \mathrm{GPa}$ \\
\hline 5,0 & $760,0 \mathrm{MPa}$ & CA-60 & $850,5 \mathrm{MPa}$ & $215 \mathrm{GPa}$ \\
\hline 6,3 & $594,3 \mathrm{MPa}$ & CA-50 & $819,4 \mathrm{MPa}$ & $190 \mathrm{GPa}$ \\
\hline 12,5 & $486,0 \mathrm{MPa}$ & CA-50 & $750,0 \mathrm{MPa}$ & $205 \mathrm{GPa}$ \\
\hline
\end{tabular}

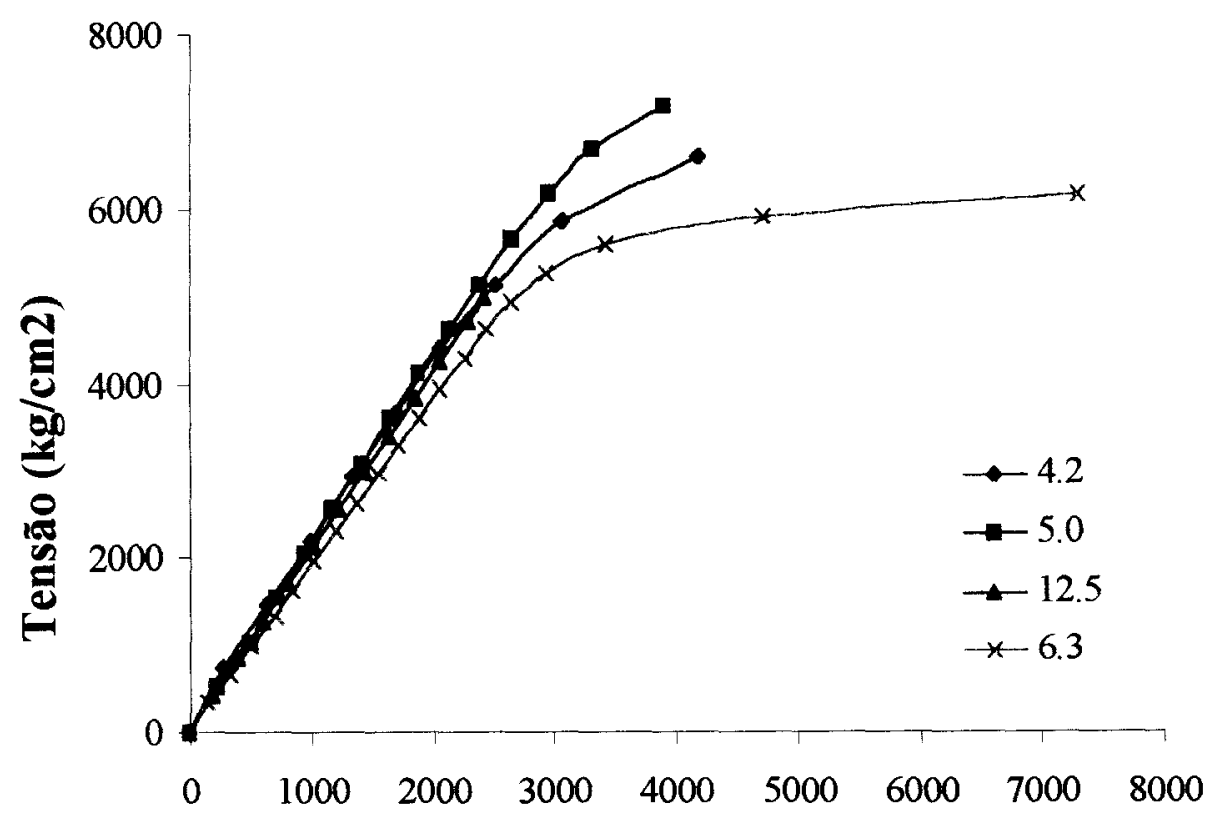

Deformação

Figura 4.4 - Gráfico tensão versus deformação da armadura

\subsection{2 - Características do concreto e procedimento de mistura}

Para a confecção dos consolos, foram utilizados dois traços: um foi o adotado por GIONGO et al. (1996) e o outro foi obtido através de estudo de traço no Laboratório de Estruturas da EESC. Estes traços consistiam em dosagem de concreto 
de alta resistência. O traço proposto por GIONGO et al. (1996) foi utilizado em todos os consolos, excetuando o consolo CH4V4*. Na tabela 4.3, podem ser vistas as quantidades de material utilizadas em cada traço.

Tabela 4.3 - Traço de concreto utilizado nos ensaios

\begin{tabular}{|l|c|c|}
\hline \multirow{2}{*}{ Material } & \multicolumn{2}{|c|}{ Consumo $\left(\mathrm{kg} / \mathrm{m}^{3}\right)$} \\
\cline { 2 - 3 } & GIONGO & L.E . EESC \\
\hline Cimento & 480,00 & 400,00 \\
\hline Sílica ativa & 48,00 & - \\
\hline Areia & 577,92 & 750,00 \\
\hline Brita 1 & 1198,09 & 1050,00 \\
\hline Superplastificante & 17,43 & 15,36 \\
\hline Água & 160,60 & 177,00 \\
\hline
\end{tabular}

$\mathrm{O}$ procedimento de mistura adotado consistiu em deixar o agregado graúdo rodando a seco na betoneira por 3 minutos, para que uma parcela do pó de pedra fosse retirada. Em seguida, adicionou-se $20 \%$ da água e foi deixada a betoneira rodar por 2 minutos. Depois foram adicionados o cimento, a sílica ativa e $50 \%$ da água, fechando a betoneira com um saco plástico, para que a sílica ativa não saísse, e deixando a betoneira rodar por 2 minutos. Por fim, adicionou-se o restante da água e deixou-se a betoneira girar por mais 3 minutos.

As resistências do concreto à tração e à compressão foram obtidas através de ensaios por compressão simples e compressão diametral, respectivamente. Para cada tipo de ensaio foram utilizados três corpos-de-prova, sendo que, em dois corpos-deprova, dos utilizados nos ensaios de compressão simples, foram colocados extensômetros elétricos para obtenção do módulo de elasticidade. O resultado final foi obtido através da média dos valores obtidos nos ensaios. Esses valores podem ser observados na tabela 4.4 . 
Tabela 4.4 - Características do concreto utilizado

\begin{tabular}{|c|c|c|c|}
\hline \multirow{2}{*}{ Consolo } & \multicolumn{2}{|c|}{ Resistência do concreto (em MPa) } & $\begin{array}{c}\text { Módulo de } \\
\text { Elasticidade (GPa) }\end{array}$ \\
\cline { 2 - 3 } & à compressão & à tração & 36,7 \\
\hline CH0V0 & 74,16 & 4,55 & 33,2 \\
\hline CH5V5 & 72,15 & 3,67 & 42,5 \\
\hline CH5V0 & 69,04 & 4,40 & 31,0 \\
\hline CH0V5 & 67,90 & 4,54 & 42,1 \\
\hline CH4V4 & 69,01 & 4,42 & 49,7 \\
\hline CH4V0 & 79,25 & 4,59 & 38,2 \\
\hline CH6V0 & 70,41 & 4,46 & 28,6 \\
\hline CH4V4* & 50,38 & 3,15 & \\
\hline
\end{tabular}

* Armadura igual ao $\mathrm{CH} 4 \mathrm{~V} 4$, concreto de resistência mais baixa

\section{4 - CONCRETAGEM E CURA}

Os consolos foram concretados em fồrmas de madeirite. Estas fôrmas eram constituídas por placas unidas por parafuso e pedaços de caibro, para garantir os cantos retos nas bordas da estrutura.

As fôrmas com as armaduras foram colocadas sobre uma mesa vibratória e o concreto foi despejado com auxílio de pás, tomando-se o cuidado para não danificar os extensômetros. A figura 4.5 ilustra como foram montadas as fồmas sobre a mesa vibratória.

A cura foi feita ao ar livre e, após o início de pega do concreto, as peças foram protegidas com espuma mantida umidecida por pelo menos dois dias, com a finalidade de diminuir a retração do concreto. Os corpos-de-prova foram colocados em tanques de cura e onde permaneceram, durante o tempo de cura das peças. 


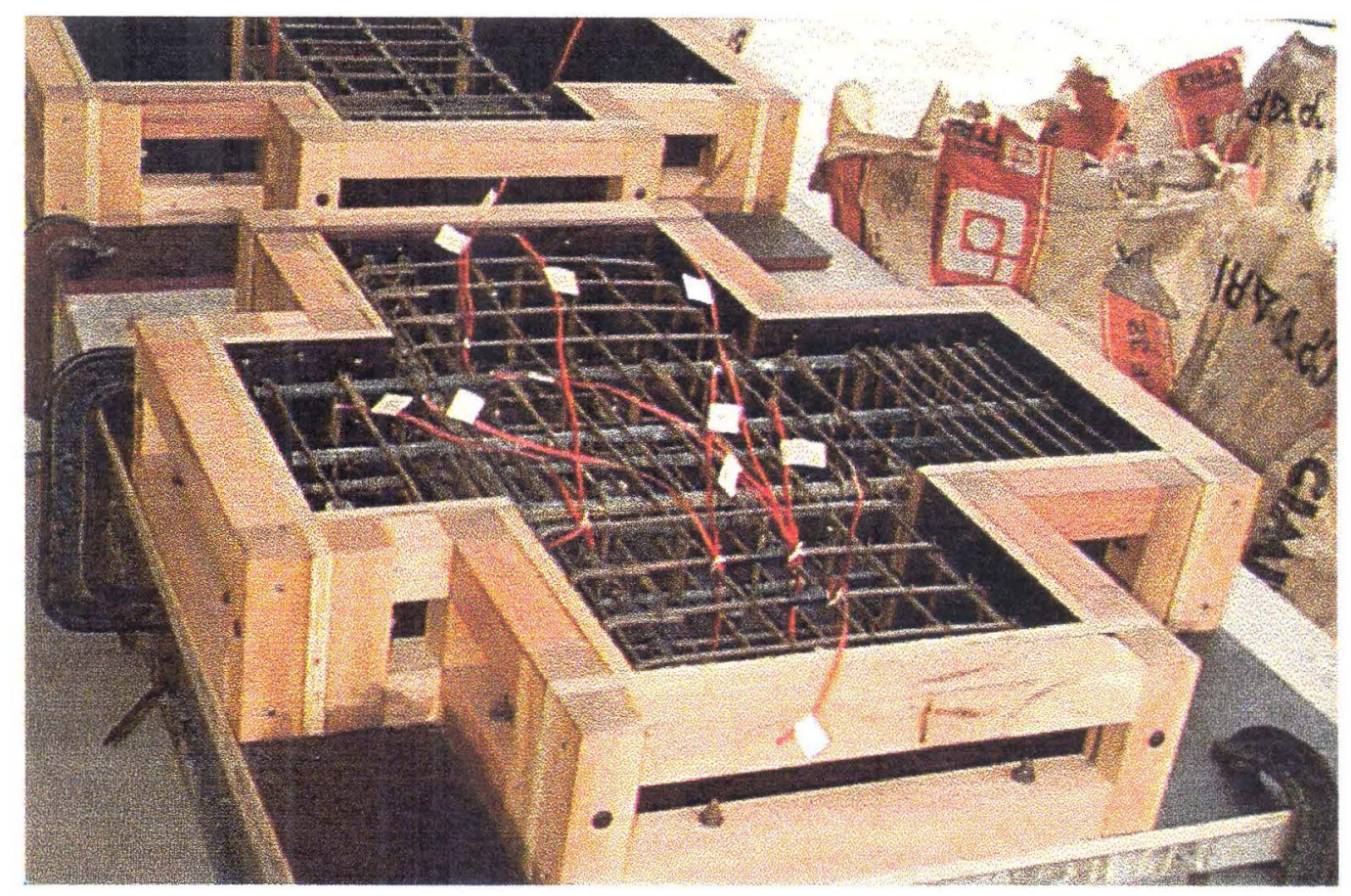

Figura 4.5 - Concretagem dos consolos

\section{5 - INSTRUMENTAÇÃO}

A instrumentação dos consolos foi dividida em duas partes: a primeira composta por extensômetros elétricos colados na armadura e a segunda de extensômetros, rosetas e defletômetros colados na superfície do concreto.

\subsection{1 - Extensômetros colados na armadura}

Foram colocados extensômetros elétricos na armadura, com a finalidade de obter a deformação em cada estágio de carregamento. A figura 4.6 apresenta um esquema geral da instrumentação colada nas barras de aços dos consolos. 


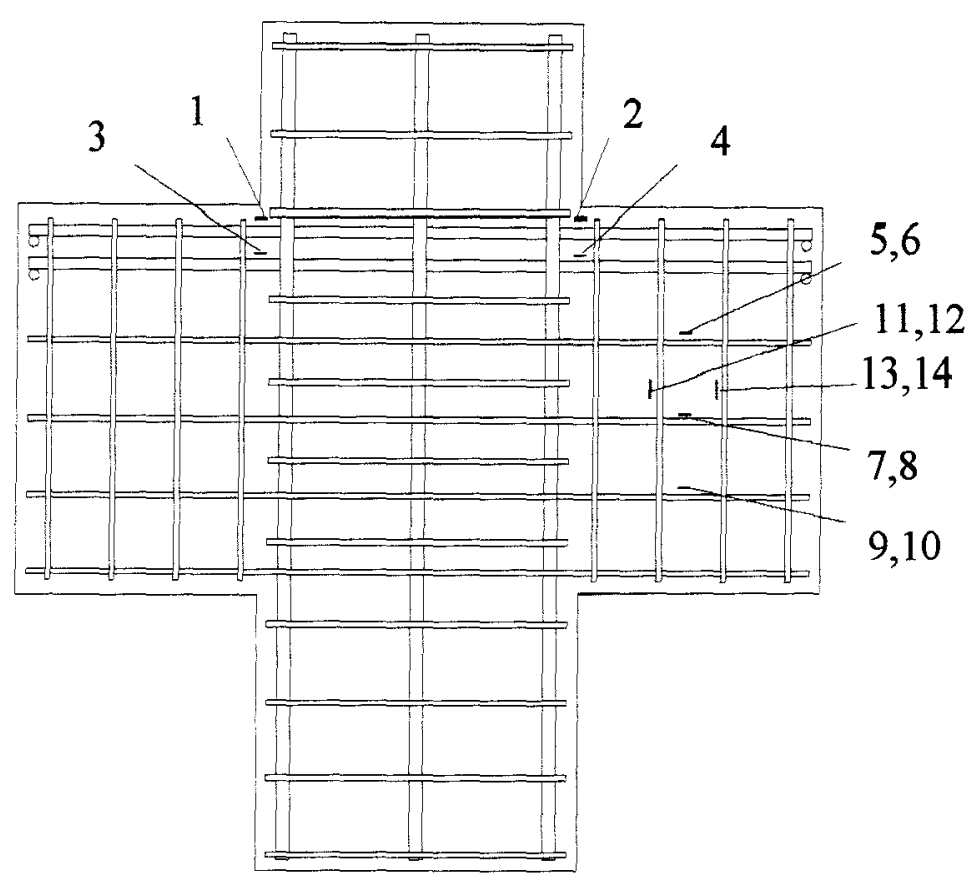

Figura 4.6 - Instrumentação na armadura dos consolos

$\mathrm{Na}$ tabela 4.5, estão indicados os extensômetros presentes em cada consolo.

Tabela 4.5 - Posicionamento dos extensômetros

\begin{tabular}{|l|c|c|c|c|c|c|c|c|c|}
\hline \multirow{2}{*}{ Consolos } & \multicolumn{7}{|c|}{ Extensômetros } \\
\cline { 2 - 10 } & 1 & 2 & 3 & 4 & 5,6 & 7,8 & 9,10 & 11,12 & 13,14 \\
\hline CH0V0 & $\bullet$ & $\bullet$ & $\bullet$ & $\bullet$ & - & - & - & - & - \\
\hline CH5V5 & $\bullet$ & $\bullet$ & $\bullet$ & $\bullet$ & $\bullet$ & $\bullet$ & - & - & $\bullet$ \\
\hline CH5V0 & $\bullet$ & $\bullet$ & $\bullet$ & $\bullet$ & $\bullet$ & - & $\bullet$ & - & - \\
\hline CH0V5 & $\bullet$ & $\bullet$ & $\bullet$ & $\bullet$ & - & - & - & $\bullet$ & $\bullet$ \\
\hline CH4V4 & $\bullet$ & $\bullet$ & $\bullet$ & $\bullet$ & $\bullet$ & $\bullet$ & - & $\bullet$ & $\bullet$ \\
\hline CH4V0 & $\bullet$ & $\bullet$ & $\bullet$ & $\bullet$ & $\bullet$ & $\bullet$ & - & - & - \\
\hline CH6V0 & $\bullet$ & $\bullet$ & $\bullet$ & $\bullet$ & $\bullet$ & $\bullet$ & - & - & - \\
\hline CH4V4* & $\bullet$ & $\bullet$ & $\bullet$ & $\bullet$ & $\bullet$ & $\bullet$ & - & $\bullet$ & $\bullet$ \\
\hline
\end{tabular}




\subsection{2 - Instrumentação na superficie do concreto}

$\mathrm{Na}$ superfície do concreto dos consolos $\mathrm{CH} 0 \mathrm{~V} 0$ e CH5V5 foram colocados: quatro extensômetros elétricos, colados no banzo comprimido dos consolos, com a finalidade de descobrir a posição da linha neutra; uma roseta elétrica para obter o ângulo de inclinação das tensões principais na região da biela e defletômetros para medir a rotação do consolo em relação ao pilar. A posição desta instrumentação está indicada na figura 4.7.a.

Na superficie do concreto dos demais consolos foram colocadas: duas rosetas elétricas, coladas no banzo comprimido do consolos, com a finalidade de descobrir a posição da linha neutra; uma roseta elétrica para obter o ângulo de inclinação das tensões principais na região da biela e defletômetros para medir a rotação do consolo em relação ao pilar. A posição desta instrumentação está indicada na figura 4.7.b.

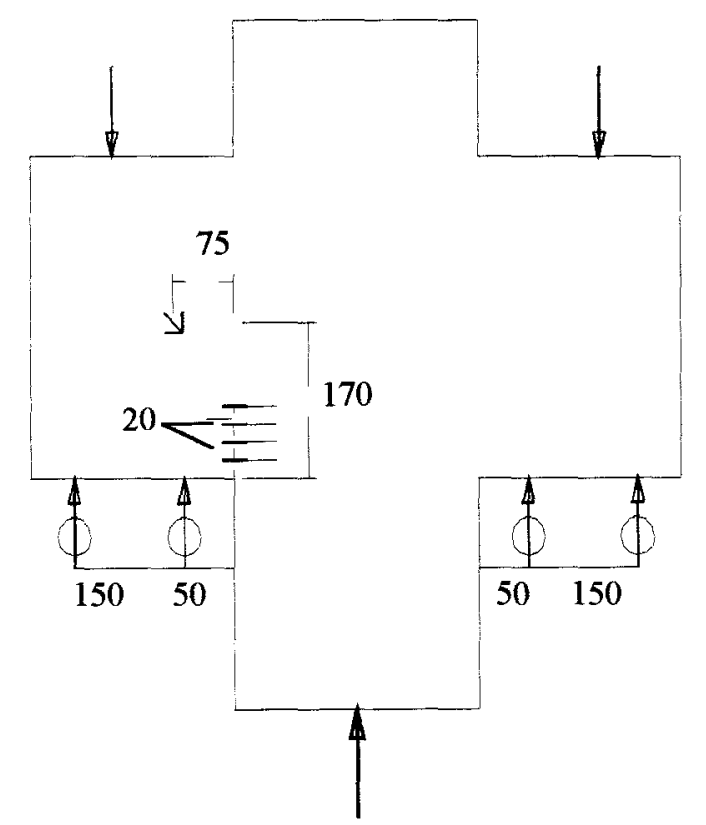

(a)

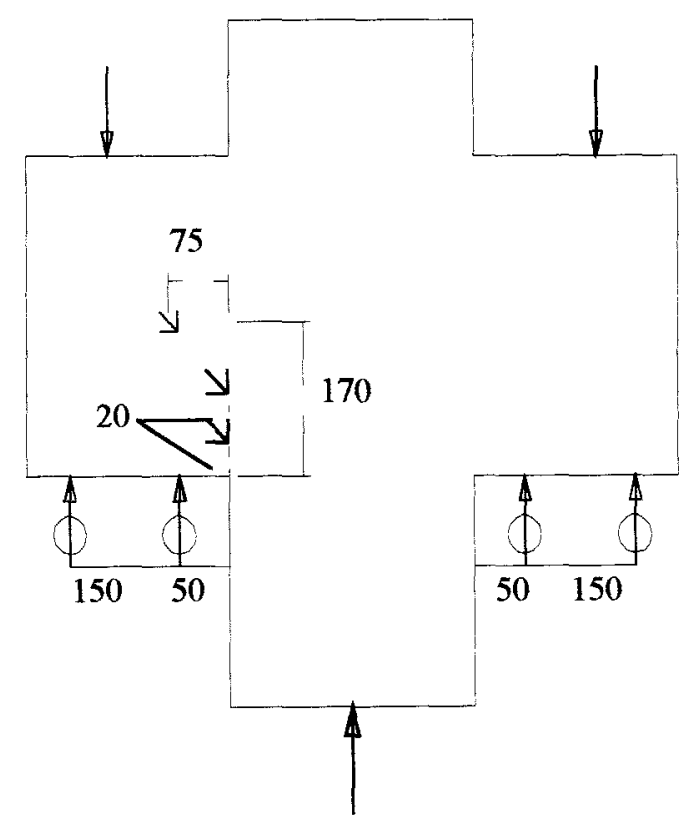

(b)

Figura 4.7 - Instrumentação na superfície do concreto 


\section{6 - ESQUEMA E PROCEDIMENTO DE ENSAIO}

O esquema de ensaio considerou os consolos de cabeça para baixo, ou seja, a estrutura foi ensaiada ao contrário de como ela normalmente é utilizada.

Os consolos foram colocados sobre apoios móveis metálicos, que reagiam em uma viga metálica. Esta viga se apoiava em um macaco de capacidade $5000 \mathrm{kN}$, que estava sobre uma viga de reação. Para reagir foi usado um pórtico metálico. A figura 4.8 ilustra como foi a montagem do ensaio.

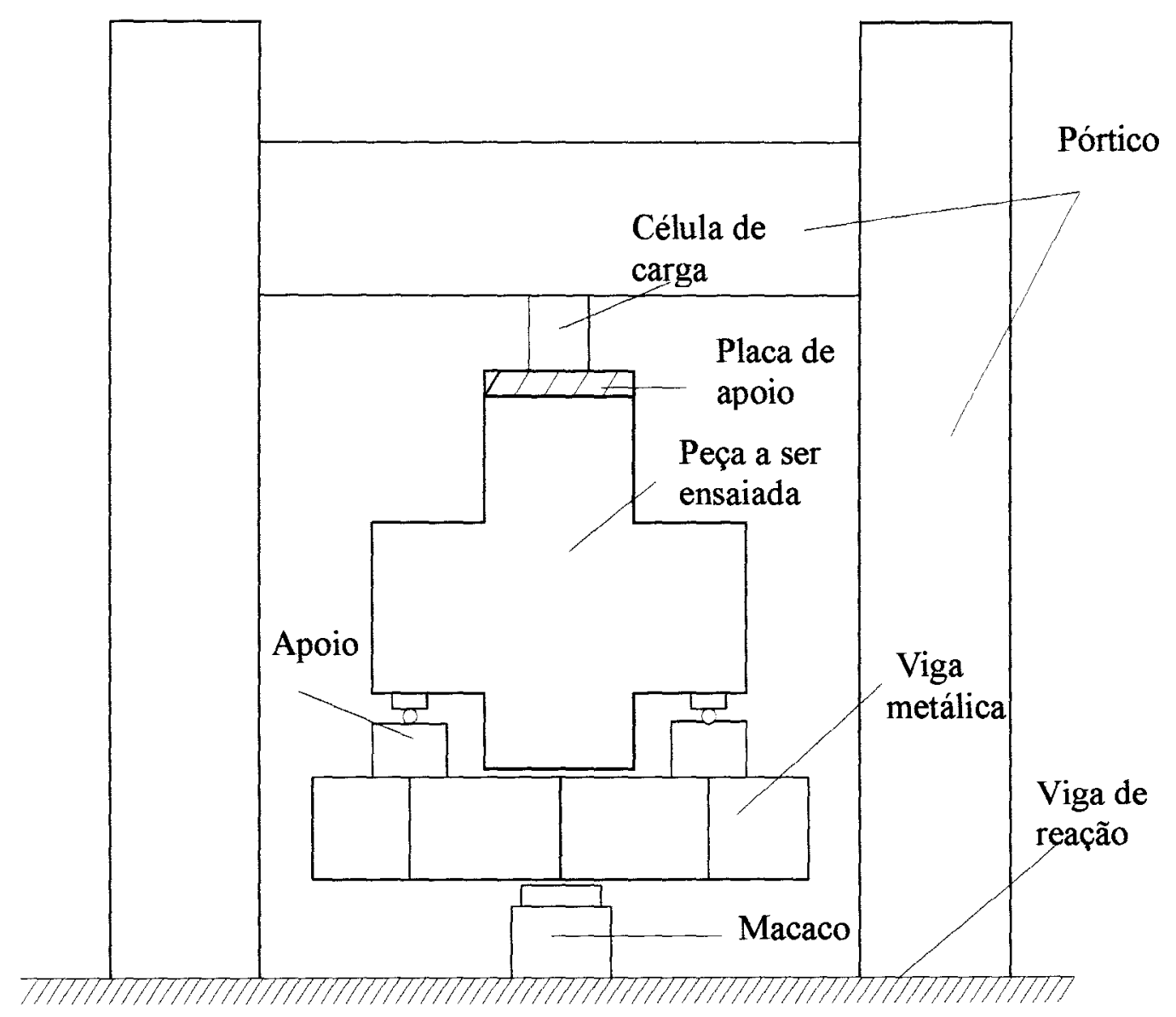

Figura 4.8 - Esquema de ensaio dos consolos

Antes de iniciar o ensaio, foram realizados testes com a instrumentação, aplicando incrementos de força de $20 \mathrm{kN}$ até atingir $100 \mathrm{kN}$. Neste estágio o conjunto foi descarregado e a instrumentação verificada. Se a instrumentação estivesse funcionando, então iniciava-se o ensaio. 
A fase inicial da aplicação de forças, que ia até o início da fissuração da peça, foi feita em incrementos de $20 \mathrm{kN}$ e, após a fissuração, a força foi aplicada em incrementos de $50 \mathrm{kN}$, até a ruína da peça. A cada estágio de aplicação de forças, foram realizadas leituras na instrumentação e marcadas as fissuras. Em estágios mais avançados de carregamento, a marcação de fissuras foi suspensa devido a riscos de acidentes.

Os ensaios duravam em média de 20 a 30 minutos. 


\section{CAPÍTULO 5 - APRESENTAÇÃo E ANÁLISE dOS RESULTADOS}

Neste capítulo são apresentadas e analisadas: as forças de início de fissuração no consolo junto ao pilar e na região da biela, as forças de ruína, os diagramas força aplicada versus deformação na armadura, força aplicada versus rotação do consolo em relação ao pilar, força aplicada versus ângulo de inclinação das tensões principais no centro geométrico dos consolos e o cálculo dos consolos de acordo com normas nacionais e internacionais. Ainda será apresentada uma análise paramétrica, em função da resistência do concreto e da taxa de armadura de distribuição dos consolos.

\section{1 - DESENVOLVIMENTO DAS FISSURAS E MECANISMOS DE RUÍNA}

Neste item, serão apresentadas as forças e o desenvolvimento das fissuras e as forças e os mecanismos de ruína.

\subsection{1 - Desenvolvimento das fissuras}

Inicialmente, as fissuras surgiram na ligação do consolo com o pilar. Estas fissuras surgiram com uma força variando de $160 \mathrm{kN}$ a $200 \mathrm{kN}$. Com o aumento da força aplicada, estas fissuras iam se desenvolvendo.

Em estágios mais avançados, surgiram fissuras na região da biela comprimida, com a força variando de $250 \mathrm{kN}$ a $400 \mathrm{kN}$. 
A partir do aparecimento das fissuras na região da biela, quase não houve surgimento de novas fissuras. O que ocorreu foi o desenvolvimento e o aumento da abertura das já existentes. As forças de início de fissuração no consolo e na biela estão indicadas na tabela 5.1 e um exemplo típico do desenvolvimento das fissuras pode ser observado na figura 5.1.

Tabela 5.1 - Forças de fissuração e de ruína das peças

\begin{tabular}{|c|c|c|c|}
\hline \multirow{2}{*}{ Consolo } & \multicolumn{2}{|c|}{ Forças de fissuração $(\mathrm{kN})$} & \multirow{2}{*}{$\begin{array}{c}\text { Força de } \\
\text { ruína }(\mathrm{kN})\end{array}$} \\
\cline { 2 - 3 } & Início & Região da biela & 1000 \\
\hline CH0V0 & 200 & 400 & 1250 \\
\hline CH5V5 & 160 & 400 & 1070 \\
\hline CH5V0 & 160 & 400 & 965 \\
\hline CH0V5 & 200 & 400 & 1080 \\
\hline CH4V4 & 180 & 320 & 1160 \\
\hline CH4V0 & 180 & 400 & 1195 \\
\hline CH6V0 & 200 & 350 & 790 \\
\hline CH4V4* & 160 & 250 & \\
\hline
\end{tabular}

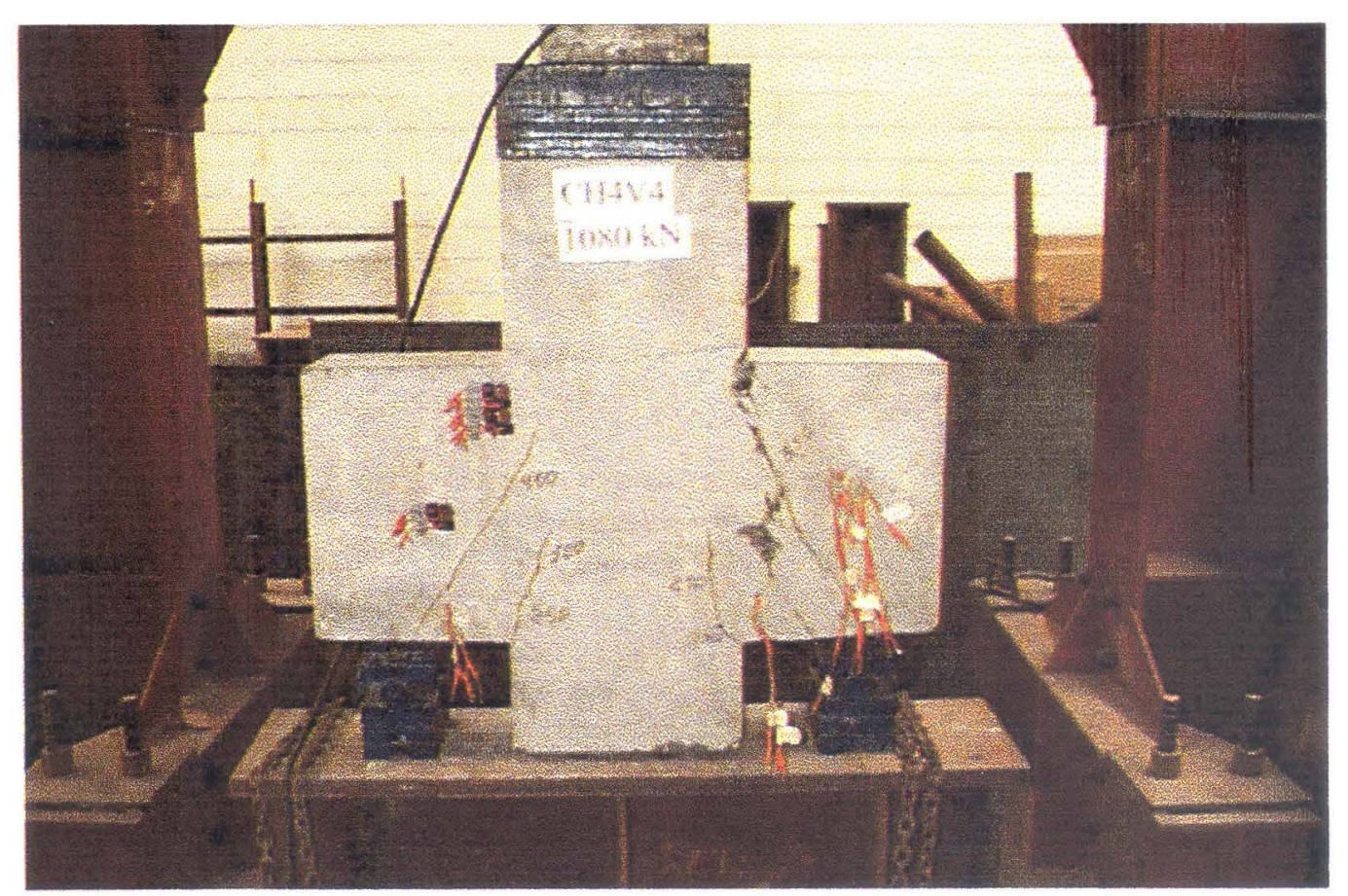

Figura 5.1 - Exemplo de fissuração e ruína dos consolos 


\subsection{2 - Mecanismos de ruína}

Como os consolos foram dimensionados e detalhados para que só ocorresse ruína por fendilhamento da biela comprimida, foi somente este tipo de ruína que ocorreu.

De maneira geral, a ruína nos consolos ocorreu com uma pequena quantidade de fissuras na região da biela comprimida. Entretanto, estas fissuras já apresentavam aberturas consideráveis.

$\mathrm{O}$ valor da força de ruína nas peças ensaiadas sofreu interferência da resistência do concreto e da taxa de armadura distribuída. Os valores das forças de ruína podem ser observados na tabela 5.1 e um exemplo típico dos mecanismos de ruína pode ser visto na figura 5.1.

\section{2 - DIAGRAMAS FORÇA APLICADA VERSUS DEFORMAÇÃO NA ARMADURA}

Em todas as peças, foram colocados extensômetros elétricos para medir a deformação das barras de aço em cada estágio de carregamento. Através dos valores obtidos nos ensaios, foram traçados gráficos de força aplicada versus deformação na armadura.

De maneira geral, para a armadura principal, as curvas apresentaram um trecho quase reto, bastante inclinado com relação à horizontal. Em seguida, estas curvas tinham um trecho curvo ou reto, porém com uma redução na inclinação, indicando que as barras passaram a ser mais solicitadas. Geralmente, esta mudança de inclinação surgiu após a força de fissuração da peça.

As curvas força aplicada versus deformação na armadura, para as barras da armadura de costura, foram bastante semelhantes às da armadura principal. Entretanto, estas curvas sofreram variações bruscas, próximas às forças de fissuração na biela. As curvas também sofreram influências do posicionamento das barras da armadura e dos extensômetros. 
Observando estes diagramas, pode-se notar a importância da armadura de costura, pois, na maioria dos consolos, quando a força aplicada estava próxima à força de ruína, a deformação na primeira camada da armadura de costura foi maior que a deformação na armadura principal.

Para as barras que compunham os estribos verticais, as curvas força aplicada versus deformação na armadura indicaram que, em consolos com relação a/d próxima a 0,5 , esta armadura praticamente não funciona com forças aplicadas próximas das solicitações de serviço.

A armadura formada pelos estribos verticais começou a funcionar após a força de fissuração do consolo na região da biela comprimida e teve um aproveitamento significativo quando a força aplicada estava próxima à força de ruína da peça.

Com base nas observações já mencionadas, nota-se que a armadura composta por estribos verticais, trabalhando junto com a armadura de costura, tem a função de ajudar na redistribuição dos esforços e melhorar a ductilidade e, em pequena quantidade, a resistência final da peça.

A seguir, serão apresentadas as figuras 5.2 a 5.9, nas quais são apresentados os gráficos força aplicada versus deformação na armadura, para todos os consolos.

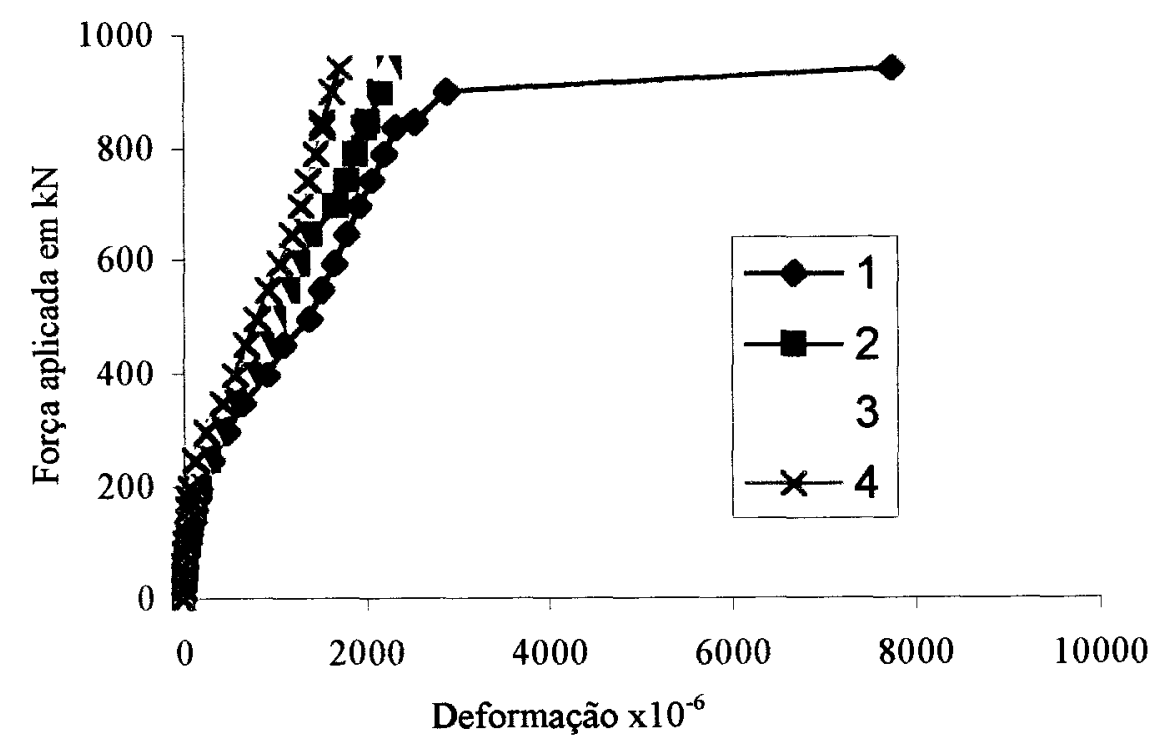

Figura 5.2 - Diagramas força aplicada versus deformação na armadura para consolo CHOVO 


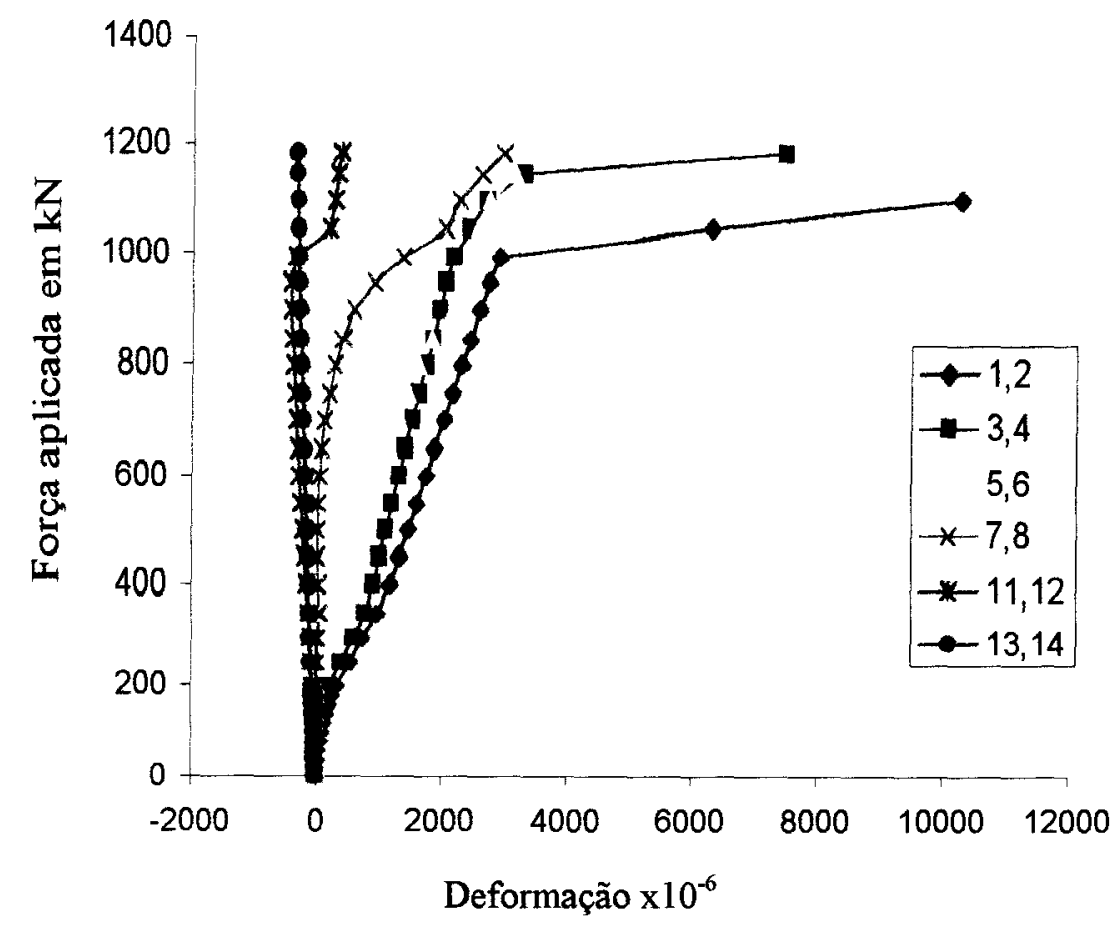

Figura 5.3 - Diagrama força aplicada versus deformação na armadura para consolo CH5V5

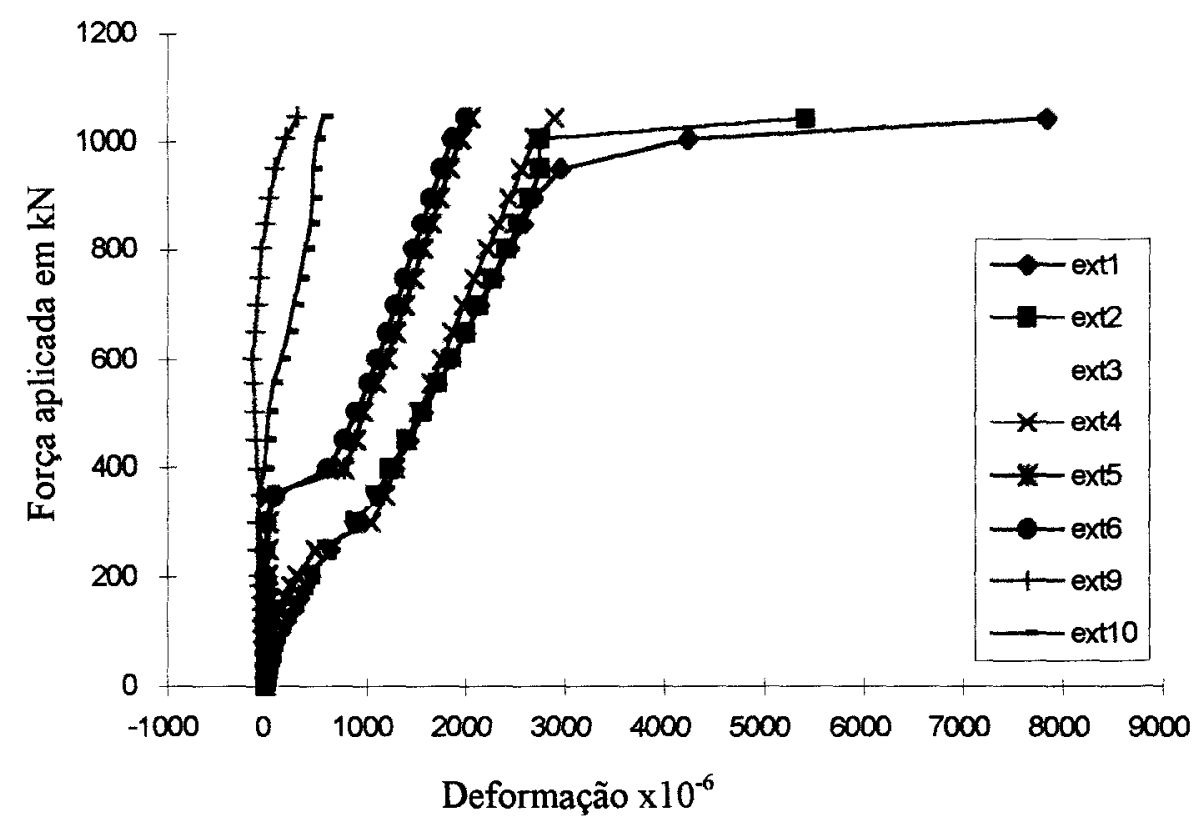

Figura 5.4 -Diagrama força aplicada versus deformação na armadura para consolo CH5VO 


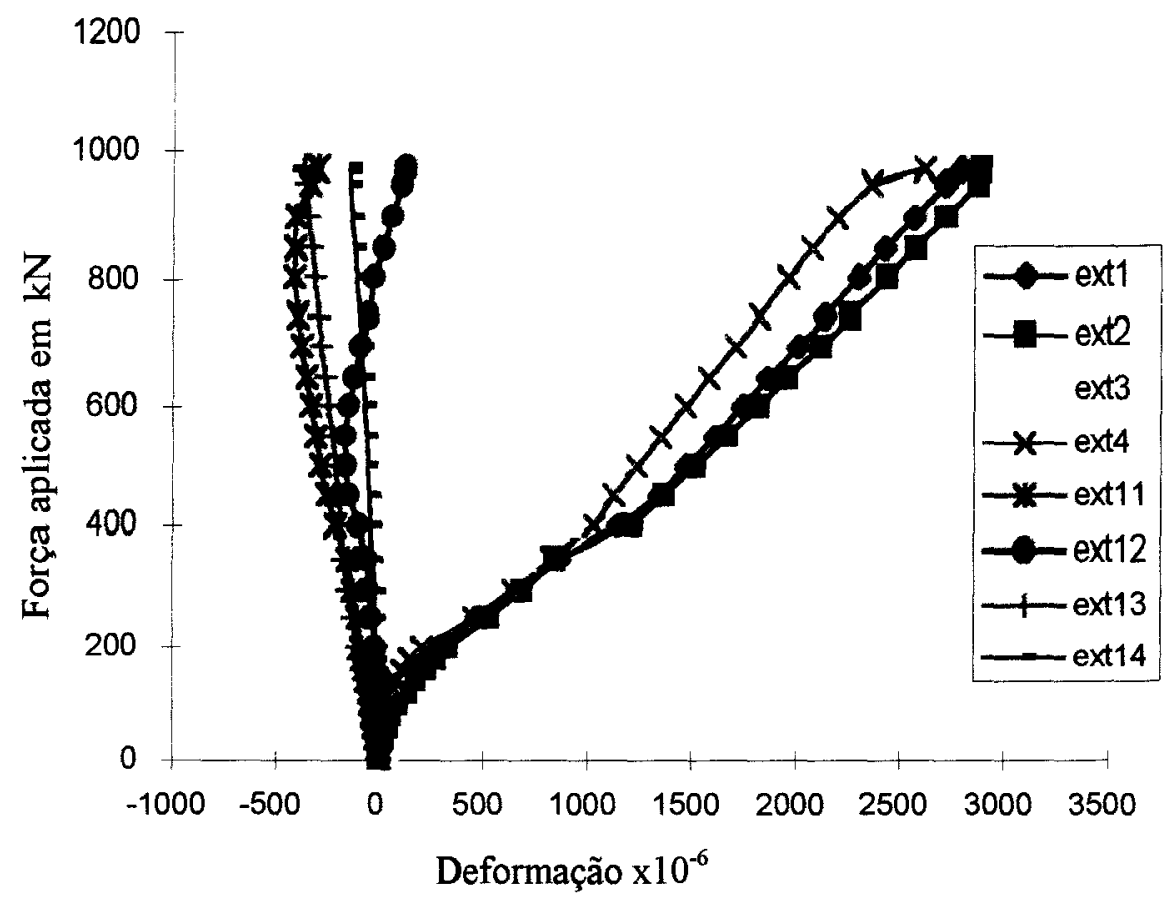

Figura 5.5 - Diagrama força aplicada versus deformação na armadura para consolo CHOV5

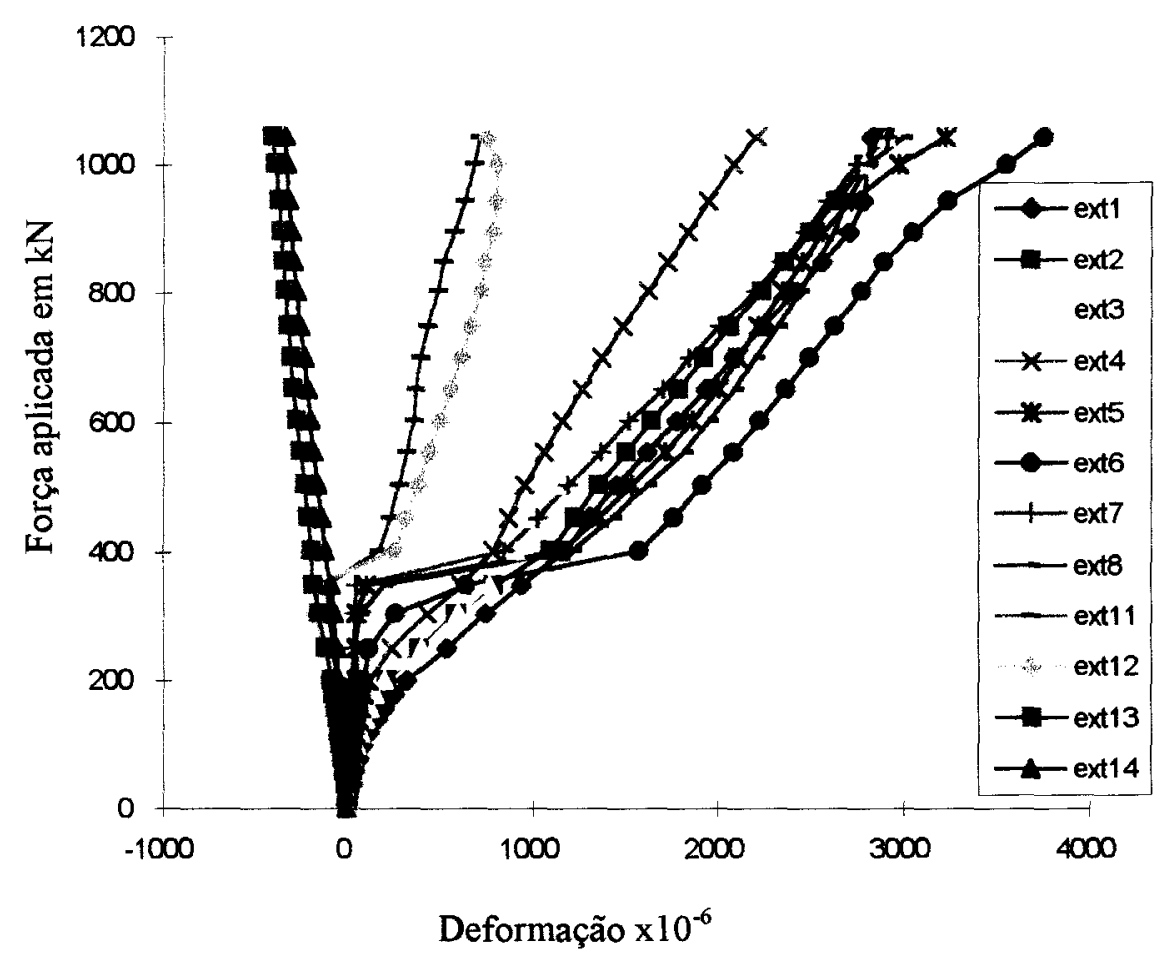

Figura 5.6 - Diagrama força aplicada versus deformação na armadura para consolo CH4V4 


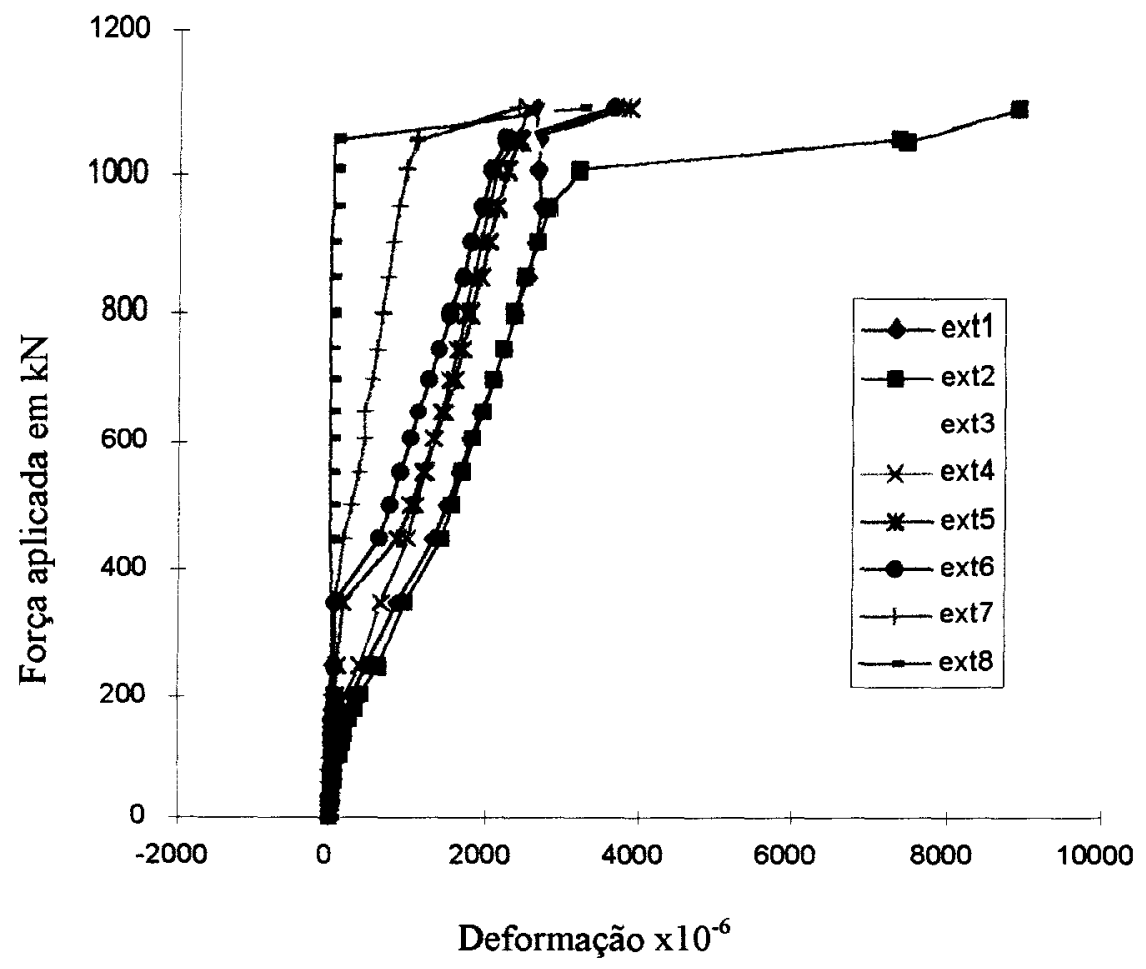

Figura 5.7 - Diagrama força aplicada versus deformação na armadura para consolo CH4V0

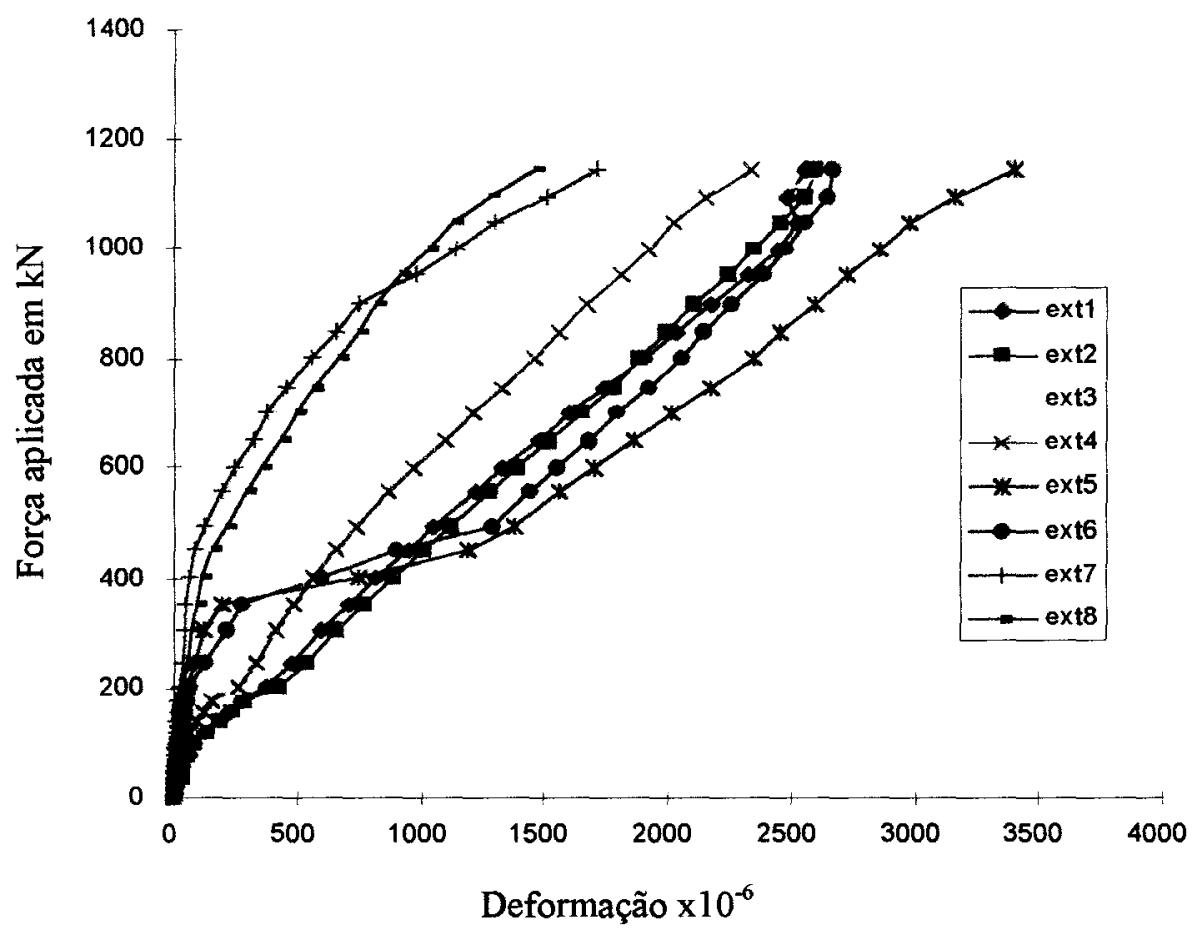

Figura 5.8 - Diagrama força aplicada versus deformação na armadura para consolo CH6V0 


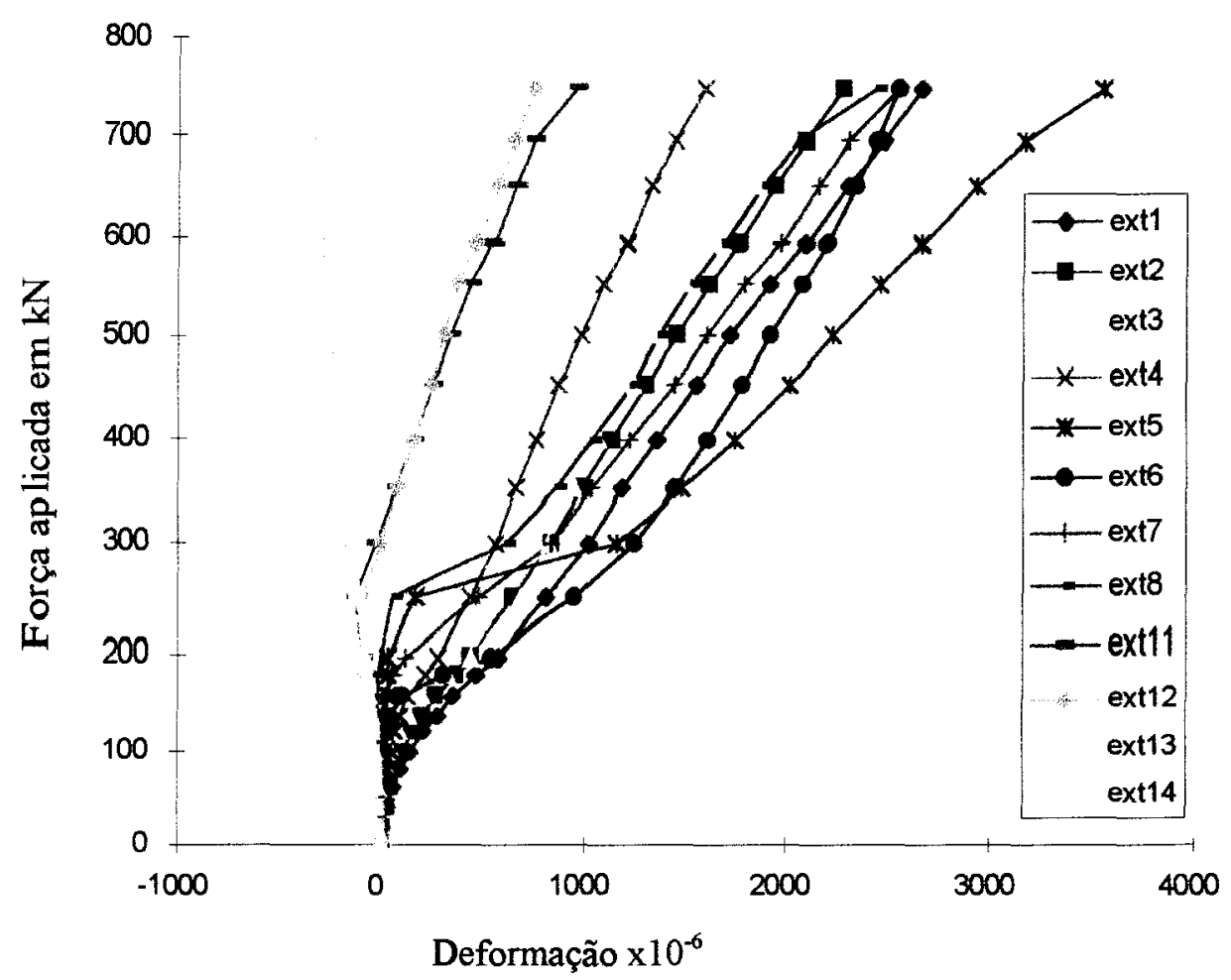

Figura 5.9 - Diagrama força aplicada versus deformação na armadura para consolo CH4V4*

\section{3 - DIAGRAMAS FORÇA APLICAdA VERSUS ROTAÇÃo DO CONSOLO EM RELAÇÃo AO PILAR}

Nas faces inferiores dos consolos, foram colocados defletômetros, fixados no pilar, para medir o deslocamento relativo do consolo com o pilar. Com os deslocamentos e com a distância entre os pontos de colocação dos defletômetros, foi calculada a rotação do consolo em relação ao pilar. Este procedimento foi realizado para cada nível de força aplicada.

A partir das rotações os consolos em relação aos pilares, foram montados gráficos de força aplicada versus rotação do consolo em relação ao pilar. Estes gráficos podem ser observados nas figuras 5.10 a 5.17 .

Com base nos gráficos, observa-se que quanto maior a taxa de armadura de costura, menor a rotação do consolo em relação ao pilar, para um mesmo nível de força aplicada. Nota-se ainda que quanto maior a taxa de armadura de costura e de 
estribos verticais, mais próximos foram os valores das rotações dos dois consolos em relação ao pilar central.

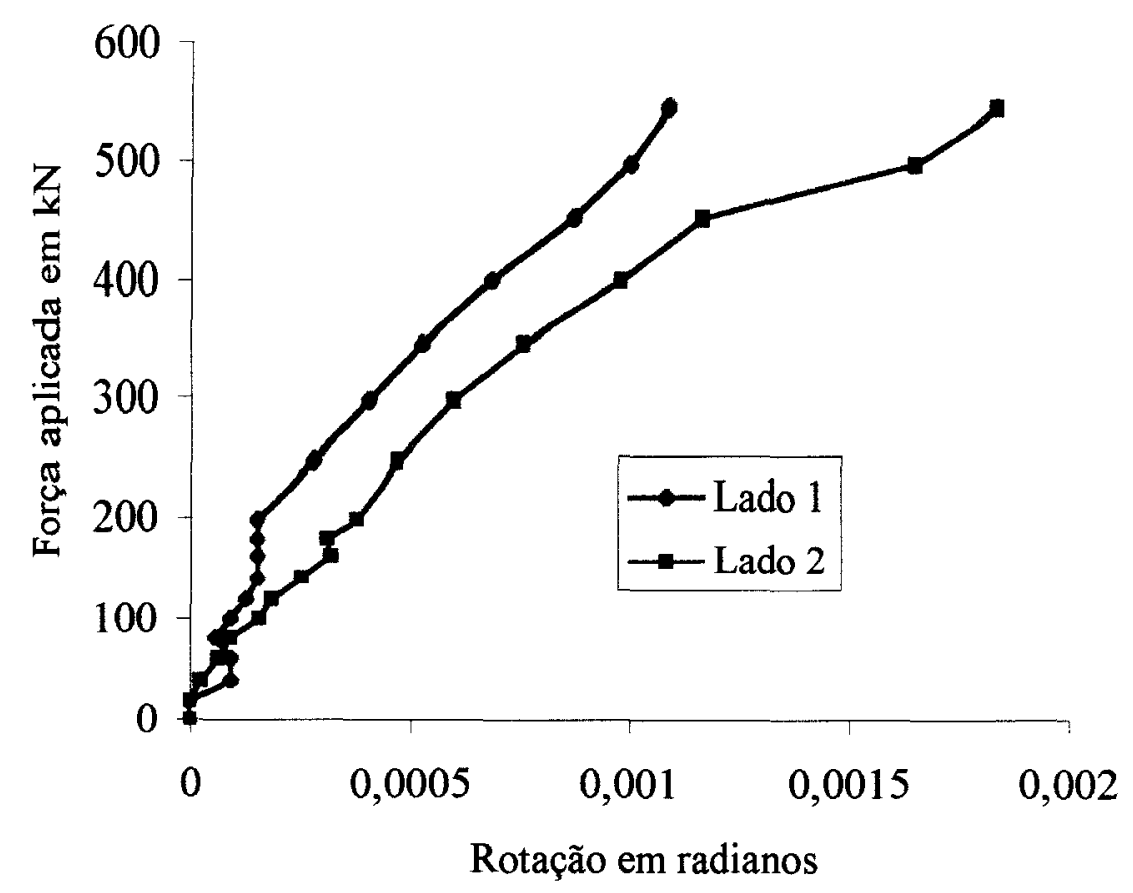

Figura 5.10 - Diagramas força aplicada x rotação do consolo em relação ao pilar para o consolo CHOVO

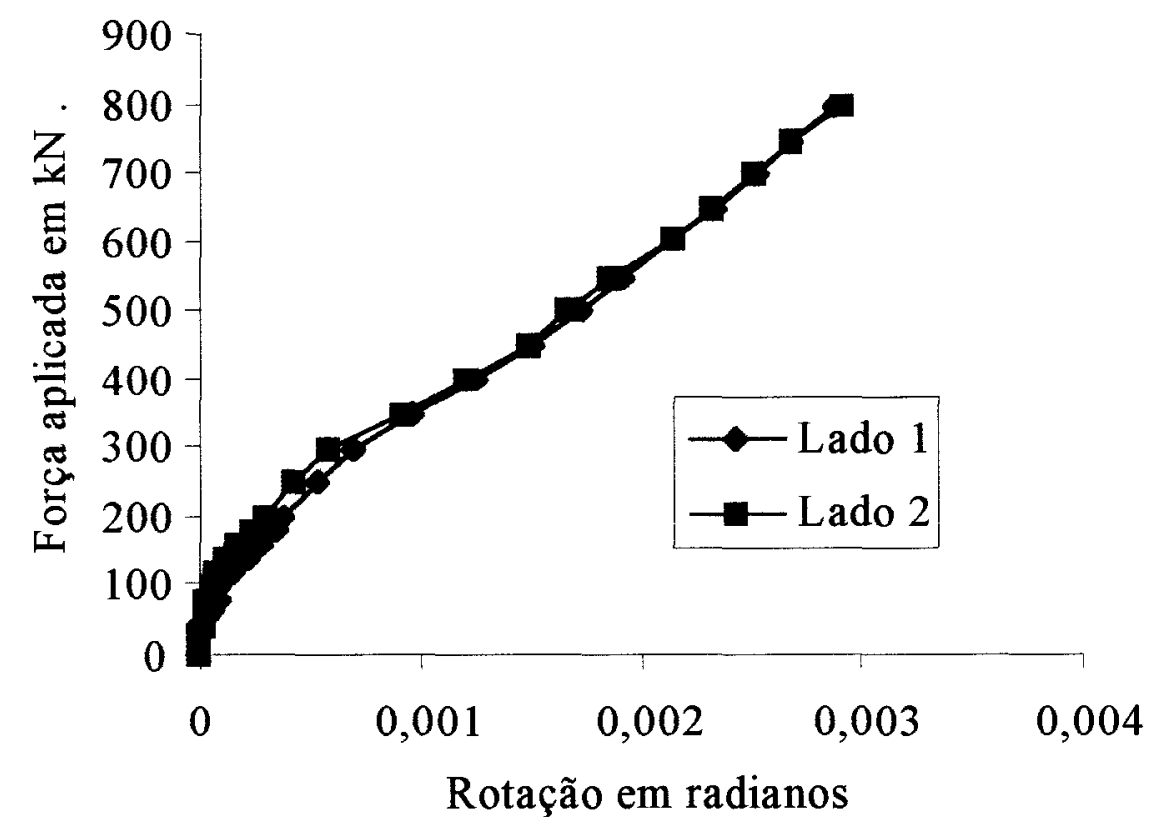

Figura 5.11 - Diagramas força aplicada x rotação do consolo em relação ao pilar para o consolo CH5V5 


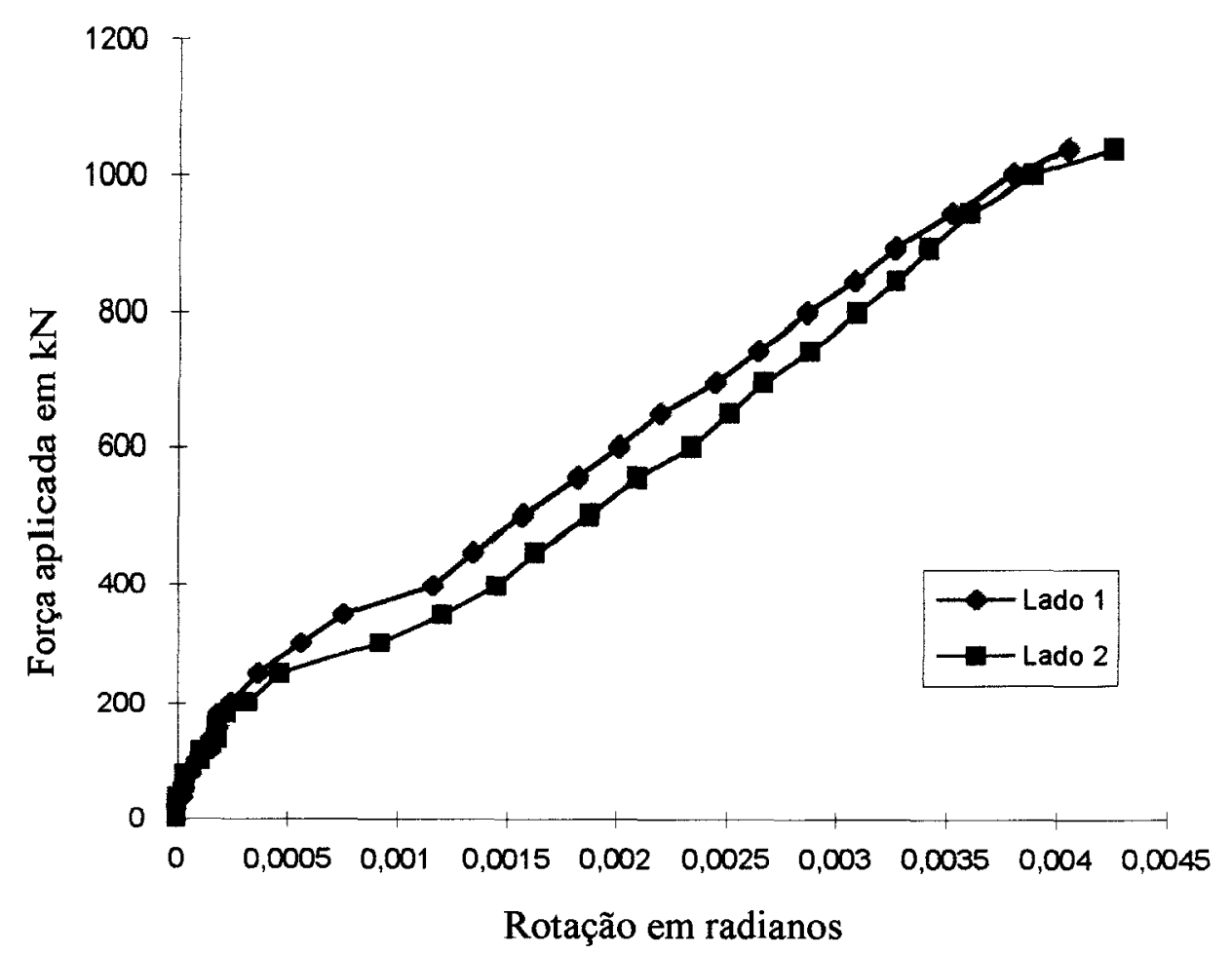

Figura 5.12 - Diagramas força aplicada x rotação do consolo em relação ao pilar para o consolo CH5Vo

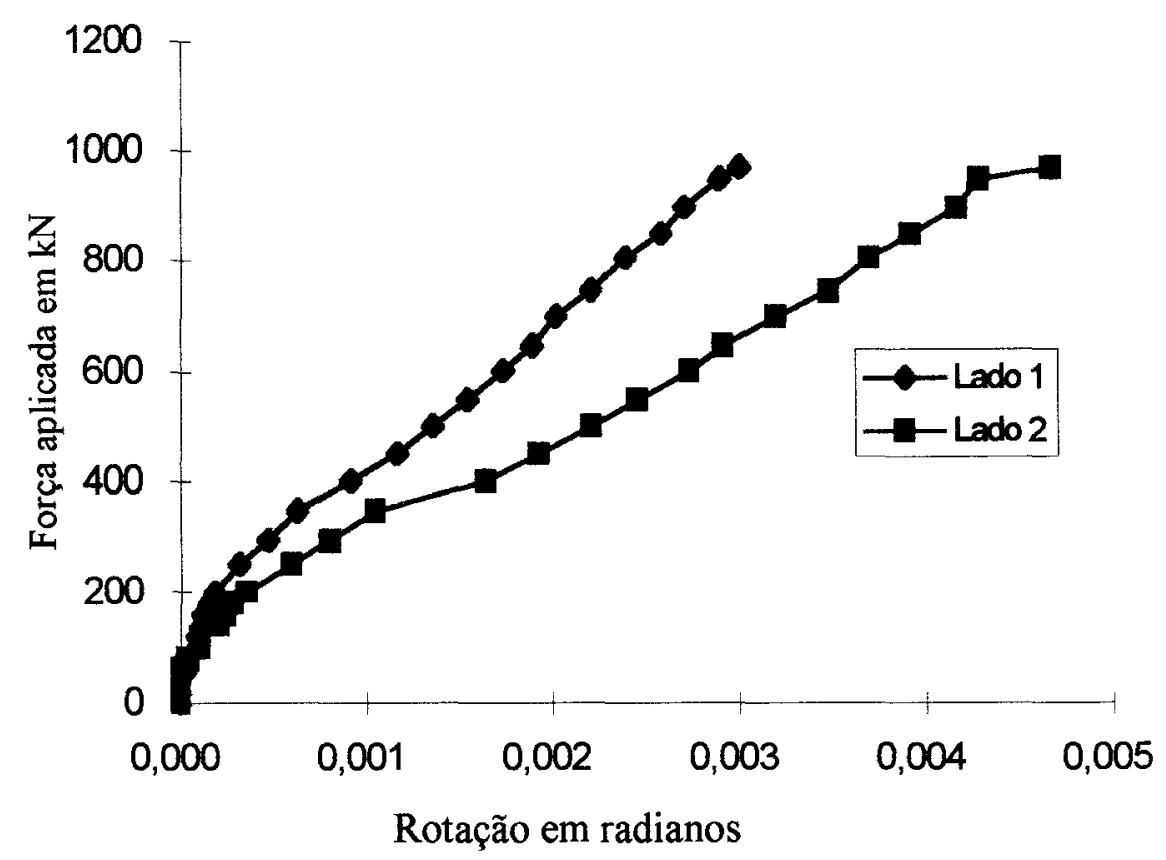

Figura 5.13 - Diagramas força aplicada x rotação do consolo em relação ao pilar para o consolo CHOV5 


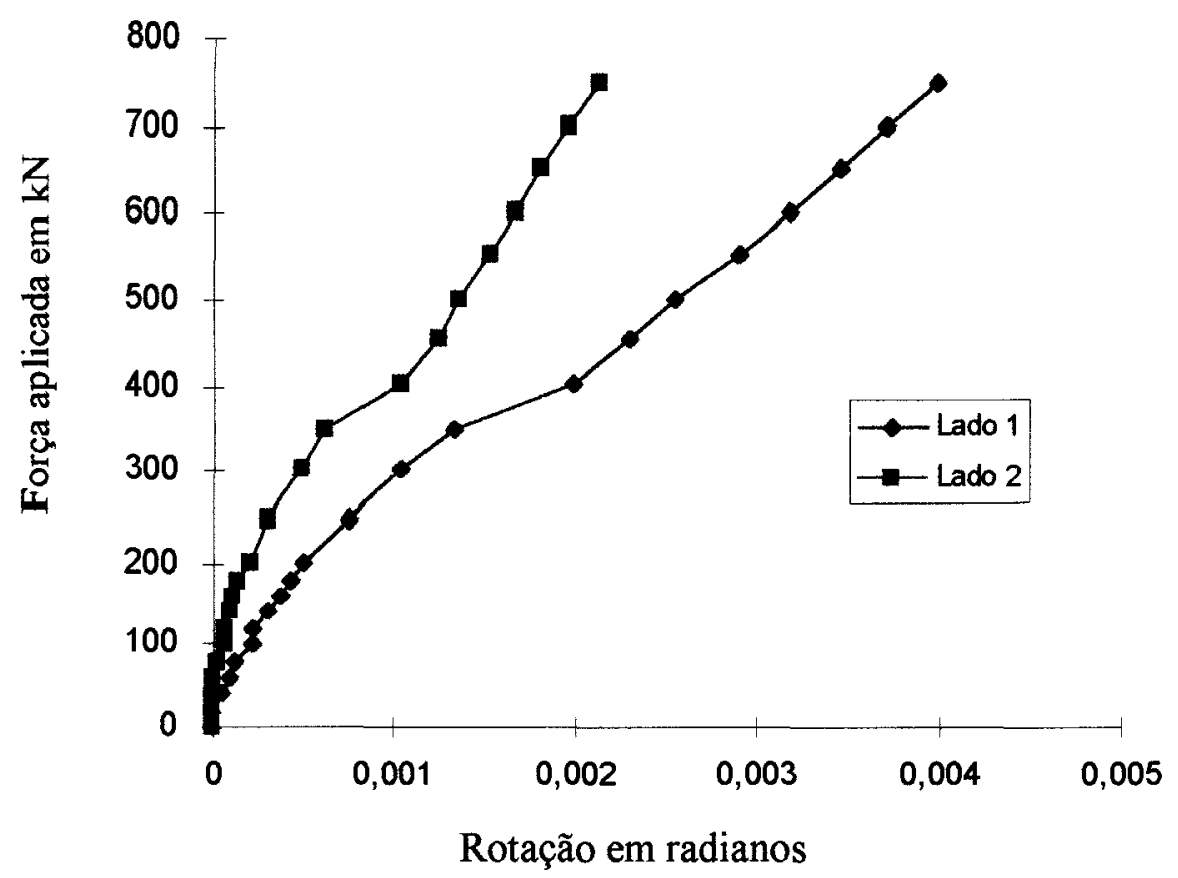

Figura 5.14 - Diagramas força aplicada x rotação do consolo em relação ao pilar para o consolo CH4V4

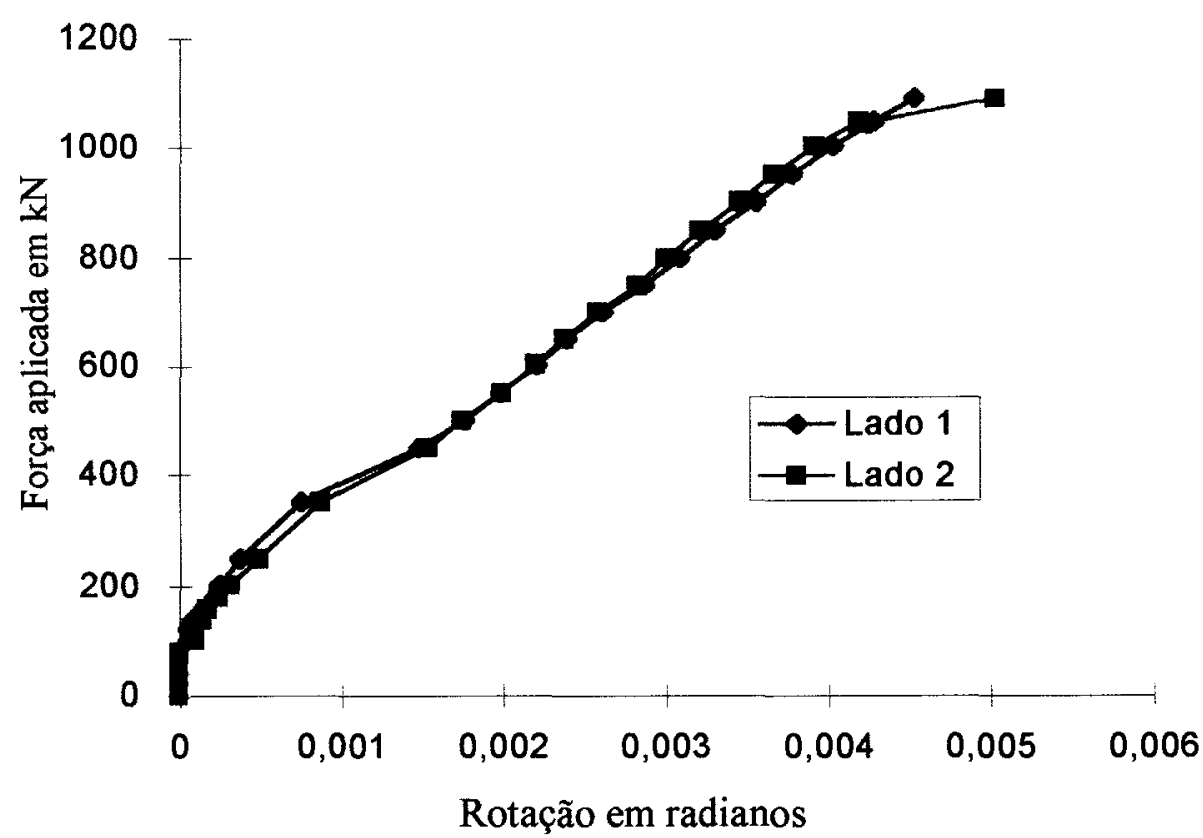

Figura 5.15 - Diagramas força aplicada x rotação do consolo em relação ao pilar para o consolo CH4Vo 


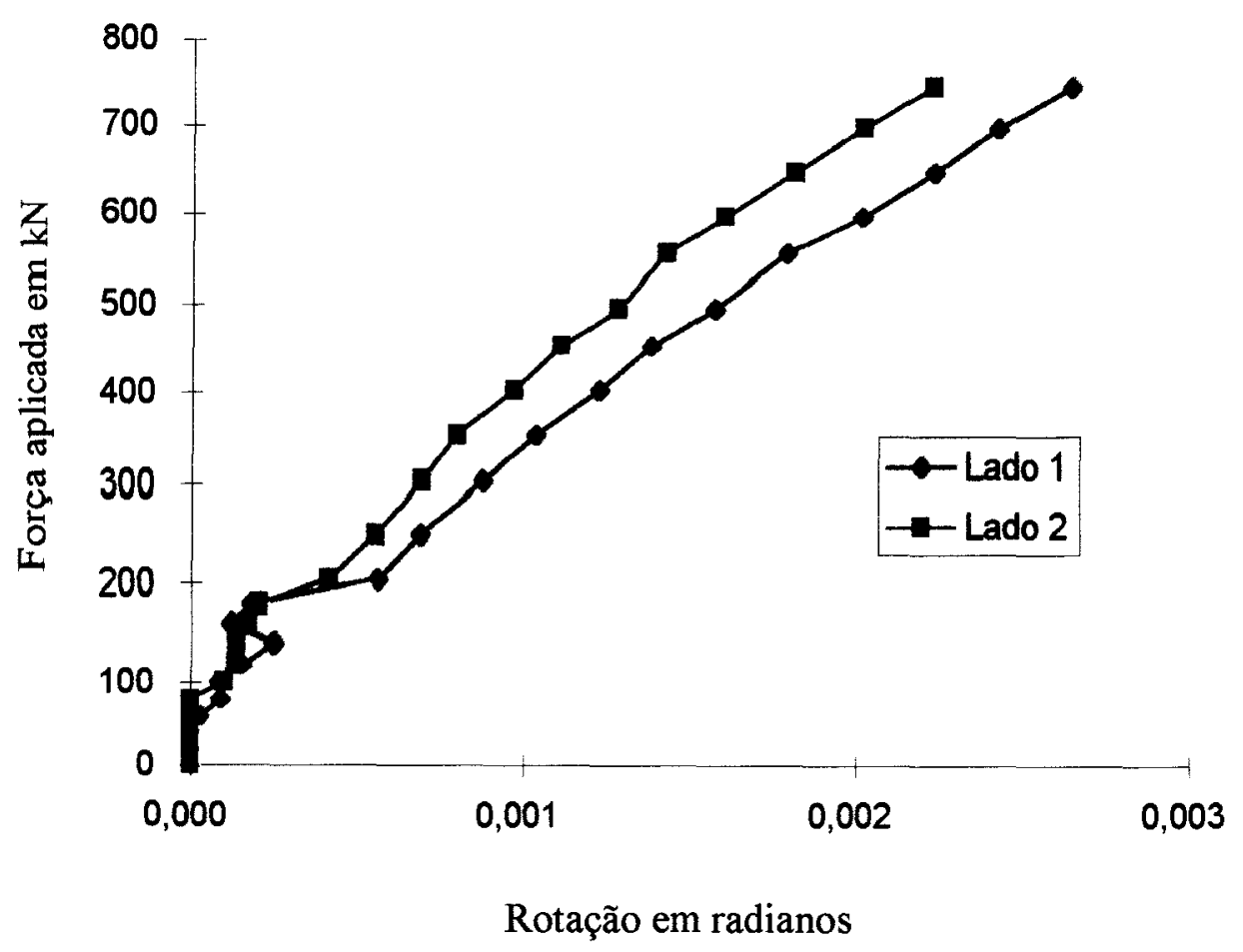

Figura 5.16 - Diagramas força aplicada x rotação do consolo em relação ao pilar para o consolo CH6V0

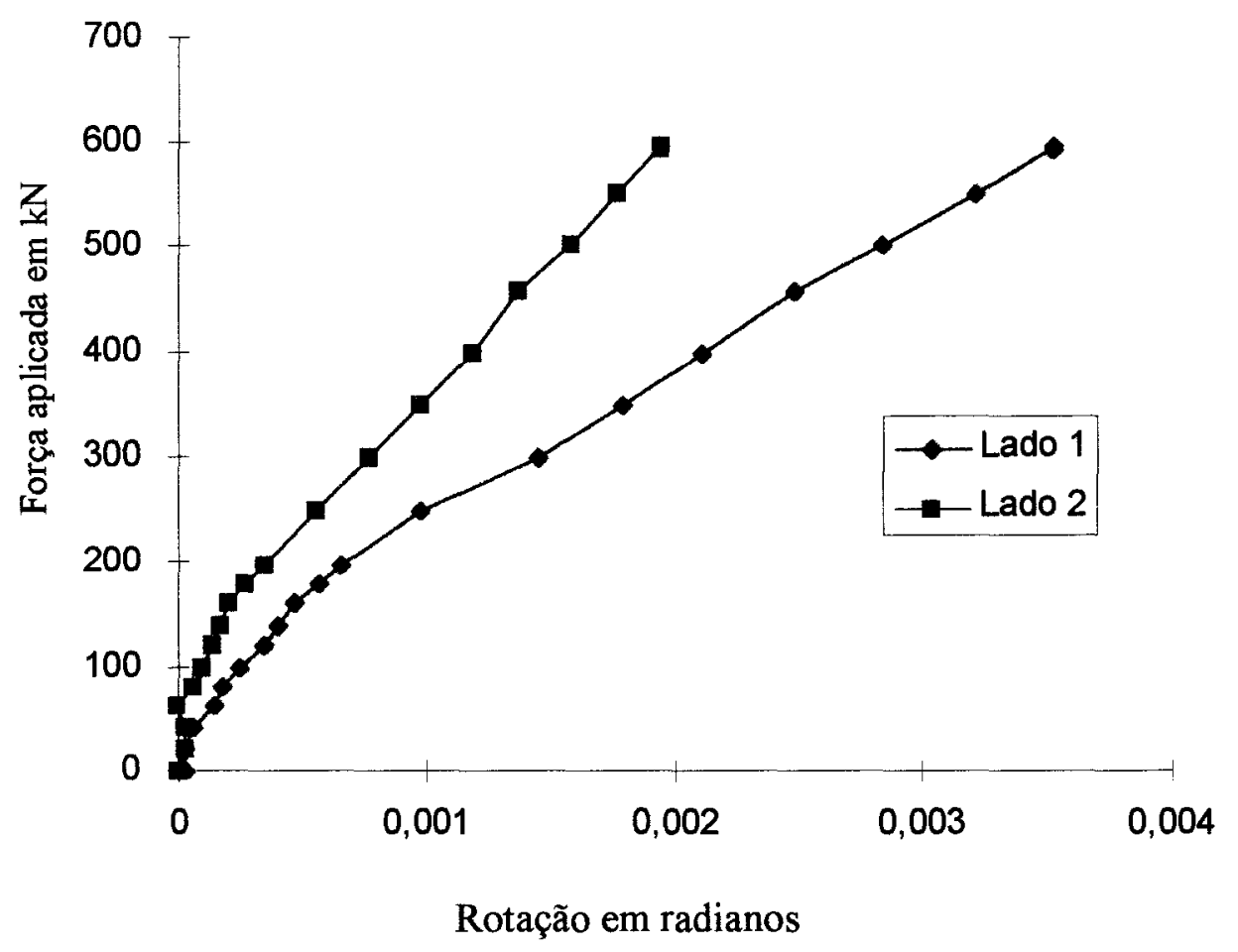

Figura 5.17 - Diagramas força aplicada x rotação do consolo em relação ao pilar para o consolo $\mathrm{CH}_{4} \mathrm{V4}^{*}$ 


\section{4 - ANÁLISE DOS CONSOLOS SEGUNDO NORMAS INTERNACIONAIS E NACIONAIS}

Os consolos ensaiados foram calculados segundo os modelos estruturais recomendados pelas normas americana ACI-318M-89, canadense CAN3-A23.3M1984 e brasileira NBR-9062. Feito isto, as forças de ruína previstas pelos métodos de cálculo foram comparadas com a força de ruína experimental.

Com o objetivo de determinar a força de ruína teórica, usando as normas, foram retirados todos os coeficientes de segurança.

A tabela 5.2 contém os valores das forças de ruína teóricas e experimentais das peças ensaiadas, os valores da relação força de ruína $\left(\mathrm{F}_{\mathrm{r}}\right)$ dividida por força de ruína calculada $\left(\mathrm{F}_{\mathrm{c}}\right)$, os valores médios e o desvio padrão da relação $\mathrm{F}_{\mathrm{r}} / \mathrm{F}_{\mathrm{c}}$, para cada uma das normas analisadas.

Com base na média e no desvio padrão dos valores de $\mathrm{F}_{\mathrm{r}} / \mathrm{F}_{\mathrm{c}}$, nota-se que todas as normas apresentaram resultados contra a segurança e que a norma que teve 0 melhor desempenho foi a Norma Brasileira, seguida pela Norma Americana e por fim a Norma Canadense.

Observa-se que quanto maior a taxa de armadura de costura, mais próximos são os valores da força de ruína calculada e da experimental.

A norma que apresentou os piores resultados foi a Norma Canadense, pois esta não possui nenhum critério bem definido para verificação da ruína por cisalhamento ou ruína na região da biela comprimida.

É importante ressaltar que nenhuma das normas utilizadas foi desenvolvida para cálculo de consolos de concreto de alta resistência. 
Tabela 5.2 - Cálculo dos consolos segundo as normas

\begin{tabular}{|c|c|c|c|c|c|c|l|}
\hline \multirow{2}{*}{ Consolo } & \multirow{2}{*}{$\begin{array}{l}\text { Força de } \\
\text { Ruína(kN) }\end{array}$} & \multicolumn{6}{|c|}{ Força de Ruína Calculada $(\mathrm{kN})$} \\
\cline { 4 - 8 } & & $\mathrm{ACI}$ & $\mathrm{F}_{\mathrm{r}} / \mathrm{F}_{\mathrm{c}}$ & $\mathrm{CAN}$ & $\mathrm{F}_{\mathrm{r}} / \mathrm{F}_{\mathrm{c}}$ & $\mathrm{NBR}$ & $\mathrm{F}_{\mathrm{r}} / \mathrm{F}_{\mathrm{c}}$ \\
\hline CH0V0 & 1000 & 1020 & 0,98 & 1255 & 0,80 & 1127 & 0,82 \\
\hline CH5V5 & 1250 & 1257 & 0,99 & 1250 & 1,00 & 1194 & 1,05 \\
\hline CH5V0 & 1070 & 1257 & 0,85 & 1242 & 0,80 & 1142 & 0,94 \\
\hline CH0V5 & 965 & 1020 & 0,95 & 1239 & 0,78 & 1123 & 0,96 \\
\hline CH4V4 & 1080 & 1084 & 1,00 & 1240 & 0,87 & 1141 & 0,95 \\
\hline CH4V0 & 1160 & 1084 & 1,07 & 1266 & 0,92 & 1252 & 0,93 \\
\hline CH6V0 & 1195 & 1320 & 0,91 & 1246 & 0,96 & 1164 & 1,03 \\
\hline CH4V4* & 790 & 945 & 0,84 & 1182 & 0,67 & 833 & 0,95 \\
\hline Média & & & 0,949 & & 0,85 & & 0,954 \\
\hline Desvio Padrão & & & 0,078 & & 0,108 & & 0,069 \\
\hline
\end{tabular}

\section{5 - ANÁliSe do ÂNGULO DE INCLINAÇÃo DAS TENSÕES PRINCIPAIS NO CENTRO DO CONSOLOS}

Com base na figura 5.18, observa-se que de maneira geral, o ângulo de inclinação das tensões principais, em relação à horizontal, aumenta com o aumento da força aplicada. Alguns saltos ocorridos nas curvas se devem principalmente ao aparecimento de novas fissuras, próximas à região onde foi colocada a roseta.

De maneira geral, o ângulo de inclinação das tensões principais variou, com forças aplicadas próximas às forças de ruína, de $63^{\circ}$ a $68^{\circ}$ com a horizontal. Estes valores são bastante semelhantes aos ângulos de inclinação da biela indicados pelos cálculos, que variaram de $62^{\circ}$ a $67^{\circ}$. 


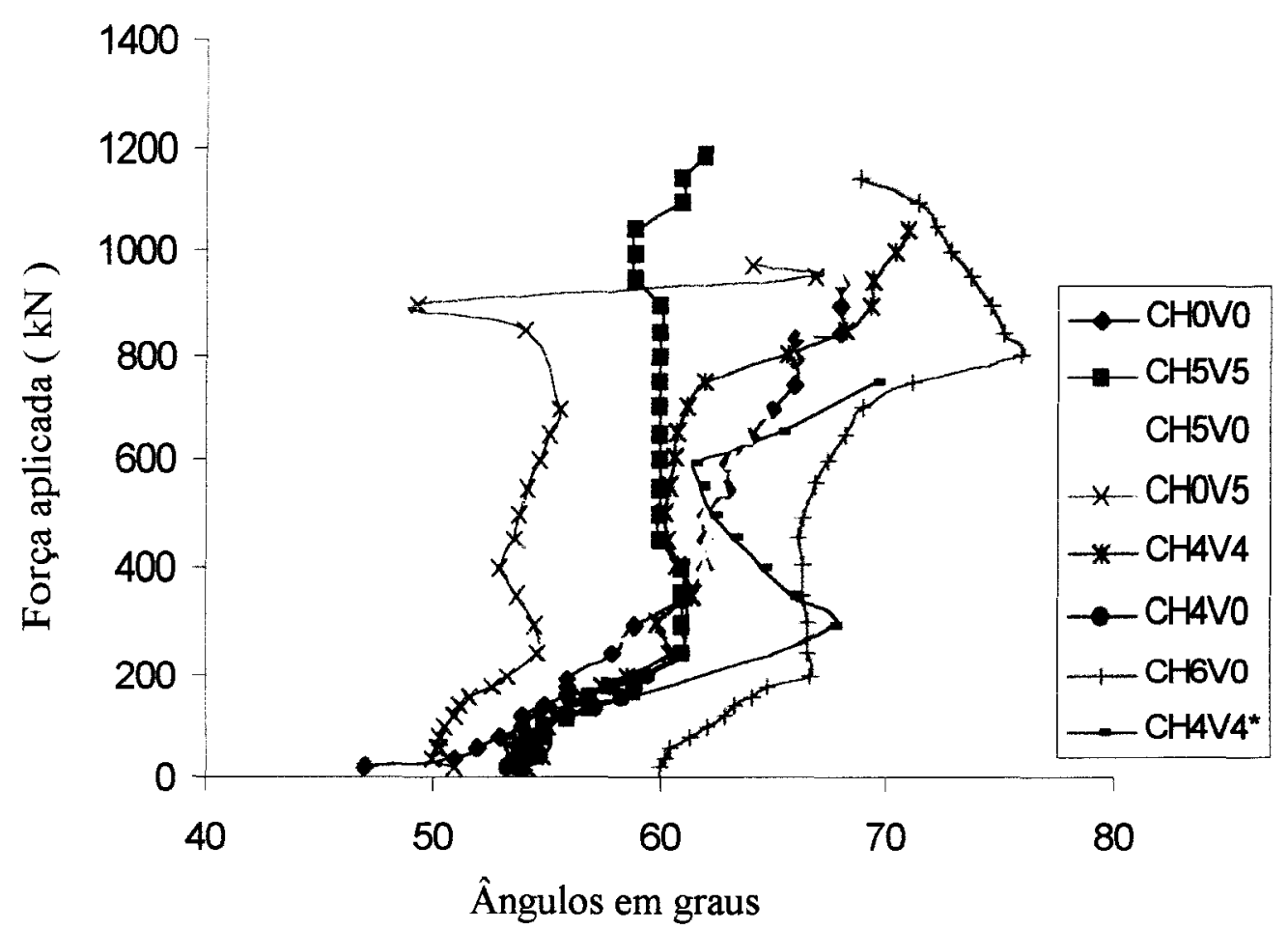

Figura 5.18 - Diagrama força aplicada $x$ inclinação das tensões principais no centro dos consolos

\section{6 - ANÁLISE PARAMÉTRICA}

Para a realização das análises paramétricas, foram traçados dois gráficos, que estão ilustrados nas figura 5.19 e 5.20. O gráfico da figura 5.19 foi montado para analisar a relação $\frac{F_{r}}{f_{c} b d}$ versus a taxa de armadura de costura dos consolos. $O$ segundo gráfico, o da figura 5.20, apresenta a análise da resistência do concreto versus a relação $\frac{F_{r}}{A_{s} f_{y}+A_{s h} f_{y}}$.

Com base no gráfico da figura 5.19, pode-se afirmar, observando a linha de tendência, que, dentro de certos limites, quanto maior a taxa de armadura de costura, melhor é o aproveitamento do concreto. Isto, tomando o cuidado para que a peça não venha a ruir antes por escoamento da armadura principal.

Observando o gráfico da figura 5.20, pode-se afirmar que quanto maior a resistência do concreto, melhor será o aproveitamento da armadura. 
Com base nestas observações, pode-se afirmar que, dentro de certos limites, quanto maior a taxa de armadura de costura e maior a resistência do concreto, melhor será o aproveitamento da armadura principal. Conclue-se, portanto, que com concreto de alta resistência e com taxa de armadura de costura adequada, pode-se construir consolos bem menores do que os que seriam feitos de concreto de baixa resistência.

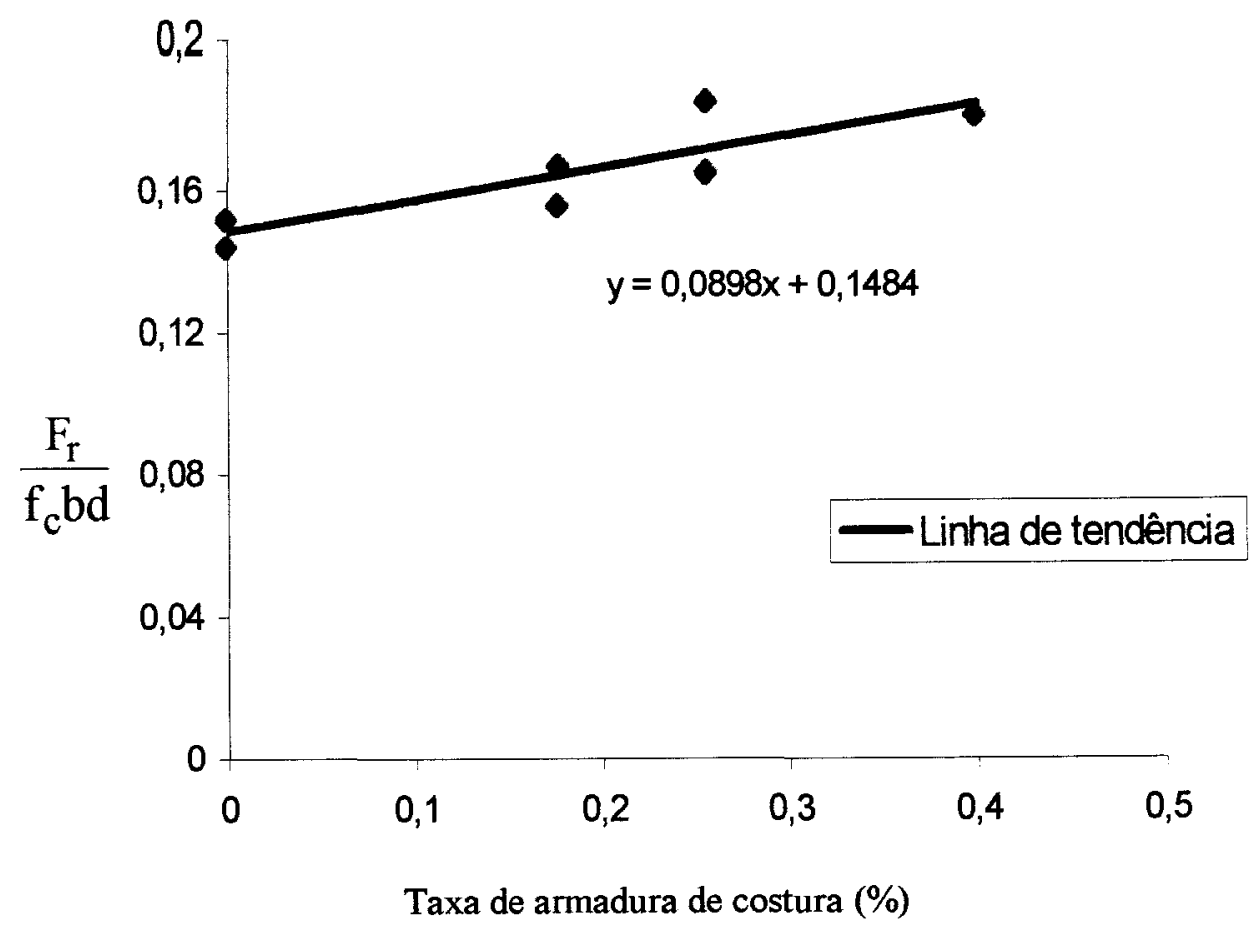

Figura 5.19 - Gráfico $\frac{F_{r}}{f_{c} b d}$ versus taxa de armadura de costura 


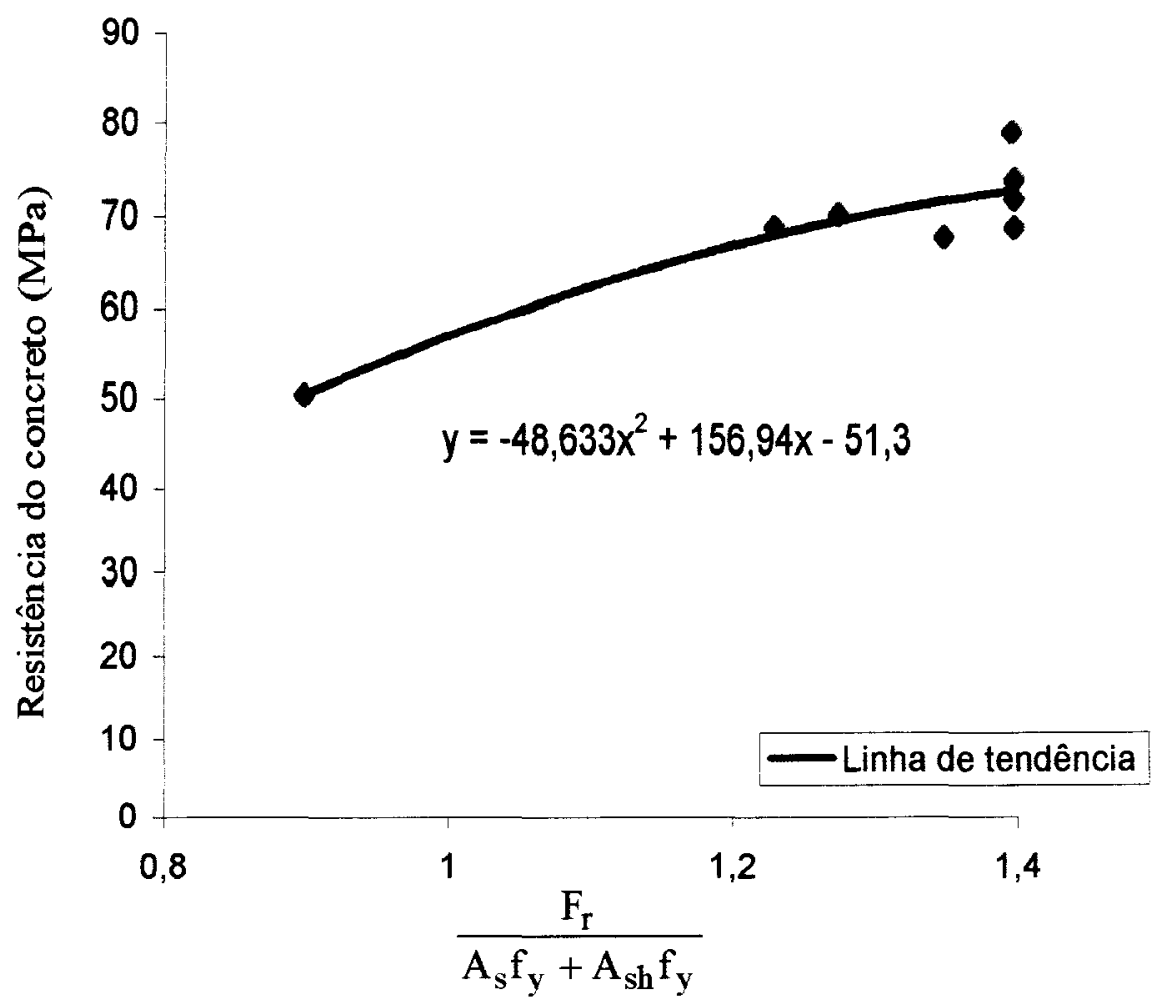

Figura 5.20 - Gráfico resistência do concreto versus $\frac{F_{r}}{A_{s} f_{y}+A_{s h} f_{y}}$ 


\section{CAPÍTULO 6 - CONCLUSÕES E SUGESTÕES}

\section{1 - CONCLUSÕES}

Após o término da análise dos consolos, pode-se concluir que a taxa de armadura de costura influencia sobremaneira o comportamento e o cálculo dos consolos de acordo com as normas nacionais e internacionais.

Com base nas análises paramétricas realizadas nos capítulos 3 e 5 , pode-se concluir que, dentro de certos limites, quanto maior é a taxa de armadura de costura, maior é o aproveitamento do concreto, e que quanto maior é a taxa de armadura de costura, maior é a resistência do concreto e melhor é o aproveitamento da armadura principal.

Em consolos com taxa de armadura muito pequena, os resultados foram muito conservadores, e em casos de consolos com taxa de armadura muito elevada, os resultados foram contra a segurança. Taxas de armadura muito alta ou muito baixa causaram grandes variações no resultado final da média e do desvio padrão da relação $F_{\mathrm{r}} / \mathrm{F}_{\mathrm{c}}$.

Todas as normas tiveram um bom desempenho na verificação dos consolos com detalhamento similar ao indicado por elas, entretanto, quando os consolos tinham taxas de armadura muito baixas ou muito altas, os resultados foram ruins, apresentando grandes discrepâncias na relação $F_{\mathrm{r}} / \mathrm{F}_{\mathrm{c}}$

A teoria de atrito-cisalhamento adotada pela Norma Americana se mostrou conservadora, principalmente para consolos com baixa taxa de armadura e sem armadura de costura. 
Os consolos com relações a/d muito pequenas ( relação a/d $<0,2$ ) apresentaram resultados muito conservadores quando calculados pelas normas ACI-318M/89 e NBR-9062/85. Para o caso da norma CAN3-A23.3-M1984, os resultados foram contra a segurança.

No que diz respeito à força horizontal, pode-se concluir que as normas utilizadas apresentaram um bom desempenho médio no cálculo de consolos com força horizontal aplicada, principalmente em consolos com armadura de costura. Entretanto, o desvio padrão indica que se deve ter cuidado, pois há uma grande variabilidade nos resultados, indicando que muitos consolos tiveram seus cálculos contra a segurança.

Observando as forças de ruína e os diagramas força aplicada versus deformação da armadura, para os consolos ensaiados no Laboratório de Estruturas da Escola de Engenharia de São Carlos, nota-se que a armadura formada pelos estribos verticais praticamente não trabalhou quando a força aplicada estava próxima à força em serviço. Entretanto, esta armadura proporcionou um aumento de ductilidade e um pequeno acréscimo da resistência final do consolos.

Com respeito à rotação do consolo em relação ao pilar, concluiu-se que a existência apenas da armadura de costura proporcionou um comportamento mais homogêneo dos consolos ligados ao pilar.

Com relação a resistência do concreto, nota-se que para consolos de concreto com resistência variando de 15 a $50 \mathrm{MPa}$, a resistência do concreto não influenciou de maneira significativa a relação $\mathrm{F}_{\mathrm{r}} / \mathrm{F}_{\mathrm{c}}$.

O uso de concreto de alta resistência proporciona a confecção de peças com menores dimensões. Entretanto, neste caso, as taxas de armadura principal e de costura devem ser mais elevadas.

$\mathrm{O}$ cálculo de consolos de concreto de alta resistência usando as normas se mostrou contra a segurança, indicando a necessidade da implementação de um coeficiente de efetividade da resistência do concreto, conforme indica NAEGELI (1997) .

Com base no estudo do ângulo de inclinação das tensões principais no centro geométrico dos consolos, observa-se que os valores do ângulo de inclinação das 
tensões próximas às forças de ruína são muito semelhantes aos valores do ângulo de inclinação da biela, indicado pelo cálculos.

Com relação aos estados limites de utilização, nota-se que com o uso de concreto de alta resistência deve-se tomar um cuidado redobrado, pois, de maneira geral, os consolos após a fissuração na região da biela não perdem a capacidade resistente, mas apresentam fissuras de aberturas excessivas, indicando um comportamento indesejável da peça. Para tal, devem ser tomadas precauções, colocando uma armadura adicional para combater esta fissuração.

\section{2 - SUGESTÕES}

Para dar continuidade a este trabalho, sugere-se o estudo dos estados limites de utilização para consolos de concreto de alta resistência, buscando principalmente indicar a quantidade e a disposição de armadura para combater a fissuração na biela comprimida.

Sugere-se ainda analisar o comportamento experimental de uma armadura de costura inclinada, para combater a fissuração na biela. 


\section{REFERÊNCIAS BIBLIOGRÁFICAS}

ASSOCIAÇÃO BRASILEIRA DE NORMAS TÉCNICAS (1995). NBR-9062 -

Projeto e execução de estruturas de concreto pré-moldado. Rio de Janeiro.

AMERICAN CONCRETE INSTITUTE (1989). ACI 318-1989 - Building code requirements for reinforced concrete. Detroit, ACI.

CANADIAN STANDARD ASSOCIATION (1985). CAN3-A23.3-M84 - Design of concrete structures for buildings. Canadian Portland Cement Association.

COMITÉ-EURO-INTERNACIONAL DU BÉTON (1991). CEB-FIP model code 1990._Bulletin d'Information, n. 203-205, July.

FATTUHI, N. I. (1987). SFRC corbels tests. ACI Structural Journal, v. 84, n. 2, p. $119-123$.

FATTUHI, N. I.; HUGHES, B.P. (1989). Ductility of reinforced concrete corbels containing either steel fiber or stirrups. ACI Materials Journal, v. 86, n. 6, p. 644651 .

FATTUHI, N. I.; HUGHES, B.P. (1989). Reinforced steel fiber concrete corbels with varios shear span-to-depth ratios. ACI Materials Journal, v. 86, n. 6, p. 590-596.

FATTUHI, N. I. (1990). Column-load effect on reinforced concrete corbels. Journal of Structural Engineering, v. 116, n. 1, p. 188-197.

FATTUHI, N. I. (1990). Strength of SFRC corbels subjected to vertical load. Journal of Structural Engineering, v. 116, n. 3, p. 701-718.

FATTUHI, N. I. (1994). Reinforced corbels made with high-strength and varios secondary reinforcements. ACI Structural Journal, v. 91, n. 4, p. 376-382. 
FATTUHI, N. I. (1994). Reinforced corbels made with plain and fibrous concrete. ACI Structural Journal, v. 91, n. 5, p. 530-536.

FATTUHI, N. I. (1994). Strength of FRC corbels in flexure. Journal Structural Engineering, v. 120 , n. 2 , p. $360-377$.

FOSTER, S.J.; POWELL, R.E.; SELIM, H. S. (1989). Performance high-strength concrete corbels. ACI Structural Journal, v. 93, n. 5, p. 555-563.

FRANZ, G.; NIEDENHOFF, H. (1963). Die Bewehrung von Konsolen and gedrungenen Balken. Beton -und Stahlbetonbau, v. 58, n. 5, p.112-120.

HAGBERG, T. (1983). Design of concrete brackets: on the application of the truss analogy. Journal of the American Concrete Institute, v. 80, n. 1, p. 3-12.

HERMANSEN, B.R.; COWAN, J. (1974). Modified shear-friction theory for bracket design. Journal of the American Concrete Institute, v. 71, n. 7, p. 55-60.

HUGHES, B.P.; FATTUHI, N. I. (1989). Reinforced steel and polypropylene fibre concrete corbels tests. The Structural Engineer, v. 67, n. 4, p. 68-72.

KRIZ, L.B.; RATHS, C.H. (1965). Connections in precast concrete structure: strength of corbels. Journal Prestressed Concrete Institute, v. 10, n. 1, p. 16-61.

LEONHARDT, F.; MÖNNIG, F. (1978). Construções de concreto. Rio de Janeiro, Interciência. v.2, p.51-58.

MATTOCK, A.H. (1976). The behavior reinforced concrete corbels. Journal Prestressed Concrete Institute, v. 21, n. 2, p, 52-77.

MATTOCK, A.H.; CHEN, K.C.; SOONGSWANG, K. (1976). Design proposals for reinforced concrete corbels. Journal Prestressed Concrete Institute, v. 21, n. 3, p. $18-42$. 
NAEGELI, C.H. (1988), Estudo experimental de consolos em concreto armado. Rio de Janeiro. Dissertação (Mestrado) - Pontificia Universidade Católica do Rio de Janeiro, Departamento de Engenharia Civil.

NAEGELI, C.H. (1997). Estudo de consolos de concreto armado. Rio de Janeiro. Tese (Doutorado) - Universidade Federal do Rio de Janeiro, COPPE/UFRJ.

PARK, R.; PAULAY, T. (1983). Reinforced concrete structures. New York, John Wiley \& Sons. p.690-700.

REIS, A.P.A.; TORRES, F.M. (1996). Estudo experimental de consolos em concreto armado. Goiânia, Universidade Federal de Goiás, Escola de Engenharia Civil. (Projeto final de curso).

ZIELINSKI, Z.A.; RIGOTTI, M. (1995). Tests on shear capacity of reinforced concrete. Journal Structural Engineering, v. 121, n. 11, p. 1600-1666.

YOUNG, Y.K.; BALAGURU, P. (1994). Behavior of reinforced high-strength concrete corbels. Journal Structural Engineering, v. 120, n. 4, p. 1182-1201.

YOUNG, Y.K.; DOUGLAS, H.; NAWY, E.G. (1985). Reinforced corbels highstrength concrete. In: RUSSELL, H.G., High-Strength Concrete. Detroit, ACI, p. 197-212. (SP 87). 


\section{BIBLIOGRAFIA COMPLEMENTAR}

ABDUL-WAHAB, H.M.S. (1989). Strength of reinforced corbels with fibers. ACI Structural Journal, v. 86, n. 1, p. 60-66

CHAKRABARTI, P.R.; KASHOU, S.I. (1989). Precompressed concrete corbels. Journal of Testing and Evaluation, v. 17, n. 4, p. 247-254.

CHAKRABARTI, P.R.; FARAHANI, D.J.; KASHOU S.I. (1989). Reinforced and precompressed concrete corbels - an experimental study. ACI Structural Journal, v. 86, n. 4 , p. $405-412$.

EL DEBS, M.K. (1996). Estruturas pré-moldadas de concreto. São Carlos, Universidade de São Paulo, Escola de Engenharia de São Carlos. (Notas de aula).

GIONGO, J.S.; MELGES, J.L.P. (1996). Consolos. São Carlos, Universidade de São Paulo, Escola de Engenharia de São Carlos. (Notas de aula)

LEONHARDT, F.; MÖNNIG, E. (1984). Construções de concreto. Rio de Janeiro, Interciência. v.3, p.209-214.

MACGREGOR, J.G. (1988). Reinforced concrete: mechanics and design. Englewood Cliffs, Prentice Hall. p. 752-757.

NAWY, E.G. (1990). Reinforced concrete: a fundamental approach. 2.ed. Englewood Cliffs, Prentice Hall. p. 182-197.

ROBINSON, J.R. (1977). Elementos constructivos singulares de hormigón armado. Barcelona, Gustavo Gili. p.99-143.

SILVA, R.C. (1991). Concreto armado: aplicação de modelos de bielas e tirantes. São Carlos. Dissertação (Mestrado) - Escola de Engenharia de São Carlos, Universidade de São Paulo. 
SIAO, W.B. (1994). Shear strength of short reinforced concrete walls, corbels, and deep beams. ACI Structural Journal, v. 91, n. 2, p. 123-132.

SOLANKI, H.; SABNIS G.M. (1987). Reinforced concrete corbels: simplified. ACI Structural Journal, v. 84, n. 5, p. 428-432.

TAN, K.H.; MANSUR, M.A. (1992). Partial prestressing in concrete corbels and deep beams. ACI Structural Journal, v. 89, n. 3, p. 251-262. 